University of Massachusetts Amherst

ScholarWorks@UMass Amherst

Open Access Dissertations

$2-2011$

\title{
Unintended Consequences of Lowering Disclosure Thresholds: Proposed Changes to SFAS No. 5
}

\author{
Kirsten Fanning \\ University of Massachusetts Amherst
}

Follow this and additional works at: https://scholarworks.umass.edu/open_access_dissertations

Part of the Business Commons

\section{Recommended Citation}

Fanning, Kirsten, "Unintended Consequences of Lowering Disclosure Thresholds: Proposed Changes to SFAS No. 5" (2011). Open Access Dissertations. 336.

https://doi.org/10.7275/1922197 https://scholarworks.umass.edu/open_access_dissertations/336

This Open Access Dissertation is brought to you for free and open access by ScholarWorks@UMass Amherst. It has been accepted for inclusion in Open Access Dissertations by an authorized administrator of ScholarWorks@UMass Amherst. For more information, please contact scholarworks@library.umass.edu. 
UNINTENDED CONSEQUENCES OF LOWERING DISCLOSURE THRESHOLDS:

PROPOSED CHANGES TO SFAS NO. 5

\author{
A Dissertation Presented \\ by \\ KIRSTEN FANNING
}

Submitted to the Graduate School of the University of Massachusetts Amherst in partial fulfillment

of the requirements for the degree of

DOCTOR OF PHILOSOPHY

February 2011

Isenberg School of Management 
(C) Copyright by Kirsten Fanning 2011

All Rights Reserved 
UNINTENDED CONSEQUENCES OF LOWERING DISCLOSURE THRESHOLDS:

PROPOSED CHANGES TO SFAS NO. 5

\author{
A Dissertation Presented \\ by \\ KIRSTEN FANNING
}

Approved as to style and content by:

Christopher P. Agoglia, Chair

David Piercey, Member

Ray Pfeiffer, Member

Ronnie Janoff-Bulman, Member

D. Anthony Butterfield, Ph.D. Program Director Isenberg School of Management 


\section{DEDICATION}

To my husband, Brendan. 


\section{ACKNOWLEDGEMENTS}

I would like to thank the members of my committee for their guidance and helpful comments throughout this project. I would especially like to thank my dissertation chair, Chris Agoglia. Chris encouraged me to pursue my Ph.D. while I was an undergraduate at Drexel. He guided me through the Ph.D. program application process, and he is still guiding me now as I complete my degree. He has made this process worthwhile and I will always be thankful for his mentorship. He is proof that a star researcher can also be a star human being.

I would also like to thank Dave Piercey for all of his support and helpful comments on my dissertation. Throughout my doctoral program Dave has been truly generous with his time, and I have learned so much from him. My first attempt at doing research of my own came at the end of my second year as a doctoral student when I began working on a study with Dave. It has been (and continues to be) a great experience. I am very lucky to have such a great person and colleague to work with.

I also owe a tremendous debt of gratitude to Ray Pfeiffer. He invited me to attend the roundtable discussions on the SFAS 5 issue at the FASB. That experience helped to give me the confidence I needed to present this paper in job workshops. Also, when times were difficult for me over the past five years, Ray would put things in perspective for me. I am grateful to have crossed paths with Ray during my stay at UMass.

I would also like to thank Ronnie Janoff-Bulman for her helpful comments on my dissertation and for making the time in her busy schedule to serve on my committee.

In addition, my fellow Ph.D. students, both past and present, have been a source of support and encouragement throughout this program. Special thanks to Tracey Riley, Rosemond Desir, Kelly McKillop, Steve Gill, Paul Goodchild, Steve Perrault, Roger 
Silvers, Erin Moore, Sherry Li, and Bill Brown for shaping the past five years of my life in their own unique ways.

I would also like to thank Tamara Lambert for all of her support and advice during the past few years. I often found myself asking her all sorts of questions while I was on the job market, or for little bits of practical advice on how to field Chris's comments on my writing and other useful things!

To my husband, Brendan, I could not have completed this program without his patience and love. He saw me through all of the good and bad times, the late nights, and the stress. I don't think I could have kept my sanity without his unwavering belief that I would ultimately succeed. I am really looking forward to our new life back near Philly, where we met and fell in love, and where we will now build a home of our own together. That is, of course, with our beautiful puppy, Godiva!

I would also like to thank my parents, Terri and Sean, my brother, Patrick, and my sister, Jodi. My family's support and love has really been important to me throughout my life. I love you all! 


\begin{abstract}
UNINTENDED CONSEQUENCES OF LOWERING DISCLOSURE THRESHOLDS:

PROPOSED CHANGES TO SFAS NO. 5
\end{abstract}

FEBRUARY 2011

\begin{abstract}
KIRSTEN FANNING, B.S.B.A., DREXEL UNIVERSITY
Ph.D., UNIVERSITY OF MASSACHUSETTS AMHERST
\end{abstract}

Directed by: Professor Christopher P. Agoglia

Recently, investors have asserted that firms' loss contingency disclosures are not adequate to allow them to assess the likelihood of material losses due to litigation (i.e., litigation risk), and a debate has developed over whether the threshold for disclosure should be lowered to provide investors with more information relating to litigation. Using an experiment, I investigate two unintended consequences of lowering a disclosure threshold, as the FASB has recently proposed. First, I find that adding low probability lawsuits to the disclosure of reasonably possible lawsuits lowers prospective investors' perceptions of litigation risk relating to the disclosure, even though more lawsuits are disclosed. Second, lowering the threshold allows firms to portray the entire disclosure opportunistically, diverting attention from higher probability to lower probability lawsuits. I find evidence that firms can use such an opportunistic presentation under a lower threshold to their advantage. Specifically, prospective investors' and even short investors' perceptions were just as favorable to the firm as long investors' when the disclosure threshold was lower and firms adopted an opportunistic disclosure strategy. Thus, my findings suggest that the FASB's proposal to require disclosure of lower 
probability loss contingencies may have unintended consequences for investors' perceptions of firms' loss exposure. 


\section{TABLE OF CONTENTS}

Page

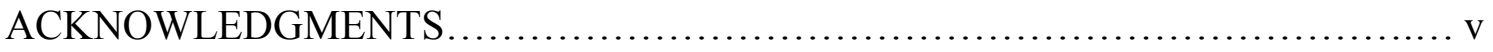

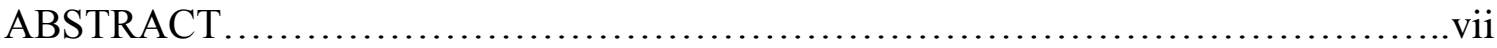

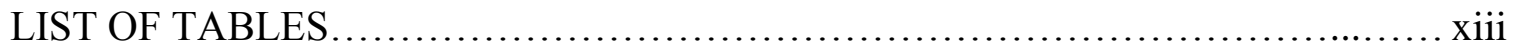

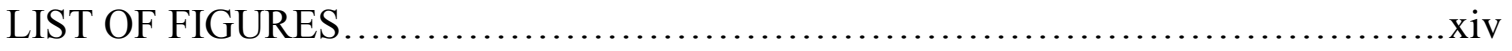

\section{CHAPTER}

1. INTRODUCTION ................................................. 1

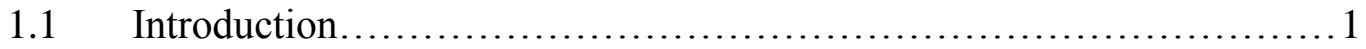

1.2 Disclosure of Lower Probability Lawsuits.........................2

1.2.1 Prospective Investors.................................. 2

1.2.2 Long and Short Investors............................ 3

1.3 Opportunistic Presentation of Lawsuits under a Lower Threshold........ 4

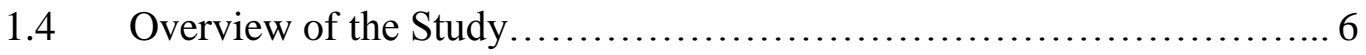

1.5 Preview of the Results....................................... 6

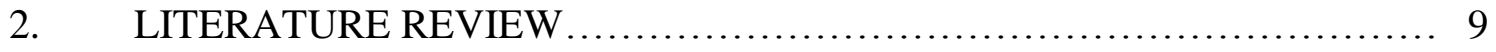

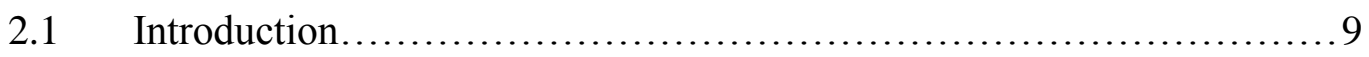

2.2 Debate over Loss Contingency Disclosures.........................9

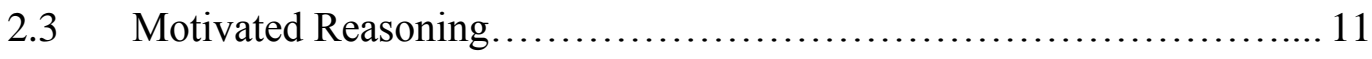

2.3.1 Motivation to Reach an Accurate Conclusion or a Preferred Conclusion.................................... 11

2.3.2 Motivated Reasoning among Auditors and Tax Professionals............................................14

2.3.3 Motivated Reasoning among Nonprofessional Investors........17 
2.3.4 Motivated Reasoning within Reasonableness Constraints..... 21

2.4 Dilution Effect.............................................23

2.4.1 Dilution Effect in the Accounting Literature.................25

2.5 Opportunistic Reporting by Management..........................26

2.6 Methods of Persuasion.............................................29

2.6.1 Emphasis Framing...................................29

2.6.1.1 Emphasis Framing in Accounting Contexts........... 31

2.6.2 Persuasion Knowledge Model............................. 34

2.6.2.1 Persuasion Knowledge Model in the Accounting Literature.................................... 37

2.7 Conclusions................................................ 38

3. HYPOTHESES AND METHODOLOGY .............................. 40

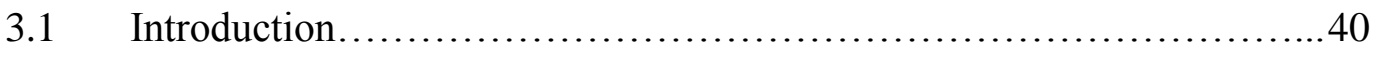

3.2 Development of Hypotheses.................................. 40

3.2.1 Debate over SFAS 5: Threshold for Disclosing Loss

Contingencies.......................................40

3.2.2 Investors' Motivated Reasoning Goals and Economic Incentives........................................ 41

3.2.3 Prospective Investors' Judgments and Lowering the Disclosure Threshold.

3.2.4 Long and Short Investors' Judgments: Motivated Reasoning within Reasonableness Constraints.......................44

3.2.5 Opportunism in Financial Reporting..................... 47

3.2.6 Opportunistic Presentation: Persuasion Knowledge Model versus Emphasis Framing................................ 48

3.2.6.1 The Persuasion Knowledge Model.................. 49 
3.3 Method.................................................... 53

3.3.1 Participants............................................. 53

3.3.2 Experimental Task and Procedure......................... 54

3.3.3 Independent Variables............................... 55

3.3.3.1 Investor Position............................. 55

3.3.3.1.1 Pretests of Two Firms used in Experimental Materials.................57

3.3.3.2 Disclosure Type..............................60

3.3.3.2.1 Opportunistic Disclosure Pretest........62

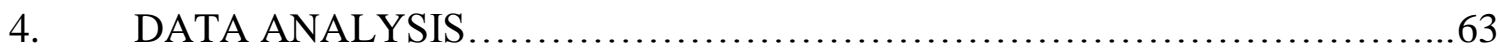

4.1 Introduction.................................................... 63

4.2 Manipulation Checks........................................ 63

4.2.1 Investor Position..................................... 63

4.2.2 Disclosure Type..................................... 64

$4.3 \quad$ Tests of Hypotheses........................................... 65

4.3.1 Introduction......................................65

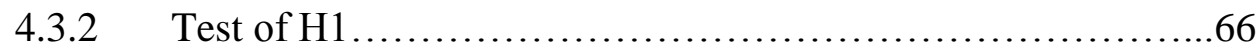

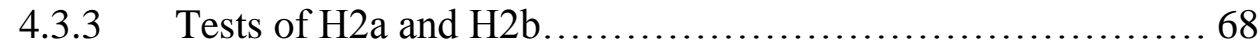

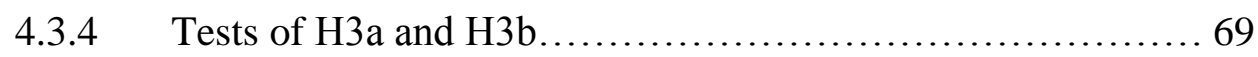

4.4 Post-Experimental and Demographic Questions......................71

4.5 Summary of Results........................................ 75

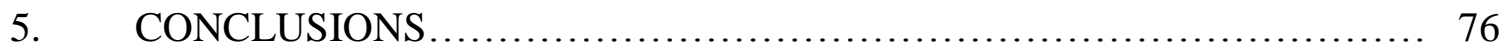

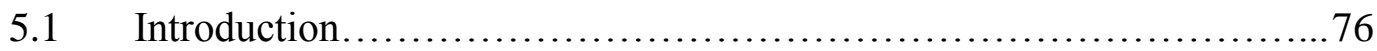


$5.2 \quad$ Discussion.................................................... 77

$5.3 \quad$ Implications................................................. 78

5.4 Directions for Future Research............................... 79

APPENDIX: Research Instrument............................................. 80

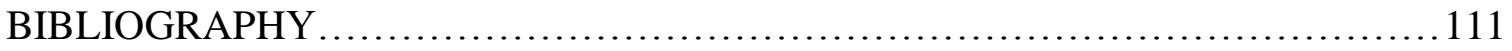




\section{LIST OF TABLES}

Table $\quad$ Page

1 Participants by Experimental Condition.................................54

2 Sample Demographic Data............................................ 55

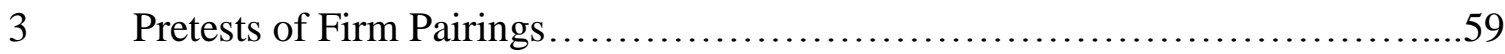

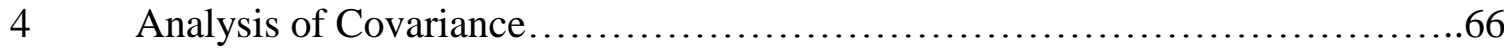




\section{LIST OF FIGURES}

Figure $\quad$ Page

1 Investors' Motivated Reasoning within Reasonableness Constraints............46

2 Excerpt from Background Experimental Materials.........................57

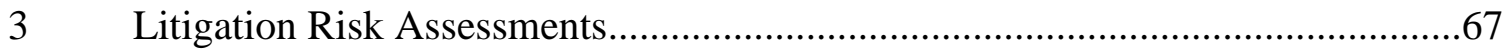




\section{CHAPTER 1}

\section{INTRODUCTION}

\subsection{Introduction}

\section{Statement of Financial Accounting Standards No. 5: Accounting for}

Contingencies (SFAS 5) is the current guidance for disclosure of loss contingencies. Under SFAS 5, loss contingencies, such as pending litigation, are required to be disclosed when the probability is "at least reasonably possible" that a material loss may be incurred (FASB 1975). Recently, the quality of firms' loss contingency disclosures has been criticized by investors, and a debate has developed about whether or not SFAS 5 should be amended (Desir et al. 2010). Investors have asserted that disclosures under SFAS 5 do not adequately allow them to predict and assess the likelihood, amount, and timing of future cash flows (FASB 2008; Desir et al. 2010). Investors further allege that too often firms are not disclosing loss contingencies until a material loss has been incurred, leaving them unable to appropriately incorporate contingencies into their judgments, which could lead to a suboptimal allocation of investors' resources (Cheney 2008; Desir et al. 2010). Because of the inherent vagueness in the verbal probability threshold under SFAS 5 of "at least reasonably possible", firms may be able to easily justify this lack of disclosure even for lawsuits with higher probabilities of loss (e.g., Reimers 1992; Amer et al. 1995; Piercey 2009).

In response to these concerns, the Financial Accounting Standards Board (FASB) issued Exposure Draft: Disclosure of Certain Loss Contingencies: An Amendment of FASB Statements No. 5 and $141(R)$ in June 2008. The FASB proposed lowering the probability threshold for disclosure of loss contingencies from "at least reasonably 
possible" to "more than remote" (FASB 2008, paragraph 5). This study investigates two unintended consequences of lowering a disclosure threshold.

\subsection{Disclosure of Lower Probability Lawsuits}

The Exposure Draft states that this lower threshold would "expand the population of loss contingencies that are required to be disclosed" (FASB 2008, p. vi). Thus, if the probability threshold for disclosure is lowered to "more than remote", the number of loss contingencies that would be required to be disclosed should increase for many firms. More recently, the FASB has also considered lowering the disclosure threshold even further to include some remote losses (FASB 2009). Thus, any additional disclosures that result from lowering the disclosure threshold would, by definition, relate to lawsuits with low probability of losses.

\subsubsection{Prospective Investors}

Psychology theory suggests that adding low probability lawsuits could potentially decrease investors' perceptions of litigation risk for the disclosure by decreasing the influence of the higher probability lawsuits (Nisbett et al. 1981; Tetlock and Boettger 1989; Hackenbrack 1992; Glover 1997; Hoffman and Patton 1997; Shelton 1999). That is, adding remote lawsuits to a disclosure may dilute, rather than add to, the impact of reasonably possible lawsuits if investors rely on the representativeness heuristic when judging the overall risk of loss due to disclosed litigation.

The representativeness heuristic is a natural cognitive strategy that people use to assess the likelihood of an event by comparing the similarity of the information about the event with other known events (Kahneman and Tversky 1972). The more similar the information about the possible event is to other known events, the more likely the event is 
predicted to be (Nisbett et al. 1981; Zukier 1982; Tversky and Kahneman 1983; Frederick and Libby 1986; Tetlock and Boettger 1989; Hackenbrack 1992).

For example, a higher probability lawsuit (i.e., a reasonably possible lawsuit) may call to mind other lawsuits that have led to material losses. However, additional low probability lawsuits may result in recollections of frivolous lawsuits. If investors rely on the representativeness heuristic to assess litigation risk, they may not perceive the additional, remote losses as adding to the reasonably possible loss, but rather lowering the similarity between the overall disclosure and lawsuits that generally lead to material losses. As a result, prospective investors may judge the firm's exposure to loss from the disclosed litigation lower, even though more lawsuits are disclosed.

\subsubsection{Long and Short Investors}

When investors take a long or a short position in a firm, theory and prior research suggest they hold the preferred conclusion that they will realize a positive return on their investment, and thus, that their investment decision was appropriate (Hales 2007; Han and Tan 2010; Thayer 2011). Consistent with their preferences for higher profitability and share price, long investors are motivated to interpret litigation disclosures as more favorable to the firm, while short investors (who require lower share prices in order to profit) are motivated to interpret litigation disclosures as less favorable.

Motivated reasoning theory suggests that when decision makers are motivated to arrive at a particular preferred conclusion, they use cognitive strategies that allow them to reach their directional goals, within reasonableness constraints (Kunda 1990). That is, people do not deliberately bias their judgments, but only reach a preferred conclusion to the extent that they can maintain an illusion of objectivity (Pyszczynski and Greenberg 
1987; Kunda 1990). Under the lower disclosure threshold, long and short investors will be motivated to perceive the likelihood of future losses consistent with their directional preferences, subject to reasonableness constraints. As Kunda (1990) notes, individuals tend to selectively use, interpret, and weight additional information in ways that support their directional preferences (see also Wilks 2002). Thus, under the lower disclosure threshold, long and short investors are likely to selectively search for and assimilate newly disclosed information about additional, relatively trivial lawsuits in a manner consistent with their motivated reasoning goals.

\subsection{Opportunistic Presentation of Lawsuits under a Lower Threshold}

Since firms have significant discretion in how they present these disclosures, it is likely that some managers will use the lower threshold to direct attention from higher probability lawsuits and portray the overall portfolio of contingent losses as favorably as possible. Such a presentation strategy would be consistent with the opinion that managers have already expressed regarding lower probability lawsuits (e.g., that they are often frivolous or filed only for publicity purposes (The Wall Street Journal 2008)). In addition, prior archival research provides evidence that managers try to present information in a light most favorable to the firm when disclosing information in order to persuade investors (Baginski et al. 2000; Schrand and Walther 2000). Thus, it is likely that some managers will attempt to present disclosures under the lower threshold in as favorable a light as possible.

Prior research has not examined how investors' directional preferences influence their judgments when management uses the discretion afforded them in accounting standards to strategically engage in opportunistic persuasion attempts. It is unclear a 
priori whether or not such a persuasion attempt would work as managers intend. I draw upon the persuasion knowledge model (PKM) and emphasis framing theory to form competing hypotheses for this effect.

PKM predicts that the influence of management's opportunistic presentation on investors' judgments may depend on investors' perspective. For example, long investors, preferring higher corporate profits / share prices, are more likely to be persuaded by management's opportunistic presentation. However, short investors, preferring lower corporate profits / share prices (so that they can personally benefit from their investment), are more likely to be skeptical of management's opportunistic presentation (Friestad and Wright 1994).

In contrast, emphasis framing theory predicts that this type of opportunistic presentation can work as intended. According to this theory, communicators can influence others' opinions by emphasizing particular considerations over other relevant considerations when giving their interpretation of an issue (Nelson et al. 1997; Nelson and Oxley 1999; Druckman 2001; McCaffery and Baron 2004; Maule and Villejoubert 2007; Slothuus 2008). For example, Shankar and Tan (2006) find audit preparers employ emphasis framing to persuade reviewers by using language that emphasizes evidence that supports their preferred conclusion and downplays evidence that contradicts their conclusion. In addition, prior research demonstrates that strategic persuasion attempts can be successful (Ricchuite 1999; Tan and Yip-Ow 2001; Kadous et al. 2005). This suggests that, by strategically framing litigation disclosures, management may successfully persuade investors to perceive the litigation in a more favorable light. 


\subsection{Overview of the Study}

In my experiment, nonprofessional investors were given financial statements and legal disclosures for a hypothetical pharmaceutical company and were asked to assess the likelihood of material loss due to disclosed pending litigation (i.e., litigation risk). Participants were randomly assigned to a long, prospective, or short investment position, and to one of three disclosure conditions. Participants received disclosures: (1) with a probability threshold of "at least reasonably possible" (i.e., consistent with existing SFAS 5); (2) with a probability threshold of "more than remote" (i.e., consistent with the FASB's proposed amendment); or (3) with a probability threshold of "more than remote" (i.e., consistent with the FASB's proposed amendment) and an opportunistic reporting strategy allowed by the lower threshold. The same reasonably possible lawsuit was presented in all three disclosure conditions because both SFAS 5 and the proposed amendment would require disclosure of lawsuits at this probability threshold. However, in both lower probability threshold conditions, three additional lawsuits with a slightly more than remote likelihood of leading to a material loss were also disclosed in either a more objective manner or in a more opportunistic manner designed to persuade investors to view the litigation, as a whole, as less serious.

\subsection{Preview of the Results}

The results of my study suggest that, when the probability threshold is higher (i.e., “at least reasonably possible"), investors assess the firms' litigation risk consistent with their directional preferences. Specifically, long investors assess the lowest and short investors assess the highest likelihood of firm loss, with prospective investors falling in between. However, when the probability threshold is lower, adding low probability 
lawsuits to the reasonably possible lawsuit causes prospective investors to assess a lower risk of loss to the disclosed litigation, even though more lawsuits are disclosed. In addition, my findings suggest that firms can use an opportunistic presentation under a lower threshold to deflect attention from higher probability to lower probability lawsuits, which leads all investor types to perceive pending litigation more favorably for the firm, despite their directional preferences. As such, prospective investors' and even short investors' judgments converge toward long investors' already favorable judgments when the disclosure threshold is lower and firms implement the opportunistic disclosure strategy it allows.

The results of my study have several important implications. My experimental design allows me to test potential unintended consequences of a proposed accounting standard, holding other factors constant (Kachelmeier and King 2002). These findings should be of interest to the FASB and other regulators as they consider modifications to disclosure thresholds and the form these disclosures should take. Although the FASB's goal in its exposure draft is to help investors make better judgments, these results should inform the FASB, as well as investors, that investors' cognitive and motivational biases may cause them to incorporate additional low probability lawsuits in a sub-optimal manner. My study also has implications concerning the form that disclosures should take. Under the lower threshold, managers would have both the incentive and the discretion to report opportunistically. My findings suggest such an opportunistic presentation can persuade all investors (long, prospective, and short) to view the litigation less critically. Therefore, it would be prudent for investors to remain attentive for management's persuasion attempts in an effort to decrease the influence of such attempts. 
Further, policy makers may want to more carefully contemplate whether and how pending litigation is disclosed, as such considerations can influence investors' judgments. While the SFAS 5 debate provides a timely setting for studying the consequences of expanding disclosure requirements, my findings may inform other situations in which similar disclosure expansions are being considered. For example, in 2010, the Securities and Exchange Commission (SEC) implemented new requirements that publicly traded companies disclose any risks that climate change might pose to their future operations or profits (SEC 2010). Firms could choose to disclose all risks objectively (i.e., present both more and less remote risks in a transparent manner). Alternatively, as this new mandate would require many firms to disclose more items, firms could use the new mandate to disclose information opportunistically (e.g., strategically disclosing a number of very remote risks to draw attention away from potentially more serious ones). Therefore, similar unintended consequences could potentially take place in other settings in which disclosure requirements are expanded, opening possible avenues for future research. 


\section{CHAPTER 2}

\section{LITERATURE REVIEW}

\subsection{Introduction}

This chapter reviews several areas of literature to develop a framework for studying the effects of lowering an accounting disclosure threshold on investors' judgments about firms' pending litigation. The second section discusses the recent debate surrounding the disclosure of loss contingencies. The third and fourth sections review the motivated reasoning and the dilution effect literatures, respectively. The fifth and sixth sections review the opportunistic reporting and persuasion literatures, respectively. Finally, the seventh section offers concluding remarks.

\subsection{Debate over Loss Contingency Disclosures}

Under the existing accounting standard for disclosure of loss contingencies, SFAS 5, management is required to disclose pending litigation if they believe the likelihood of a material loss is "at least reasonably possible" (FASB 1975). Recently, however, investors have asserted that too frequently firms are not disclosing loss contingencies until the loss has already been realized, leaving them unable to adequately assess the risks that companies are facing due to pending litigation (FASB 2008; Cheney 2008). In response to investors' claims, the FASB issued an Exposure Draft (FASB 2008) which proposes to lower the probability threshold for disclosure from "at least reasonably possible" to "more than remote." This would result in the disclosure of previously undisclosed lawsuits that fall between these two thresholds. ${ }^{1}$ As the FASB (2008) notes,

\footnotetext{
${ }^{1}$ Prior accounting research consistently finds that individuals judge the numerical equivalent of the phrase "remote" to be substantially lower than "reasonably possible" (typically around 10 percent versus approximately 50 to 60 percent) (Reimers 1992; Amer et al. 1994; Laswad and Mak 1997; Simon 2002). Further, many other verbal probability phrases have been shown to be more than remote but not reasonably
} 
lowering the probability threshold for disclosure would require many firms to disclose a larger number of lawsuits.

Managers and attorneys from many companies are strongly against expanding loss contingency disclosures. A recent Wall Street Journal editorial noted that: "Senior litigators from 13 companies, including Pfizer, General Electric, DuPont, Boeing and McDonald's have signed a letter to FASB Chairman Robert Herz, objecting to the plan. 'Too often, lawsuits are filed for publicity or to pressure companies, only to be dropped later,' they wrote" (The Wall Street Journal 2008, August 7, p. A12). Herz later responded, "The new disclosures are aimed at providing information earlier to existing and potential investors in order to give them a greater understanding of the risks companies are facing. I believe that information would improve their ability to make informed investment decisions" (Herz 2008). Thus, the contentiousness of this issue exists, in part, because firms assert that increased disclosures will lead to lower quality judgments if investors do not assimilate the information appropriately, while investors believe that increased disclosures will lead to better judgments since they will have more transparent information.

In general, the effect of lowering an accounting threshold on users' judgments has not been studied in the accounting literature. Thus, it is unclear how investors would incorporate additional low probability lawsuits into their perceptions of the likelihood of litigation losses. The recent debate surrounding the proposal to lower the threshold for disclosure of pending litigation provides a timely setting in which to study this effect.

possible, suggesting there is a gap along the probability continuum between these two terms (Amer et al. 1994; Laswad and Mak 1997). Thus, the idea of lowering the threshold for disclosure is to require firms to begin disclosing litigation that falls between these two probability thresholds (FASB 2008). 


\subsection{Motivated Reasoning}

Motivated reasoning has been studied extensively in the psychology literature as well as a variety of other applied areas, such as accounting. Motivated reasoning is a process by which a decision maker's preference for a particular conclusion results in a tendency to search for and interpret evidence in an effort to support or otherwise justify that conclusion (Kunda 1987, 1990, 1999; Pyszczynski \& Greenberg 1987). Because of this biased information search, decision makers are left with a biased set of evidence to interpret (Klayman and Ha 1987; Kunda 1990). Further, motivated reasoning theory suggests decision makers have a tendency to interpret this evidence in a manner consistent with their preferred conclusions (Kunda 1990; Ditto and Lopez 1992; Kunda 1999). Thus, motivated reasoning results in both a biased information search and biased interpretation of the resulting evidence. This tends to result in judgments that are more consistent with decision makers' preferred outcomes.

\subsubsection{Motivation to Reach an Accurate Conclusion or a Preferred Conclusion}

Motivated reasoning theory predicts that decision makers are often motivated to arrive at a particular preferred conclusion or at an accurate conclusion (Kunda 1990). Prior psychology research suggests that when decision makers have a motive to arrive at a preferred conclusion, they tend to engage in a biased and incomplete search for information while overweighting preference-consistent evidence and underweighting preference-inconsistent evidence (Kunda 1990; Ditto and Lopez 1992). Conversely, when decision makers are motivated to be accurate, they expend more cognitive effort on their task, attend to and process information more carefully, and generate and evaluate 
more hypotheses and more balanced sets of evidence (Kunda 1990; Ditto and Lopez 1992).

Psychology research suggests that information consistent with decision makers' preferences tends to be accepted with less scrutiny than information inconsistent with their preferences (Kunda 1999). In a well-cited study, Ditto and Lopez (1992) performed a series of experiments designed to test whether individuals are differentially skeptical of information that is preference-consistent versus preference-inconsistent. In their first experiment, participants were asked to decide which student (a likable student or a dislikable student) was more intelligent. The results show that participants looked at fewer items of information to determine that a dislikable student was less intelligent, but more items of information to determine that a dislikable student was more intelligent. However, in a control group where the students were described as equally likable (so participants did not hold a preferred conclusion), participants required equal information to make their judgment about intelligence. These results suggest that less information is required to reach a preferred conclusion than a non-preferred conclusion, consistent with motivated reasoning theory.

The second experiment in the Ditto and Lopez (1992) study asked participants to perform a fictitious medical test to determine whether or not they had a particular enzyme deficiency. The results show that participants led to believe they had the deficiency took more time to make their final decision about the result and were more likely to engage in a variety of behaviors to test and retest the validity of their result than participants led to believe they did not have the deficiency. In addition, participants led to believe they had the deficiency subsequently judged the accuracy of the test to be lower and rated the 
disorder as less serious and more common than participants led to believe they did not have the deficiency. These results suggest that when individuals are faced with evidence suggestive of a conclusion they prefer not to reach, they apply more scrutiny to the evidence, engage in a more thorough evaluation, attempt to gather more additional evidence, and spend more time on the task before arriving at a final conclusion.

A number of other psychology studies are consistent with the Ditto and Lopez (1992) findings. For example, Liberman and Chaiken (1992) find that when a message suggesting caffeine consumption is a threat to one's health was highly relevant to participants (i.e., when they were consumers of caffeine), they were less likely to believe in the validity of the message and found more weaknesses and fewer strengths with the message than when the threatening message was irrelevant to participants (i.e., when they were not consumers of caffeine). Edwards and Smith (1996) provide evidence that when arguments are preference-inconsistent, they are scrutinized longer and in more depth, and are also judged to be weaker than preference-consistent arguments. Ditto et al. (1998) find that when participants received favorable medical diagnoses, their evaluations of the accuracy of the diagnoses were not influenced by the probability of alternative explanations, however, when the diagnoses were unfavorable, participants' accuracy evaluations were influenced by the probability of alternative explanations. Lundgren and Prislin (1998) find that when participants are motivated to reach a directional conclusion, they spend more time reading arguments that are preference-consistent versus preferenceinconsistent. Together, this literature suggests that decision makers tend to search for, accept, and use preference-consistent evidence more than preference inconsistent- 
evidence, and they tend to think of alternative interpretations for preference-inconsistent evidence and scrutinize it more.

\subsubsection{Motivated Reasoning among Auditors and Tax Professionals}

Prior accounting research suggests that auditors and tax professionals engage in motivated reasoning to arrive at judgments that are consistent with their preferred conclusions (Cuccia et al. 1995; Hackenbrack and Nelson 1996; Wilks 2002; Kadous et al. 2003; Kadous et al. 2008). If preferred conclusions are sub-optimal, this can lead to poor judgment and decision making in a variety of accounting contexts (Bonner 2008). Much of the research in this area of the accounting literature has focused on situations where preferred conclusions are consistent with economic incentives. For example, research has examined how auditors' and tax professionals' judgments are influenced by their clients' or superiors' preferences (Cuccia et al. 1995; Hackenbrack and Nelson 1996; Kadous et al. 2003; Kadous et al. 2008; Wilks 2002).

One study demonstrating motivated reasoning among auditors is Hackenbrack and Nelson (1996). In their study, they manipulated engagement risk by telling auditors that their audit firm has either a high or a moderate exposure to fines, litigation, and loss of reputation regarding the audit discussed in the case. In addition, they manipulated the accounting standard used in the task by providing some auditors with a task that requires the use of SFAS 5 and other auditors a task that requires the use of SFAS 77.

Participants were given two alternative reporting choices (i.e., one aggressive and one conservative) that could be made depending on whether they believe uncollectible receivables are reasonably estimable. They were told the client prefers the aggressive option in all conditions. Auditors were asked to choose either the aggressive or 
conservative reporting option as well as to rate the degree to which they believe the amount could be reasonably estimated. Results indicate that auditors tended to make reporting decisions that were consistent with their incentives, and they used the vague language in accounting standards (i.e., "reasonably estimable") to justify their position. When engagement risk was high, they tended to favor the conservative option under both accounting standards. However, when engagement risk was lower they tended to favor the aggressive option. This suggests that even though auditors are supposed to be independent, they engage in motivated reasoning and justify their preferred conclusions by using the vague language in SFAS 5 and SFAS 77 to rationalize their reporting choice. Kadous et al. (2003) extend Hackenbrack and Nelson (1996) by investigating whether requiring auditors to evaluate the quality of various accounting methods mitigates (as regulators predicted) or exacerbates (as motivated reasoning theory predicts) auditors' tendency to comply with clients' preferred methods. Interestingly, they found that quality assessments actually exacerbate the influence of auditors' directional goals on their acceptance of clients' preferred aggressive accounting treatments.

In addition to auditors' tendencies to reach the preferred conclusions of their clients, auditors have also been shown to adopt their superiors' preferred conclusions (Wilks 2002). In one experimental condition, participants were told that the partner was concerned that, in prior years, his audit team was unduly optimistic in its evaluation of evidence relevant to the going-concern task, while in another experimental condition, they were told the partner feels past audit teams have been too pessimistic. In addition, the timing of the partner's concern was manipulated by telling participants about the partner's concern either immediately before or after they evaluated evidence items related 
to the going-concern task. Participants were then asked to evaluate twenty evidence items pertaining to a client's going-concern status and then make a going-concern judgment. The results indicate auditors who were told of the partner's concern before evaluating evidence judged the individual evidence items and made going-concern judgments that were more consistent with the partner's preferred conclusion than auditors who were told about the partner's concern after evaluating the evidence. These findings suggest that auditors engage in directional processing of evidence when they know the audit partner's preferred conclusion prior to evidence evaluation.

Prior accounting research has also investigated the influence of tax professionals' preferred conclusions on their judgments. One study in this area is Cuccia et al. (1995). Tax professionals in this study were given a description of a tax issue, relevant guidance on the issue, a description of the client, and a fictitious practice standard. Tax professionals' preferred conclusions were manipulated by describing the client as having either an aggressive or a conservative preference for the preparation of their taxes. Participants were asked to make a reporting decision (i.e., an aggressive or conservative choice), to make an assessment of the evidence supporting their decision, and to interpret the vague language used in the accounting standard. The results suggest that tax professionals' judgments were more conservative when their client's preferences were more conservative and more aggressive when their client's preferences were more aggressive. Results also suggest tax professionals use the intrinsic vagueness in a verbal accounting standard or in the facts to justify reporting decisions that are consistent with their client's preferences. 
In more recent research, the influence of clients' preferred conclusions on tax professionals' judgments has been shown to be reduced when the costs of making inappropriate judgments are made salient (Kadous et al. 2008). Future research may follow the lead of Kadous et al. (2008) by investigating other variables that may reduce the influence of clients' preferred treatments on both auditors' and tax professionals' judgments.

Much of the research described above examines settings in which decision makers' preferred conclusions are also consistent with their economic incentives. Thus, the cognitive influence of auditors' and tax professionals' preferred conclusions on their judgments is difficult to isolate when their preferred conclusions are also aligned with their economic incentives (e.g., adopting the preferred conclusion of a client or audit partner). It is possible that auditors and tax professionals are merely rationally reacting to their economic incentives by interpreting evidence and making judgments consistent with those incentives. Thus, the extent to which motivated reasoning in accounting settings is purely a rational reaction to economic incentives versus a psychological bias resulting from holding a preferred conclusion is difficult to determine in the auditing and tax contexts studied to date (Hales 2007).

\subsubsection{Motivated Reasoning among Nonprofessional Investors}

Studying the influence of directional preferences on nonprofessional investors' judgments allows researchers to separate rational reactions to economic incentives from the purely motivational biases predicted by motivated reasoning theory (Hales 2007). According to economic theories, nonprofessional investors should process information objectively in order to reach the most accurate conclusion about a particular investment 
(Hales 2007). If investors process information in a non-objective manner, it could lead to a sub-optimal allocation of resources within their portfolios and, therefore, lower returns. Prior accounting studies examining the influence of motivated reasoning goals on nonprofessional investors' judgments show that nonprofessional investors tend to make judgments consistent with the preferred conclusion that they will earn a positive return on their investment, even though they have an economic incentive to be objective (Hales 2007; Han and Tan 2010; Thayer 2011).

The first study that examined the influence of directional preferences on nonprofessional investors' judgments is Hales (2007). In his study, investor participants were presented with a real (but unidentified) firm's EPS for the prior four years, along with excerpts from press releases, individual analysts' and consensus forecasts, and selected comments from analysts' reports. Investors' directional preferences were manipulated by assigning participants to take a long or a short position in the firm. In addition, half of the participants were provided with an earnings benchmark that was three cents above the consensus analyst forecast and the other half were provided with a benchmark that was three cents below the forecast. This created the following four experimental conditions: (1) short investors receiving preference-inconsistent information (i.e., an earnings benchmark above the consensus forecast), (2) short investors receiving preference-consistent information (i.e., an earnings benchmark below the consensus forecast), (3) long investors receiving preference-inconsistent information (i.e., an earnings benchmark below the consensus forecast), and (4) long investors receiving preference-consistent information (i.e., an earnings benchmark above the consensus forecast). Participants were asked to make EPS forecasts for the firm, and were given a 
monetary incentive to be as accurate as possible by making forecasts as close to the firm's real EPS as possible. Results suggest that investors tended to interpret information differently depending on their investment position in the firm (i.e., long or short), particularly when the information was preference-inconsistent. This is particularly striking because participants also had a salient economic incentive to be objective and make an accurate EPS forecast. Yet, they tended to agree with information that suggested they might have a profit on their investment and disagree with information that suggested they might have a loss, consistent with motivated reasoning theory. Thus, Hales (2007) demonstrates that nonprofessional investors are influenced by their preferred conclusions, even when they have an economic incentive to be accurate.

Thayer (2011) is another related study in this literature. In this study, nonprofessional investors were assigned to either a long or a short investment position. They were asked to choose one firm (out of two) in which to take that assigned position. Following Hales (2007), half of the participants are provided with an earnings benchmark that is four cents above the consensus analyst forecast and the other half are provided with a benchmark that is four cents below the forecast. This design created four experimental conditions which manipulated whether the information is good news (i.e., preference-consistent) or bad news (i.e., preference-inconsistent) with respect to the profitability of the participant's investment position. Participants received quarterly earnings information and historical stock prices for the past three years, as well as consensus and ranges of four individual analysts' forecasts for the upcoming year. After receiving the preference-consistent (or preference-inconsistent) information, participants were given the option of searching for more information by viewing the analysts' detailed 
forecasts before making a final EPS forecast for their firm. Results suggest nonprofessional investors searched for a greater amount of additional information after receiving preference-inconsistent news about their investment than when they received preference-consistent news, supporting the predictions of motivated reasoning theory.

Han and Tan (2010) is another recent study to examine the influence of nonprofessional investors' directional preferences on their judgments. Nonprofessional investors' directional preferences were manipulated by assigning participants to take a long position, a short position, or no position in a firm (i.e., a control condition similar to a prospective investor position). Participants were asked to make earnings forecasts and investment-related judgments after receiving management's earnings guidance. Both the valence (positive or negative news) and format (point estimate or range) of management's earnings guidance was manipulated. The results suggest that nonprofessional investors' directional preferences influenced their interpretations of management's guidance more as the ambiguity of the guidance increased (i.e., when guidance was positive and provided as range). The authors posit that the reason for this is likely to be because a range is ambiguous and allows long and short investors to interpret the range guidance in a manner consistent with their preferences. In addition, since management has greater incentives to disclose good news than bad news, long investors receiving good news from management may take it at face value, while short investors may discount it as self-serving. The results demonstrate that nonprofessional investors' judgments are influenced by the form and direction of management's earnings guidance differently depending on their motivated reasoning goals. 
In general, this literature suggests that nonprofessional investors process information differently depending on whether it is consistent or inconsistent with their preferred conclusions about their investment, consistent with psychology research on motivated reasoning. In an investment setting, unlike generic psychology settings, this literature demonstrates that the influence of motivated reasoning goals persists even when decision makers (e.g., nonprofessional investors) have an economic incentive to evaluate information in an objective manner.

\subsubsection{Motivated Reasoning within Reasonableness Constraints}

Motivated reasoning theory also suggests that the influence of decision makers' preferred conclusions will be bounded by reasonableness constraints (Pyszczynski and Greenberg 1987; Kunda and Sanitioso 1989; Kunda 1990, 1999). When a preferenceconsistent conclusion deviates from salient benchmarks, it becomes more difficult for people to justify a preferred conclusion (Pyszczynski and Greenberg 1987). A sufficiently large deviation between the preferred conclusion and the information invokes reasonableness constraints. That is, people do not overtly bias their judgments, but only reach a preferred conclusion to the extent that they can maintain an illusion of objectivity (Pyszczynski and Greenberg 1987; Kunda 1990). Kunda notes (1999, p. 224), "Motivation can color my judgment, but we are not at liberty to conclude whatever we want to conclude simply because we want to. Even when we are motivated to arrive at a particular conclusion, we are also motivated to be rational and to construct a justification for our desired conclusion that would persuade a dispassionate observer. We will draw our conclusion only if we can come up with enough evidence to support it." 
For example, Kunda and Sanitioso (1989) demonstrate how the influence of motivated reasoning is bounded by reasonableness constraints. In their study, graduate student participants' preferred conclusion was manipulated by providing them with the results of a fictitious study that claimed academic success is related to either extroversion or introversion. Participants were then shown a number of trait adjectives on a computer screen one at a time. Participants were asked to respond to each trait by selecting whether the trait described them or not. The results show participants led to believe introversion was related to success tended to select fewer extroversion traits as selfdescriptive than did participants led to believe extraversion was related to success.

A number of studies in the accounting literature have investigated motivated reasoning within reasonableness constraints. One such study is Kadous et al. (2003). The findings of this study suggest that auditors' agreement with their clients' preferred accounting treatment increases when auditors perform a quality assessment to determine the most appropriate method. However, the authors posit that this can only occur to the extent that the client's preferred treatment can be reasonably justified as a sufficiently acceptable method.

Ng and Shankar (2010) investigate how advice from an audit firm's technical department and the strength of the client's justification for their preferred treatment moderate the findings of Kadous et al. (2003) by changing auditors' reasonableness constraints. The results suggest that quality assessments do reduce auditors' agreement with their client's preferred treatment when the audit firm's technical department explicitly advises the use of the most appropriate method (which differs from the client's preference) and when the client's justification for their preferred treatment is strong. 
The authors posit this occurs because the technical department's advice to use a more appropriate method tightens auditors' reasonableness constraints, making it more difficult for them to continue to support their client's preferred treatment when advised of a more appropriate method. This effect is more observable when the client provides a strong (rather than a weak) justification for their preference because auditors are more likely to already agree with the client's preference when their arguments in favor of the treatment are strong. Thus, when the client's justification is strong, there would be more room for auditors' agreement to decrease (as their reasonableness constraints shift) in response to the technical department's advice.

\subsection{Dilution Effect}

The weight decision makers give to certain items of information can be diluted (i.e., reduced), when additional information is also considered. For example, the dilution effect occurs when the presence of irrelevant information weakens the implication of relevant information (Nisbett et al. 1981). The dilution effect was first documented in the psychology literature, but it has also been studied in applied settings, such as accounting, for many years. Typically, studies on the dilution effect show that judgments made using both diagnostic and nondiagnostic evidence are less extreme than judgments made using diagnostic evidence only. For example, Nisbett et al. (1981) is an early study of the

dilution effect. In that study, participants predicted the GPA of a student when they were provided with only relevant information (i.e., they were told the student studied for either 3 hours or 31 hours per week). Participants moderated their judgments about the student's GPA when they also received information that pretest participants judged to be irrelevant (e.g., the number of plants the student kept). 
Throughout the literature, researchers have posited that the dilution effect results because people use the representativeness heuristic to make likelihood assessments (Kahneman and Tversky 1972; Tetlock and Boettger 1989; Hackenbrack 1992; Shelton 1999; Bonner 2008). The representativeness heuristic is a natural cognitive strategy that people use to judge the likelihood of a potential event by comparing the similarity of the information about the potential event with other known events (Kahneman and Tversky 1972). According to this theory, people will judge the likelihood of a potential event by comparing the information about it to their mental representations of other known events. The more similar the information about the potential event is to people's mental representations of other known events, the higher their likelihood judgments are predicted to be (Nisbett et al. 1981; Zukier 1982; Tversky and Kahneman 1983; Frederick and Libby 1986; Tetlock and Boettger 1989; Hackenbrack 1992).

There have been several studies in the psychology literature that have investigated boundary conditions of the dilution effect. For example, Zukier and Jennings (1983) found that the dilution effect does not hold when the nondiagnostic information is extreme and atypical. Further, other studies suggest that when people's beliefs about the diagnosticity of the information are weak, the dilution effect does not hold (Ruble and Stangor 1986; Higgins and Bargh 1987; Fiske and Neuberg 1990).

In an effort to investigate methods to debias the dilution effect, psychologists have found a factor that unexpectedly amplifies the dilution effect. That is, Tetlock and Boettger (1989) found that accountability exacerbates the dilution effect. The authors suggest this probably occurs because accountability increases participants' complexity of thought. As participants' thoughts become more complex and integrative, they tend to 
suffer from the effects of dilution more because they are more attentive to all of the evidence provided.

\subsubsection{Dilution Effect in the Accounting Literature}

Studies investigating the dilution effect in accounting to date are generally set in auditing contexts. Recently, researchers in accounting have begun to question whether the dilution effects documented in auditing studies exist in other accounting settings, such as investment settings (Bonner 2008).

In general, studies in the accounting literature are consistent with the dilution effect. For example, Hackenbrack (1992) found evidence of the dilution effect in an audit setting. He asked auditors to first make judgments about how much a company's exposure to fraudulent reporting changed during a year when they were given both diagnostic and nondiagnostic information. Then, he asked them to make the same judgment using only diagnostic information. Findings show that auditors' probability of fraud judgments were less extreme when both relevant and irrelevant information was presented than when they received only relevant information.

Hoffman and Patton (1997) also find support for the dilution effect in an auditing task. This study provides evidence that accountability does not exacerbate the dilution effect among auditors. The authors argue this probably resulted since auditors tended to make more conservative judgments when held accountable since they are trained to be conservative and likely anticipate their superiors' preference for conservative judgments. This result is contrary to the findings of Tetlock and Boettger (1989) in the psychology literature, who suggest that accountability exacerbates the dilution effect. However, in generic psychology studies participants could not anticipate the preferences of those to 
whom they were accountable, which could explain the reason for these divergent findings across disciplines.

Prior work in this area of the accounting literature has found factors that moderate the dilution effect. For example, Glover (1997) found that accountability had no influence on the dilution effect, but that when auditors were put under time pressure, the dilution effect was reduced but not eliminated. Shelton (1999) found that the dilution effect was moderated by experience in an audit going concern judgment task. Auditors with different levels of experience were asked to make a going concern judgment either with only diagnostic evidence or with both diagnostic evidence and nondiagnostic evidence. The results suggest that audit seniors' judgments suffer from dilution but audit managers' and partners' judgments do not. This suggests that, as people gain expertise in a field, they may become better at filtering out irrelevant information and only incorporate relevant information into their judgments.

In general, findings in accounting are consistent with the dilution effect; however there are some inconsistencies between the psychology findings and findings in auditing settings. These inconsistencies are likely due to the unique audit environment. Since the studies that have been done on the dilution effect in accounting are mostly in audit settings, future research should investigate dilution effects in other accounting settings, such as investment tasks. This would enable accounting researchers to further develop a theory of dilution (Bonner 2008).

\subsection{Opportunistic Reporting by Management}

For a number of reasons (e.g., power, obtaining goals, being liked), we prefer to present ourselves in the most favorable light possible to manage others' impressions of us 
(Baumeister 1982; Leary and Kowalski 1990; Nezlek and Leary 2002; Fiske and Taylor 2008). Similarly, managers of firms also prefer to present themselves and their firms in a favorable light (Baginski et al. 2000; Schrand and Walther 2000). Hackenbrack and Nelson (1996, p. 43) note, "Managers have incentives to use accounting standards to report in ways that are in their best interest, even at the expense of stakeholders." Bloomfield (2002, p. 238) also notes, "Managers make many decisions motivated, at least partly, by a desire to make it harder for investors to uncover information that the managers do not want to affect their firms' stock prices."

Management's propensity for opportunistic reporting is a well documented and commonly studied in the accounting literature both experimentally and archivally (Hackenbrack and Nelson 1996; Baginski et al. al 2000; Schrand and Walther 2000; Bloomfield 2002; Barton and Mercer 2005; Krische 2005; Hirst et al. 2007). For example, Baginski et al. (2000) report archival evidence suggesting management tends to explain bad news in voluntary disclosures by attributing it to external factors outside of management's control, but they tend to attribute internal causes to good news. Thus, managers appear willing to take credit for things that go right, but distance themselves from things that go wrong.

Barton and Mercer (2005) experimentally investigated how financial analysts react to management's external attributions for bad news. They provided financial analysts with historical financial statement information showing a firm that experienced poor performance over the year. Two groups of analysts received management's explanation for the poor performance, which provided an external cause for the bad news. For half of the participants, management's explanation was plausible, and for the other 
half, the explanation was implausible. There was also a control group that did not receive any explanation from management. Results show that when management's external attributions were plausible, analysts made higher stock price judgments and earnings forecasts than when the attributions were implausible. This suggests that if management provides implausible external attributions for bad news in voluntary disclosures in an attempt to persuade investors, it may not work as intended by management. Instead, it may backfire among professional investors (e.g., analysts).

Further evidence of managers' tendencies to be opportunistic is provided by Schrand and Walther (2000). They present archival evidence suggesting that managers strategically select the prior-period earnings benchmark that they use to compare to current earnings. Managers appear to be more likely to remind investors of a prior loss than a prior gain. Including prior period losses but not prior period gains in an earnings benchmark creates a lower benchmark which is used to compare to current earnings. This creates the perception of a larger positive change in earnings. After providing evidence of management's opportunistic choice of benchmark, the authors also provide archival evidence that investors appear to be influenced by management's strategic choice of benchmark. They provide an analysis of excess stock returns at the earnings announcement date which suggests investors use the benchmark that managers provide to evaluate current earnings.

Krishe (2005) experimentally investigates why managers' strategic choice of earnings benchmark influences investors' judgments. Results suggest that nonprofessional investors' evaluations of a firm's current period earnings were influenced by whether or not management used earnings benchmarks which strategically 
included prior period losses but not prior period gains. These results are consistent with the archival evidence provided by Schrand and Walther (2000). Further, results suggest that the effect seems to be driven by limitations in nonprofessional investors' memories for the prior period gain or loss. Results also suggest that when management reminds investors of the prior period gain or loss in the current period earnings announcement, this effect is reduced. In general, this stream of research suggests that nonprofessional investors are influenced by the opportunistic disclosures of managers.

\subsection{Methods of Persuasion}

There are many theories of persuasion that have been studied in basic disciplines such as psychology and in applied disciplines such as accounting, marketing, and political science. For example, Emphasis Framing Theory (e.g., Nelson et al. 1997; Druckman 2001) is a persuasion theory primarily developed in the political science literature, and the Persuasion Knowledge Model (e.g., Friestad and Wright 1994) is a persuasion theory primarily developed in the marketing literature. Although individual persuasion theories differ in their specific predictions, they are all concerned with how a person's attitudes or behaviors can be changed by the social influence of others (Bonner 2008; Fiske and Taylor 2008). Emphasis Framing Theory and the Persuasion Knowledge Model are discussed in the following sub-sections. These theories have divergent predictions about how investors' positions in a firm would influence how they respond to management's opportunistic legal disclosures.

\subsubsection{Emphasis Framing}

Emphasis framing theory suggests communicators can influence others' opinions by emphasizing particular considerations over other relevant considerations when giving 
their interpretation of an issue (Nelson et al. 1997; Nelson and Oxley 1999; Druckman 2001; McCaffery and Baron 2004; Maule and Villejoubert 2007; Slothuus 2008). For example, a politician may strategically emphasize a particular issue (e.g., the economy), over other relevant issues (e.g., foreign policy) during a campaign. Assuming economic issues are a strength of the politician, framing the campaign around the economy may allow the politician to persuade voters to perceive the economy as an important aspect of the election and, in turn, make them more likely to vote for this candidate.

Emphasis framing theory has been primarily studied in the political science literature. Nelson et al. (1997) examined emphasis framing effects by asking undergraduate students to make judgments about the Ku Klux Klan (KKK) after watching a local news story about a recent KKK rally. The researchers manipulated the frame of the news story by reporting the rally in terms of the KKK's right to free speech or in terms of the KKK's disruption of public order. In the free speech frame, the reporter emphasized the right of KKK members to speak in public and the right of their supporters and the public to listen to what they had to say. In the disruption of public order frame, the reporter emphasized the disturbances that ensued during the rally which included visuals of police officers in riot gear. Interestingly, when the news story was framed in terms of free speech, participants' judgments tended to be more tolerant of the KKK than when it was framed as a disruption of public order. The results of this study suggest that by strategically emphasizing a particular relevant aspect of an issue, communicators are able to influence individuals' judgments in a particular direction.

Nelson et al. (1997) note that, with emphasis framing, communicators of politically persuasive messages "devote considerable effort toward influencing not only 
what information gets on the air but how it is presented" (Nelson et al. 1997, p. 224). A communicator may introduce individuals to aspects of an issue that they were not previously aware of, or were not previously considering, by framing an issue with a subset of relevant information. Entman (1993) notes that framing effects depend on the recipient's cognitive schemata. For example, Druckman finds that, while they still exist, emphasis framing effects are less pronounced among people with expertise than without expertise in the domain.

In general, this stream of research in the political science literature suggests that emphasis framing effects are most prominent when the target of the message is not an expert on the issue. This suggests that nonprofessional investors may be particularly prone to emphasis framing effects in financial disclosures due to their lack of expertise in the subject matter.

\subsubsection{Emphasis Framing in Accounting Contexts}

There are a few recent studies that investigate emphasis framing effects in accounting settings (Tan and Yip-Ow 2001; McCaffery and Baron 2004; Shankar and Tan 2006; Lambert and Agoglia 2010). These studies have investigated emphasis framing in audit review and tax settings. To date, there has not been any emphasis framing studies done in investment contexts. In general, these studies suggest that auditors and tax professionals are persuaded by emphasis framing in certain accounting contexts, but research on these effects in the accounting literature is just beginning.

Tan and Yip-Ow (2001) examine audit preparers' use of emphasis framing to stylize workpapers that persuade reviewers. They used an experiment in which participants reviewed the work of an audit preparer who had either concluded that the 
client's major customer's account was either collectable or uncollectable. The participants were also provided workpapers that emphasized evidence which supported the preparer's conclusion and downplayed evidence that did not support the conclusion or workpapers with evidence that was not framed. Participants used the workpapers and conclusion provided by the preparer to make their own assessment about the collectability of a customer's account. Results suggest that reviewers placed less weight on the preparer's conclusion when the workpapers were stylized versus neutral. This suggests that reviewers may see through preparers' stylization attempts and do not seem to suffer from emphasis framing effects in this setting. However, this finding appears to be at odds with what would be expected based on emphasis framing theory from the political science and mass media literatures. It is also somewhat inconsistent with other recent auditing research which suggests that reviewers are often not very good at adjusting for shortcomings in preparers' workpapers, and thus would be likely to suffer from emphasis framing effects (Agoglia et al. 2009a; Agoglia et al. 2009b). These inconsistencies could be due to the subtle nature of the framing manipulation in Tan and Yip-Ow (2001). However, the underlying reasons could be investigated in future research.

A more recent study on emphasis framing in the accounting literature is Shankar and Tan (2006). This study examines the nature and extent of audit preparers' workpaper justifications when their conclusions are either similar or dissimilar to a reviewer's preferred conclusion. After reading case materials, auditors were asked to make an initial assessment about whether to allow a client to provide footnote disclosure regarding the collectability of accounts receivable or to require an allowance for doubtful accounts. 
Then, the next day, participants were informed of the reviewer's preferred treatment. Participants were then asked to write a memo to the reviewer justifying their assessment (made the day before) about the appropriate accounting treatment to use. Participants' tacit managerial knowledge and technical knowledge were measured independent variables. The results show that audit preparers with high tacit managerial knowledge were more likely than preparers with low tacit managerial knowledge to use emphasis framing to strategically present audit evidence to support their conclusion when the reviewer prefers the same accounting treatment. Technical knowledge did not moderate this effect. These results suggest that audit preparers with high tacit managerial knowledge use emphasis framing to persuade reviewers with similar preferences by using language that emphasizes evidence that supports the their preferred conclusion, while downplaying evidence that does not support their preferred conclusion.

Lambert and Agoglia (2010) examine emphasis framing in an audit review context. Participants' task involved closing review notes on audit workpapers. The review was either completed in a timely manner or with a time delay. After the review was completed, participants were presented with seven review notes, four of which contained a framing manipulation. Holding the reviewer's directive constant, the review notes were framed by either emphasizing the importance of documentation in the workpapers or by emphasizing the importance of drawing an appropriate conclusion. The results suggest that conclusion-framed review notes resulted in greater effort levels among preparers while closing the notes than documentation-framed review notes, but only when the review was timely. This study demonstrates that the way an audit reviewer frames review notes influences how preparers respond to their review notes. 


\subsubsection{Persuasion Knowledge Model}

Another theory that may predict how nonprofessional investors holding particular investment positions in a firm react to opportunistic disclosures is the Persuasion Knowledge Model (PKM). PKM predicts how people cope with the persuasion attempts of others (Friestad and Wright 1994). This theory describes targets of persuasion as "resourceful participants who pursue their own goals" in the interpretation of a persuasive message and not merely passive information processors (Friestad and Wright 1994, p. 3). Targets of a persuasive message are posited to consider their own goals or desired outcomes and to select coping mechanisms that will enable them reach their goals (Friestad and Wright 1994; Kirmani and Campbell 2004).

Consumers are thought to develop persuasion knowledge throughout life (Friestad and Wright 1994). Persuasion knowledge is suspicion about marketers' ulterior motives (Kirmani and Zhu 2007). Targets of persuasive messages are hypothesized to draw upon their own persuasion knowledge to identify when a communicator is attempting to persuade them (Friestad and Wright 1994; Kirmani and Zhu 2007). Importantly, PKM predicts that targets will not always use coping mechanisms to try to resist persuasion attempts. Instead they may be receptive to persuasion attempts if that information allows them to reach their goals (Friestad and Wright 1994).

Campbell and Kirmani (2000) found that consumers apply their persuasion knowledge to cope with the persuasion attempts of salespeople when salespeople's persuasion motives are more salient to them. When salespeople's motives are more salient, deep processing of the message is not necessary for consumers to use their persuasion knowledge to process the interaction. However, when salespeople's 
persuasion motives are less salient to consumers, their use of persuasion knowledge involves higher-order reasoning that requires they engage in deeper processing of the interaction. In general, the results suggest that a target's persuasion knowledge is more likely to be activated when the target expends more effort processing the persuasive message.

Kirmani and Zhu (2007) extend the work of Campbell and Kirmani (2000). Their study suggests that even when holding depth of processing constant, persuasion knowledge can influence consumers' judgments differently depending on motivational factors. Kirmani and Zhu (2007) examine the effect of an interesting motivational factor, regulatory focus, on consumers' activation of persuasion knowledge. Regulatory focus is the relationship between the motivation of a person and the way in which they achieve their goal (Higgins et al. 1994). That is, people are thought to be motivated to reach their goals in a way that either focuses on maximizing gains (i.e., promotion-focus) or focuses on minimizing losses (i.e., prevention-focus). Promotion-focused people perceive their goals as hopes and aspirations (e.g., I want to purchase a superior product, so I eagerly process positive information about the product), while prevention-focused people perceive their goals as duties and obligations (e.g., I want to purchase a superior product, so I must be vigilant and make sure I process negative information about the product). Promotion-focused people are more likely to focus on positive signals in information that allow them to reach their goals. In contrast, prevention-focused people are more likely to focus on negative signals in information that would prevent them from reaching their goal. Kirmani and Zhu (2007) manipulate consumers' regulatory focus by priming participants to either think about their hopes, dreams, and ideals or to think about their 
duties, obligations, and responsibilities prior to assessing an advertisement. They also manipulated the salience of the advertiser's persuasive intent within the advertisement to be low, medium, or high. They asked participants to assess their attitude toward the advertised brand and their perceived quality of the brand. They also gathered measures of participants' persuasion knowledge through a skepticism scale and thought protocols. They found that when the advertiser's persuasive intent is medium or high, preventionfocused consumers are more likely to activate their persuasion knowledge than promotion-focused consumers. The results of this study suggest that motivational factors can influence how consumers' interpret persuasive advertising messages through differential activation of persuasion knowledge.

Another related study in this literature is Kirmani and Campbell (2004). They provide qualitative evidence about how consumers respond to salespeople's persuasion attempts. They find that consumers' relationships with salespeople and experience with persuasion interactively affect consumers' coping strategies. They conceptualize consumers as either "goal seekers" or "persuasion sentries". Goal seekers attempt to use the salesperson to achieve their own goals, whereas persuasion sentries attempt to guard against unwanted persuasion attempts. They find that consumers are more likely to be goal seekers when they have a cooperative or highly dependent relationship with salespeople. In contrast, consumers are more likely to be sentries when they have a competitive or a task-oriented relationship with salespeople. The results of Kirmani and Zhu (2007) have been tied to Kirmani and Campbell (2004). That is, sentry strategies may be more likely to be used when consumers have a prevention-focus and seeker strategies may be more likely to be used when consumers have a promotion-focus. 
In general, these results suggest that people with different motivations may be differentially persuaded by a message. Since long, short, and prospective investors hold different motivations with respect to a particular firm, they may be differentially persuaded by management's opportunistic disclosures if PKM is a descriptive theory in investment settings.

\subsubsection{Persuasion Knowledge Model in the Accounting Literature}

Most of the studies that have examined PKM have been marketing studies. However, there have been a few studies in the accounting literature that have used PKM to test predictions about how auditors and managers make judgments using persuasive information.

For example, Rich et al. (1997) characterizes the audit review process from a persuasion perspective that is based on the persuasion knowledge model. During the review process, audit preparers are likely to present stylized workpapers to audit reviewers in order to persuade reviewers that the work performed and conclusions reached by the preparer are appropriate and justified. This study describes a number of persuasion tactics that preparers can use to stylize their workpapers such as a biased selection, ordering, and framing of evidence. The researchers also posit that audit reviewers may learn coping strategies to deal with the persuasion attempts put forth by preparers, but that reviewers may also be "co-composers" of the persuasive message started by preparers as reviewers' work, in turn, is passed on to a superior. Consistent with PKM, the authors theorize that reviewers' selection of coping mechanisms depends on their own goals. 
Kadous et al. (2005) also draw upon the persuasion knowledge model in developing their model of how quantified information influences managers' judgments. The researchers note that conventional wisdom suggests that quantified information is more persuasive than non-quantified information. However, they suggest that according to PKM this may not always be the case. They develop and test a model in a setting where a manager is writing a proposal intended to persuade colleagues to postpone routine, but expensive, maintenance on machinery. The results of this study suggest that managers will draw upon their persuasion knowledge to cope with the persuasion attempts of colleagues presenting proposals. The extent of their coping strategies depends on contextual factors related to the source of the message and the objectivity of the information underlying the message itself.

Kaplan et al. (2008) is a recent auditing study suggesting that, as auditors become more experienced, they develop persuasion knowledge which allows them to cope with their clients' persuasion attempts. This study demonstrates that, as auditors gain professional experience, they tend to be less accepting of management's self-serving persuasive messages, presumably because auditors gain persuasion knowledge throughout their careers.

\subsection{Conclusions}

In this chapter I have reviewed the literature from accounting, psychology, marketing, political science, and other fields that is relevant to motivated reasoning theory, the dilution effect, management's opportunistic reporting behavior, emphasis framing theory, and the persuasion knowledge model. In the following chapter, I use this 
research to build hypotheses. I will also describe the experimental method I use to test these hypotheses in the subsequent chapter. 


\section{CHAPTER 3}

\section{HYPOTHESES AND METHODOLOGY}

\subsection{Introduction}

This chapter develops hypotheses and discusses the methods I used to test my hypotheses. The second section draws upon relevant theory and prior research to develop the hypotheses. The third section discusses the experimental methods that I used to test my hypotheses.

\subsection{Development of Hypotheses}

\subsubsection{Debate over SFAS 5: Threshold for Disclosing Loss Contingencies}

Under the current accounting standard for disclosure of loss contingencies, SFAS

5, management must disclose pending lawsuits if they believe the likelihood of a material loss is "at least reasonably possible" (FASB 1975). Recently, however, investors have asserted that too often firms are not disclosing loss contingencies until the loss has already been realized, leaving them unable to appropriately assess the risks that companies are facing due to pending litigation (FASB 2008; Desir et al. 2010). In response to investors' assertions, the FASB issued an Exposure Draft (FASB 2008) which proposes to lower the probability threshold for disclosure from "at least reasonably possible" to "more than remote." This would result in the disclosure of previously undisclosed lawsuits that fall between these two thresholds. ${ }^{2}$ As the FASB (2008) notes,

\footnotetext{
${ }^{2}$ Recall that prior accounting research consistently finds that individuals judge the numerical equivalent of the phrase "remote" to be substantially lower than "reasonably possible" (typically around 10 percent versus approximately 50 to60 percent) (Reimers 1992; Amer et al. 1994; Laswad and Mak 1997; Simon 2002). Further, many other verbal probability phrases have been shown to be more than remote but not reasonably possible, suggesting there is a gap along the probability continuum between these two terms (Amer et al. 1994; Laswad and Mak 1997). Thus, the idea of lowering the threshold for disclosure is to require firms to begin disclosing litigation that falls between these two probability thresholds (FASB 2008).
} 
lowering the probability threshold for disclosure in this way would require many firms to disclose a greater number of lawsuits.

Managers and attorneys from many companies are strongly opposed to expanding loss contingency disclosures. A recent Wall Street Journal editorial noted that: "Senior litigators from 13 companies, including Pfizer, General Electric, DuPont, Boeing and McDonald's have signed a letter to FASB Chairman Robert Herz, objecting to the plan. 'Too often, lawsuits are filed for publicity or to pressure companies, only to be dropped later,' they wrote" (The Wall Street Journal 2008, August 7, p. A12). Herz later responded, "The new disclosures are aimed at providing information earlier to existing and potential investors in order to give them a greater understanding of the risks companies are facing. I believe that information would improve their ability to make informed investment decisions" (Herz 2008). Thus, the contentiousness of this issue exists, in part, because firms argue that increased disclosures will lead to worse judgments if investors do not incorporate the information appropriately, while investors believe that increased disclosures will lead to better judgments since they will have more transparent information.

\subsubsection{Investors' Motivated Reasoning Goals and Economic Incentives}

Motivated reasoning theory suggests that decision makers often either have a motive to arrive at a particular preferred conclusion or an accurate conclusion (Kunda 1990). Prior psychology research suggests that when decision makers have a motive to arrive at a preferred conclusion, they tend to conduct a biased and incomplete search for information while overweighting preference-consistent evidence and underweighting preference-inconsistent evidence (Kunda 1990; Ditto and Lopez 1992). Conversely, 
when decision makers are motivated to be accurate, they expend more cognitive effort on their task, attend to and process information more carefully, and generate and evaluate more hypotheses and more balanced sets of evidence (Kunda 1990; Ditto and Lopez 1992). While increased cognitive effort has been shown to improve judgment quality in many circumstances, it also has been shown to amplify certain judgment biases (Tetlock and Boettger 1989; Hackenbrack 1992; Hoffman and Patton 1997).

Prior accounting research suggests that auditors, managers, tax professionals, and investors engage in motivated reasoning to arrive at judgments that are consistent with their preferred conclusions (Wilks 2002; Kadous et al. 2003; Hales 2007; Kadous et al. 2008; Han and Tan 2010; Ng and Shankar 2010; Peecher et al. 2010; Thayer 2011). Motivated reasoning among investors is a particularly interesting phenomenon because investors also have a concurrent economic incentive to reach the most objective conclusion about the investment value of a particular firm (Hales 2007). Objectivity is economically important to investors because processing information in a non-objective manner could lead to a sub-optimal allocation of resources within their portfolios and, therefore, lower returns.

\subsubsection{Prospective Investors' Judgments and Lowering the Disclosure Threshold}

Consistent with their economic incentives, prospective investors have a motivated reasoning goal to reach an objective conclusion when evaluating a potential firm (Han and Tan 2010). Since they have not yet made an investment decision, they should not hold a preferred conclusion about a particular stock. Under the existing SFAS 5

threshold, the disclosed lawsuit has an "at least reasonably possible" likelihood of leading to a material loss. Thus, I expect that under this disclosure threshold, prospective 
investors' judgments will represent a relatively objective probability assessment of the "at least reasonably possible" lawsuit and will not be directionally biased by a particular preferred conclusion.

However, under a lower disclosure threshold such as the one proposed by the FASB (2008), firms would be required to disclose additional low probability lawsuits. Prior research in psychology and accounting suggests that disclosure of additional low probability lawsuits may dilute the influence of the reasonably possible lawsuit, leading prospective investors to assess the risk of litigation lower even though more lawsuits are disclosed (Nisbett et al. 1981; Tetlock and Boettger 1989; Hackenbrack 1992; Glover 1997; Hoffman and Patton 1997; Shelton 1999).

Specifically, adding remote losses to a disclosure may dilute, rather than add to, the impact of reasonably possible losses if investors rely on the representativeness heuristic when assessing the overall risk of loss due to disclosed litigation. The representativeness heuristic is a natural cognitive strategy that people use to judge the likelihood of a potential event by comparing the similarity of the information about the potential event with other known events (Kahneman and Tversky 1972). If information about the potential event is sufficiently similar to other known events, people tend to judge the potential event as more likely to occur. According to this theory, prospective investors will judge a firm's likelihood of material loss (i.e., likelihood of the potential event) by comparing the firm's litigation disclosures (i.e, the information about the potential event) to their mental representations of lawsuits that generally lead to material losses (i.e., other known events). The more similar the firm's disclosures are to prospective investors' mental representations of lawsuits that generally lead to material 
losses, the higher their perceptions of the firm's litigation risk are predicted to be (Nisbett et al. 1981; Tetlock and Boettger 1989; Hackenbrack 1992).

For example, a higher probability lawsuit (i.e., a reasonably possible lawsuit), is consistent with the mental representation of a lawsuit that generally leads to a material loss. However, additional low probability lawsuits are inconsistent with the mental representation of lawsuits that generally lead to a material loss. If investors rely on the representativeness heuristic to form their overall perceptions of firm loss, they may not view additional, remote losses as adding to the reasonably possible loss, but rather lowering the similarity between the overall disclosure and prospective investors' mental representations of lawsuits that generally lead to material losses. As a result, they will judge the firm's exposure to loss from the disclosed litigation lower, even though more lawsuits are disclosed. This leads to the following hypothesis:

H1: Prospective investors will judge the risk from disclosed litigation lower under the lower "more than remote" threshold than under the higher "at least reasonably possible" threshold, even though additional lawsuits are disclosed.

\subsubsection{Long and Short Investors' Judgments: Motivated Reasoning within Reasonableness Constraints}

Motivated reasoning theory suggests that when decision makers are motivated to arrive at a particular preferred conclusion, they employ cognitive strategies that enable them to reach their directional goals (Kunda 1990). When investors take a long or a short position in a firm, theory and prior research suggest they hold the preferred conclusion that they will realize a positive return on their investment, and thus, that their investment decision was sound (Hales 2007; Han and Tan 2010; Thayer 2011). Consistent with their preferences for higher profitability and share price, long investors are motivated to interpret litigation disclosures as more favorable to the firm, while short investors (who 
require lower share prices in order to profit) are motivated to interpret litigation disclosures as less favorable. When judging the likelihood of loss under the higher SFAS 5 threshold, I expect that long and short investors will interpret the "at least reasonably possible" lawsuit in a manner consistent with their respective directional goals (cf. Kunda 1990; Hales 2007; Han and Tan 2010; Thayer 2011). Thus, long investors are likely to assess lower litigation risks than short investors under the existing SFAS 5 threshold.

Motivated reasoning theory also suggests that the influence of decision makers' preferred conclusions will be bounded by reasonableness constraints (Kunda 1990). That is, people do not overtly bias their judgments, but only reach a preferred conclusion to the extent that they can maintain an illusion of objectivity (Pyszczynski and Greenberg 1987; Kunda 1990). For example, while long (short) investors are motivated to view disclosures in a more favorable (unfavorable) light, the potential for actual investment losses also provides strong pressure to maintain some sense of reasonableness in their beliefs about an investment rather than simply believing what they want to believe about it (Hales 2007). When factors are present that make reasonableness constraints more salient in settings such as these, directional motivated reasoning goals (while strong) can also become quickly bounded (Peecher et al. 2010). Thus, investors' long or short positions can provide them with strong directional goals that will likely bias their judgments, but can also provide them with similarly strong reasonableness constraints that limit further motivated reasoning (see Figure 1).

Under the lower disclosure threshold, long and short investors will be motivated to view the likelihood of future losses consistent with their directional preferences, 


\section{FIGURE 1 \\ Investors' Motivated Reasoning \\ within Reasonableness Constraints}

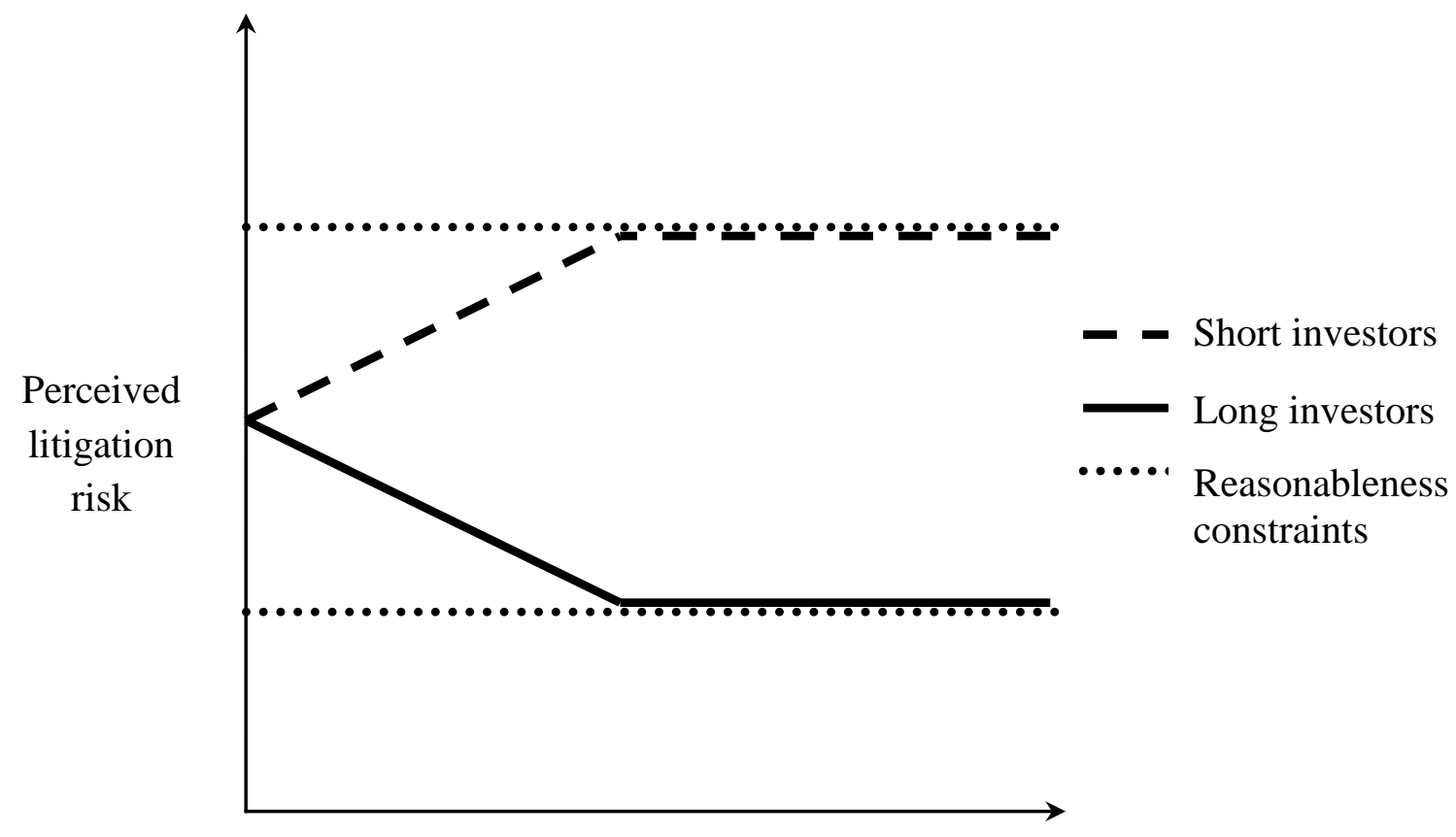

Directional goal strength

\section{Note:}

When directional goal strength is low, directional goals have little observable influence on investors' litigation risk judgments. As directional goal strength increases along the $\mathrm{X}$-axis, investors will increasingly engage in motivated reasoning, with long (short) investors decreasing (increasing) their judgments until they approach their reasonableness constraint at which point they can no longer justify further decreases (increases) (see also Kadous et al. 2003, Figure 1).

subject to reasonableness constraints. As Kunda (1990) notes, individuals tend to selectively use, interpret, and weight additional information, and use other cognitive heuristics, in ways that support their directional preferences (see also Wilks 2002). Thus, under the lower disclosure threshold, long and short investors are likely to selectively search for and assimilate newly disclosed information about additional, relatively inconsequential lawsuits in a manner consistent with their motivated reasoning goals. 
For example, long investors could selectively focus constraints (Figure 1). However, if they are not already at the bounds of their reasonableness constraints under the higher disclosure threshold, there would be room for their judgments to move in the directions consistent with their respective motivated reasoning goals. This leads to the following hypotheses:

H2a: Long investors' judgments of litigation risk under the lower "more than remote" threshold will be less than or equal to their judgments under the higher "at least reasonably possible" threshold.

H2b: Short investors' judgments of litigation risk under the lower "more than remote" threshold will be greater than or equal to their judgments under the higher "at least reasonably possible" threshold.

\subsubsection{Opportunism in Financial Reporting}

For a variety of reasons (e.g., power, obtaining goals, being liked), we prefer to present ourselves in the most favorable light possible to manage others' impressions of us (Baumeister 1982; Leary and Kowalski 1990; Nezlek and Leary 2002; Fiske and Taylor 2008). Similarly, managers of firms also prefer to present themselves and their firms in a favorable light (Baginski et al. 2000; Schrand and Walther 2000). Prior accounting research suggests that management tends to behave opportunistically when disclosing information (Hackenbrack and Nelson 1996; Baginski et al. 2000; Schrand and Walther 2000; Bloomfield 2002; Barton and Mercer 2005; Krische 2005; Hirst et al. 2007). For example, Baginski et al. (2000) report archival evidence suggesting managers tend to explain bad news in voluntary disclosures by attributing it to temporary external factors outside of their control, possibly to persuade investors to interpret the bad news more favorably. Also, Schrand and Walther (2000) provide archival evidence suggesting managers are more likely to include a prior-period loss than a prior-period gain in the 
earnings benchmark they use to compare to current earnings, presumably to strategically create the perception of the largest positive change possible.

The proposed changes to SFAS 5 lend themselves to a specific type of opportunistic reporting that is unique to settings in which thresholds are lowered. Since lowering the disclosure threshold would cause firms to disclose additional low probability lawsuits, firms can use this to their advantage. Specifically, since the FASB's amendment does not specify how the disclosures should be presented, managers could portray the entire disclosure as a portfolio consisting mostly of remote, and therefore frivolous, lawsuits that they only disclose to comply with the proposed rule. Such a presentation strategy would be consistent with the view that managers have already expressed regarding lower probability lawsuits (e.g., that they are often frivolous or filed solely for publicity purposes (The Wall Street Journal 2008)). Without changing the fundamental information they provide about each lawsuit, managers could focus attention away from reasonably possible lawsuits to the more remote ones.

\subsubsection{Opportunistic Presentation: Persuasion Knowledge Model versus Emphasis Framing}

It is unclear a priori whether or not such a persuasion attempt would work as managers intend. The Persuasion Knowledge Model predicts that an opportunistic presentation may successfully persuade investors only when it helps them reach their directional conclusions (i.e., long investors), but it may backfire when it is inconsistent with their directional conclusions (i.e., short investors). Alternatively, Emphasis Framing Theory predicts an opportunistic presentation may successfully persuade investors, despite their motivated reasoning goals, to view pending litigation more favorably. 


\subsubsection{The Persuasion Knowledge Model}

The Persuasion Knowledge Model (PKM) predicts that investors will be persuaded by management's opportunism if it allows them to reach their preferred conclusions. PKM is a theory developed in the marketing literature that predicts how people cope with the persuasion attempts of others (Friestad and Wright 1994). Targets of a persuasive message are described as not merely passive information processors, but rather as resourceful participants who consider their own goals or desired outcomes and select coping mechanisms that will enable them reach their goals (Friestad and Wright 1994; Kirmani and Campbell 2004). PKM predicts that targets will not always actively resist persuasion attempts, but instead may be receptive to persuasion attempts if it allows them to reach their own goals (Friestad and Wright 1994).

Investors taking a long position in a firm want to believe management's opportunism is earnest, as it helps them reach their preferred conclusion (i.e., that the company they have invested in will perform strongly). PKM predicts that long investors will be less likely to actively guard against management's opportunistic persuasion attempt and, thus, are likely to be persuaded by it (Campbell and Kirmani 2000). In contrast, short investors want to believe the company will not perform strongly, which is contrary to management's interpretation. Short investors are more likely to spend greater effort critically processing management's opportunism, and thus more likely to perceive management's presentation as a persuasion attempt (Friestad and Wright 1994; Campbell and Kirmani 2000). If so, PKM predicts management's opportunism will backfire for short investors and lead them to further increase their loss likelihood judgments (Friestad and Wright 1994). Since prospective investors are motivated to be objective, they are 
likely to continue to remain fairly neutral with respect to management's persuasion attempts and, in turn, objectively assess the information management is opportunistically disclosing and its influence on litigation risk. Thus, PKM suggests management's opportunistic presentation would amplify the effect of investors' motivated reasoning goals on their litigation risk assessments.

The extent to which investors' directional interpretations of management's opportunism further decreases long investors' and increases short investors' litigation risk judgments depends on how close they already are to the bounds of reasonableness constraints when management presents the additional low probability lawsuits in a more objective manner. If investors are already close to their reasonableness constraints in the objective amendment condition, when management presents the lawsuits opportunistically, there may be little room for long investors' judgments to decrease and short investors' judgments to increase and still be within their reasonableness constraints. However, if investors are not already at the limits of their reasonableness constraints in the objective amendment condition, there would be room for their judgments to move in the directions consistent with their respective motivated reasoning goals. This would lead to greater differences between investors' judgments when disclosures are presented in a more opportunistic manner than when they are presented in a more objective manner. The following hypothesis will be tested:

H3a: The differences across long, prospective, and short investors' litigation risk judgments when litigation disclosures are presented opportunistically under the lower threshold will be greater than or equal to the differences when litigation disclosures are presented more objectively under the lower threshold. 


\subsubsection{Emphasis Framing Theory}

In contrast to PKM, emphasis framing theory predicts that management's opportunistic presentation will work as intended, despite investors' motivated reasoning goals. According to this theory, communicators can influence others' opinions by emphasizing particular considerations over other relevant considerations when giving their interpretation of an issue (Nelson et al. 1997; Nelson and Oxley 1999; Druckman 2001; McCaffery and Baron 2004; Maule and Villejoubert 2007; Slothuus 2008). For example, Shankar and Tan (2006) find audit preparers use emphasis framing to persuade reviewers by using language that emphasizes evidence that supports their preferred conclusion and downplays evidence that contradicts their conclusion. In addition, prior research demonstrates that strategic persuasion attempts can be successful (Ricchuite 1999; Tan and Yip-Ow 2001; Kadous et al. 2005). This suggests that, by strategically framing litigation disclosures, management may successfully persuade investors to perceive the litigation in a light most favorable to the firm.

Under the recently proposed lower probability threshold, managers would now have a mechanism to persuade investors to see the litigation in a more favorable light. A lower threshold would allow managers to point out that the accounting standard requires disclosure of lawsuits with very small probabilities of material loss and would provide investors with examples of such lawsuits. These low probability examples may increase the credibility of management's opportunistic presentation and lead investors to interpret the disclosed litigation, on the whole, as fairly innocuous.

Motivated reasoning theory would predict this type of opportunistic disclosure to influence different types of investors differently, depending on their motivated reasoning 
goals. Even without the opportunistic presentation of the litigation, long investors are likely already assessing the likelihood of firm loss as low as they can within reasonableness constraints. An opportunistic presentation would further decrease their judgments only if they are not already at the bounds of their reasonableness constraints when the same lawsuits are disclosed more objectively (and then only to the extent of their bounds). In contrast, short investors are likely to interpret the more objective disclosure of the lawsuits as suggesting the highest litigation risk that they can reasonably justify. If these investors are persuaded by management's opportunism as suggested by emphasis framing theory, their perceptions of litigation risk have much more room to decrease than long investors' judgments. These investors still have motivations to interpret the disclosure as unfavorably for the firm as they can reasonably justify. However, if management's opportunistic presentation is successful, they may find it more difficult to rationalize a negative interpretation of the disclosure and, in turn, assess the likelihood of firm losses lower (their directional goals notwithstanding). Thus, persuasive opportunistic disclosures can shift the reasonableness constraint on short investors' natural goals to assess the likelihood of loss as high as possible. Factors that shift reasonableness constraints against individuals' preferences tend to counteract the effects of directional goals to reach a preferred conclusion (e.g., Peecher et al. 2010, Ng and Shankar 2010). The extent to which prospective investors' judgments can similarly decrease in response to management's opportunism depends upon how strongly the assimilation effect predicted in $\mathrm{H} 1$ already decreased their judgments (i.e., how close they already are to the lowest reasonable judgment in the objective amendment condition due to a heuristic incorporation of additional low probability lawsuits). 
Thus, emphasis framing theory predicts that management's opportunistic presentation will tend to persuade all investors, leading them all to assess the firm's litigation risk to be relatively low, within reasonable limits. As a result, the differences across long, prospective, and short investors' perceptions of the firm should be smaller when disclosures are presented in a more opportunistic manner than when the same lawsuits are presented in a more objective manner. The following hypothesis will be tested:

H3b: The differences across long, prospective, and short investors' litigation risk judgments will be smaller when litigation disclosures are presented opportunistically under the lower threshold than when they are presented more objectively under the lower threshold.

\subsection{Method}

\subsubsection{Participants}

Consistent with prior research, I use graduate business students as a source for nonprofessional investors (e.g., Maines and McDaniel 2000; Sedor 2002; Barton and Mercer 2005; Krishe 2005; Mercer 2005; Elliott et al. 2007; Hales 2007; Elliott et al. 2010; Han and Tan 2010; Thayer 2011). One hundred fifty individuals enrolled in MBA courses served as my participants (see Table 1 for number of participants by experimental condition). ${ }^{3}$ On average, participants had approximately seven years of professional business experience, and $95 \%$ had previously invested or planned to invest in the stock market (see Table 2 for sample demographic data).

\footnotetext{
${ }^{3}$ A substantial majority of the participants (117) were enrolled as MBA students, with another 32 enrolled in similar programs (e.g., Master of Management Practice). Results are unchanged if only those identifying themselves as MBA students are included in the sample. Nonprofessional investors are an important group to study in this setting, as they own one-third of all U.S. stocks (Bogle 2006). As of 2005, 23.3 million people held shares of individual companies' stock outside of employer plans (Elliott et al. 2010). Research in finance suggests that this class of investors influences security prices (DeLong et al. 1989, 1991). Furthermore, the FASB has expressed their concern for nonprofessional investors in the debate over the proposed changes to SFAS 5 (Herz 2008).
} 


\subsubsection{Experimental Task and Procedure}

Participants completed a web-based instrument which I developed using Qualtrics (see appendix for screen shots of the instrument). The case asked participants to evaluate financial information relating to a hypothetical pharmaceutical firm. Participants received the firm's income statements and balance sheets for each of the last three years,

TABLE 1

Participants by Experimental Condition

Disclosure Type

\begin{tabular}{|l|c|c|c|}
$\begin{array}{l}\text { Investor } \\
\text { Position }\end{array}$ & SFAS 5 & $\begin{array}{c}\text { Objective } \\
\text { Amendment }\end{array}$ & $\begin{array}{c}\text { Opportunistic } \\
\text { Amendment }\end{array}$ \\
\hline Long & $\mathrm{n}=21$ & $\mathrm{n}=16$ & $\mathrm{n}=15$ \\
\hline Prospective & $\mathrm{n}=19$ & $\mathrm{n}=18$ & $\mathrm{n}=16$ \\
\hline Short & $\mathrm{n}=16$ & $\mathrm{n}=12$ & $\mathrm{n}=17$ \\
\hline
\end{tabular}

along with financial statement disclosures regarding pending litigation. After examining the firm's financial statements and legal disclosures, participants assessed the likelihood that the firm will incur a future material loss due to the disclosed litigation (i.e., litigation risk). I asked participants for the likelihood of loss due to the disclosed litigation (rather than all litigation) to insure the internal validity of my tests of $\mathrm{H} 1$ and $\mathrm{H} 2 .{ }^{4}$ Participants recorded their responses on an eleven-point scale, where $0=$ "material loss not at all

\footnotetext{
${ }^{4}$ That is, if an individual presumes any undisclosed (below-the-disclosure-threshold) lawsuits exist, these suits should not factor into the individual's assessment of risk due to disclosed litigation. Thus, any decrease in this assessment when low probability lawsuits are included in the disclosure is unambiguously non-normative.
} 
likely" and $10=$ "material loss very likely." Participants then answered a series of caserelated and demographic questions, including manipulation checks.

\subsubsection{Independent Variables}

\subsubsection{Investor Position}

Two independent variables (investor position and litigation disclosure type) were manipulated between participants resulting in a $3 \times 3$ analysis of variance (ANOVA)

TABLE 2

Sample Demographic Data

Panel A: Proportion of participants who invested in the past or planned to do so in the future

\begin{tabular}{ccc} 
& n & percent \\
\cline { 2 - 3 } Yes & 142 & 94.7 \\
No & 8 & 5.3
\end{tabular}

Panel B: Gender

\begin{tabular}{lcc} 
& n & percent \\
\cline { 2 - 3 } Male & 96 & 64 \\
Female & 54 & 36
\end{tabular}

Panel C: Participants' professional and academic experience

\begin{tabular}{lcc} 
Demographic Variable & $\begin{array}{c}\text { Sample } \\
\text { Mean }\end{array}$ & $\begin{array}{c}\text { Standard } \\
\text { Deviation }\end{array}$ \\
\hline Years of Professional Experience & 6.98 & 6.20 \\
Number of Accounting Courses Taken & 3.25 & 2.60 \\
Number of Finance Courses Taken & 2.53 & 2.21 \\
\hline
\end{tabular}


design. I manipulated investor position at three levels: long, short, and prospective. All participants read summary financial information relating to two pharmaceutical firms (see Figure 2). Following Thayer (2011), I designed these firms to have similar investment potential, and pretested this summary information on 59 masters of accounting students to ensure that the two firms were equally attractive $(\mathrm{p}=0.865)$ and chosen with equal frequency $(\mathrm{p}=0.369)$ (pretest discussed in more detail in following subsection). Long (short) investors then chose one of the two firms in which to invest (sell short), aware that they would receive $\$ 15$ if their chosen firm outperformed (underperformed) the other firm, or $\$ 5$ otherwise (adapted from Thayer 2011 and Han and Tan 2010). Prospective investors were told that they would receive $\$ 10$ for evaluating one of the two firms, selected at random by the computer (adapted from Han and Tan 2010). All participants then evaluated the financial statements of the selected firm, which I held constant for both firms (as in Thayer 2011). ${ }^{5}$ Thus, long and short investors had directional preferences for their chosen investment, which could influence their beliefs about the financial statements they would evaluate, while prospective investors evaluated the same financial statements without directional preferences.

Having participants choose an investment for which they will actually be paid based on their investment position is a fairly strong manipulation of directional preferences (Thayer 2011), especially compared to other accounting research that merely gives participants the directional preferences of fictional sources (e.g., audit supervisors, clients). I feel that this is an appropriate design choice in my setting given that real-world investors face similar economic consequences when choosing among firms in which to

\footnotetext{
${ }^{5}$ As the summary information for both firms is based on the same underlying set of financial statements, the subsequent financial statements and disclosures participants received were identical regardless of which of the two firms was selected.
} 
invest. As a result, my experimental participants (like real-world investors) will be likely

to have both relatively strong directional goals and relatively salient reasonableness

constraints (as discussed in $\mathrm{H} 2 \mathrm{a}$ and $\mathrm{b}$ ).

\subsection{Pretests of Two Firms used in Experimental Materials}

Prior to gathering data for my main experiment, I ran two pretests to ensure that

the firms presented in Figure 2 were approximately equally attractive investments and

FIGURE 2

Excerpt from Background Experimental Materials

\begin{tabular}{|c|c|c|c|c|c|c|c|}
\hline \multicolumn{4}{|c|}{ Karlow Pharmaceuticals, Inc. } & \multicolumn{4}{|c|}{ Bower Pharmaceuticals, Inc. } \\
\hline & $\underline{2009}$ & $\underline{2008}$ & $\underline{2007}$ & & $\underline{2009}$ & $\underline{2008}$ & $\underline{2007}$ \\
\hline Net Income Growth Rate & $2.76 \%$ & $1.90 \%$ & $1.71 \%$ & Revenue Growth Rate & $4.16 \%$ & $3.78 \%$ & $2.75 \%$ \\
\hline Net Profit Margin & $24.90 \%$ & $25.24 \%$ & $25.71 \%$ & Operating Profit Margin & $35.19 \%$ & $35.78 \%$ & $36.47 \%$ \\
\hline Return on Equity & $34.99 \%$ & $33.26 \%$ & $32.53 \%$ & Return on Assets & $21.95 \%$ & $21.50 \%$ & $21.18 \%$ \\
\hline \multicolumn{4}{|c|}{$\begin{array}{l}\text { Opened new manufacturing facilities located in the UK, Spain, } \\
\text { Japan, Morocco, \& China. }\end{array}$} & \multicolumn{4}{|c|}{$\begin{array}{l}\text { Recent Phase III clinical trial data suggests the company's } \\
\text { drug, Precor }(\text {, was successful at preventing blood clotting in } \\
\text { patients undergoing knee replacement surgery. }\end{array}$} \\
\hline \multicolumn{4}{|c|}{$\begin{array}{l}\text { Funding stem cell research at the University of Texas Health } \\
\text { Science Center in Houston. The research is investigating } \\
\text { whether stem cell therapy can reverse the neurological damage } \\
\text { caused by multiple sclerosis. }\end{array}$} & \multicolumn{4}{|c|}{$\begin{array}{l}\text { Currently running a successful television marketing campaign } \\
\text { for several top-selling products. This allows for direct to } \\
\text { consumer advertising. }\end{array}$} \\
\hline \multicolumn{4}{|c|}{$\begin{array}{l}\text { Launched two new products in the consumer segment: topical } \\
\text { antihistamine lotion, CalmItch } \otimes \text {, and topical antibacterial } \\
\text { ointment, CureAllß. }\end{array}$} & \multicolumn{4}{|c|}{$\begin{array}{l}\text { According to the Senate Office of Public Records, the } \\
\text { company is one of the top spenders in the industry on } \\
\text { Congressional lobbying efforts. }\end{array}$} \\
\hline \multicolumn{4}{|c|}{2010 March of Dimes corporate partner. } & \multicolumn{4}{|c|}{$\begin{array}{l}\text { Recently signed joint ventures with laboratories in Germany, } \\
\text { Mexico, Brazil, \& India. A licensing agreement is also held } \\
\text { with one Australian laboratory. }\end{array}$} \\
\hline
\end{tabular}

All other factors were similar across the two firms, including the prices of the respective stocks.

Note:

All participants were given this summary information prior to evaluating the selected firm. Long and short investors were asked to pick one of these two firms in which to take their assigned investment position. Prospective investors were also given this information, but were not asked to pick a firm. Instead, prospective investors were told they would be asked to objectively evaluate one of these two firms (subsequently chosen at random by the computer). 
would be chosen by participants with approximately equal frequencies, following Thayer (2011). For both pretests, I presented participants with four different pairs of firms (see Figure 2), including the two that were ultimately used in the main experiment.

The four pairs of firms were developed by me. I included three financial statement ratios and four qualitative statements for each firm in each pair. This was done to create different firms with similar investment potential within each pair. The financial statement ratios were developed from the same underlying financial statements within each pair, but the actual ratios shown for each firm were different (e.g., Return on Assets is presented for one firm versus Return on Equity for the other). I created some of the qualitative statements and adapted others from Thayer (2011). My goal was to create pairs of firms that had similar investment potential, but that appeared to have unique characteristics so that participants felt there was a choice between the firms. That is, while I did not want one firm to clearly outperform the other, I wanted them to be different on some (non-financial) dimensions so that participants might genuinely have a preference for one over the other (in an effort to increase the likelihood the feel "invested" in their company).

In the first pretest, 31 masters of accounting students were presented with these four different pairs of firms. ${ }^{6}$ For each pair, I asked participants to make a choice to invest in one of the two firms. The results of the pretest (displayed in Table 3) showed that 18 participants chose Karlow and 13 chose Bower (the two firms used in the experimental materials), indicating that each firm was chosen with similar frequency $\left(\chi^{2}\right.$ $=0.806, \mathrm{p}=0.369)$.

\footnotetext{
${ }^{6}$ To control for any possible order effects, I presented the four pairs of firms in reverse order to half of the participants in both pretests. No significant differences were found between participants that received the four pairs in the original order or in the reverse order.
} 
In a second pretest, 28 masters of accounting students were asked to rate the investment attractiveness of each firm from each of the four pairs on scales of 0 (not attractive) to 10 (very attractive). Pretest participants rated Karlow (mean $=7.39$ ) and Bower $($ mean $=7.32)$ as approximately equally attractive investments $(t=0.171, p=$ 0.865). Ultimately, I chose the Karlow and Bower pair for the main experiment because they were both chosen with similar frequency and their attractiveness ratings were the most similar among all the pairs.

TABLE 3

Pretests of Firm Pairings

\begin{tabular}{ccccc} 
Pair & $\begin{array}{c}\text { Firm } \\
\text { Names }\end{array}$ & $\begin{array}{c}\text { Frequency } \\
\text { Chosen }^{\mathbf{a}}\end{array}$ & $\begin{array}{c}\text { Mean } \\
\text { Attractiveness }\end{array}$ & $\begin{array}{c}\text { Attractiveness } \\
\text { bifferences } \\
\text { within each } \\
\text { Pair }^{\mathbf{c}}\end{array}$ \\
\hline 1 & Samper & 13 & 6.64 & 0.50 \\
1 & Groft & 18 & 7.14 & 0.46 \\
\hline 2 & Troper & 14 & 6.93 & 0.07 \\
2 & Rone & 17 & 7.39 & 1.00 \\
\hline 3 & Karlow & 18 & 7.39 & \\
\hline 3 & Bower & 13 & 7.32 & \\
\hline 4 & Varic & 18 & 7.86 & \\
4 & Milex & 12 & 6.86 & \\
\hline
\end{tabular}

Notes:

${ }^{a}$ Thirty-one pretest participants were asked to chose to invest in one of the two firms within each of the four pairs. One participant failed to make a choice for the fourth pair.

${ }^{\mathrm{b}}$ Twenty-eight pretest participants rated the attractiveness of each paired firm as a potential investment opportunity. Participants recorded their responses on an eleven-point scale, where $0=$ "not attractive" and $10=$ "very attractive".

' The absolute value of the difference between pretest participants' mean attractiveness ratings within each pair. 


\subsubsection{Disclosure Type}

The second independent variable, disclosure type, was manipulated at three levels and refers to whether the legal disclosures were in compliance with: (1) current SFAS 5 (SFAS 5 condition); (2) the FASB's proposed amendment presented more objectively (objective amendment condition); or (3) the FASB's proposed amendment presented more opportunistically (opportunistic amendment condition). The disclosure in the SFAS 5 condition contained one reasonably possible lawsuit. Management introduced the litigation by stating that the existing accounting standard (i.e., SFAS 5) requires disclosure of lawsuits that management believes have at least a reasonably possible likelihood of resulting in a material liability. The two proposed amendment conditions each contained the same reasonably possible lawsuit as the SFAS 5 condition, as well as three additional lawsuits that are less than reasonably possible but more than remote. In all three disclosure type conditions, each lawsuit was individually identified as having either a "reasonably possible" or a "slightly more than remote" likelihood of leading to a material loss. Thus, in both the objective and opportunistic amendment conditions, the financial statements provided the same set of lawsuits and disclosed the same likelihoods of loss for each.

In the objective amendment condition, management relayed the facts of the pending litigation in a fairly straightforward and direct manner, with little "spin". Management introduced the litigation by stating that the accounting standard requires disclosure of lawsuits that management believes have more than a remote likelihood of resulting in a material liability. The reasonably possible lawsuit was the first disclosed, 
followed by the three lower probability lawsuits. All lawsuits were labeled to clearly distinguish one lawsuit from the next.

To create disclosures in compliance with the lower probability threshold that were more opportunistically presented, I referred to actual financial statement disclosures, emphasis framing theory, and the prior accounting literature. Based on this examination, I identified persuasion tactics that are available to management in a litigation disclosure setting: the placement, labeling, and framing of lawsuits within the disclosure (Bouwman 1982; Hunton and McEwen 1997; Nelson et al. 1997; Nelson and Oxley 1999; Maines and McDaniel 2000; Druckman 2001; Lipe and Salterio 2002; McCaffery and Baron 2004; Maule and Villejoubert 2007; Slothuus 2008; Bonner 2008). Following prior persuasion research in accounting, the presentation of the disclosures under the proposed amendment in this study made use of all three persuasion tactics that would be available, practicable, and likely to be used simultaneously by managers to craft disclosures which are more opportunistic versus more objective (Rich et al. 1997; Tan and Yip-Ow 2001). I did this to more fully distinguish the opportunistic condition from the more objective condition (Kerlinger and Lee 2000). Specifically, in the opportunistic amendment condition, management introduced the litigation by discussing the litigious nature of the industry and by strategically emphasizing that the accounting standard requires disclosure at a very low probability threshold. Within the disclosure, management did not individually label each lawsuit and presented the reasonably possible lawsuit in the middle of the disclosure. 


\subsection{Opportunistic Disclosure Pretest}

I used a pretest prior to gathering data in the main experiment to ensure that participants would perceive the disclosures in the opportunistic amendment condition to be more strategic and less objective than the disclosures in the objective amendment condition. A pretest with 29 senior accounting undergraduates suggests that the disclosures in the objective amendment condition were less strategic than the disclosures in the opportunistic amendment condition (means $=4.48$ versus $8.17, \mathrm{t}=-7.97$, on a scale where $0=$ "not at all strategic" and $10=$ "very strategic"; $p<0.001)$. In addition, the disclosures in the objective amendment condition were viewed as more objective than the disclosures in the opportunistic amendment condition (means $=8.04$ versus $3.82, \mathrm{t}=$ 9.03, where $0=$ "not at all objective" and $10=$ "very objective"; $p<0.001$ ). Further, all pretest participants also selected the objective amendment condition disclosure as the presentation that was the more objective and less opportunistic of the two. 


\section{CHAPTER 4}

\section{DATA ANALYSIS}

\subsection{Introduction}

In this chapter, I provide the results of the manipulation checks, hypothesis tests and post-experimental questions. To test my hypotheses, I analyze participants' responses using a $3 \times 3$ analysis of covariance (ANCOVA) with investor position and disclosure type as the independent variables and participants' perceptions of industry litigiousness as a covariate. First, I test how prospective investors assimilate additional low probability lawsuits into their litigation risk assessments (H1). Next, I test how long and short investors assimilate additional low probability lawsuits into their litigation risk assessments (H2a and $\mathrm{H} 2 \mathrm{~b})$. Finally, I test how an opportunistic disclosure strategy allowed by a lower accounting threshold influences investors' judgments (H3a and H3b).

\subsection{Manipulation Checks}

\subsubsection{Investor Position}

I randomly assigned participants to one of three investor position conditions: (1) long (2) short and (3) prospective. After reading the investment position manipulation in the case materials, I asked participants the following:

"To ensure that you understand the manner in which you will be paid for your investment position, which of the following statements is true?” (I will be paid $\$ 15$ if the company I selected is the better performer or $\$ 5$ if it is the worse performer. / I will be paid $\$ 15$ if the company I selected is the worse performer or $\$ 5$ if it is the better performer. / I will be paid a flat $\$ 10$ for providing my judgments.). Participants successfully identified their respective compensation scheme based on their investment position $99 \%$ of the time, similar to Hales (2007) and Thayer (2011). This suggests that 
my manipulation of investor position was successful. Results of my hypothesis testing are unchanged if the two participants who failed to correctly recall their investment position compensation scheme are removed from the analyses.

\subsubsection{Disclosure Type}

I randomly assigned participants to one of three disclosure type conditions: (1) current SFAS 5 (SFAS 5 condition); (2) the FASB's proposed amendment presented more objectively (objective amendment condition); or (3) the FASB's proposed amendment presented more opportunistically (opportunistic amendment condition). In the postexperimental questionnaire, I asked participants, “Approximately how many lawsuits were disclosed in the footnotes to Karlow's [Bower's] 2009 financial statements?" (one / four). Participants correctly recalled the number of lawsuits disclosed $89 \%$ of the time. Next, participants responded to the following prompt: "According to the disclosures in Karlow's [Bower's] financial statements, the prevailing accounting standard requires Karlow [Bower] to disclose pending lawsuits when the likelihood they would lead to a material loss is:" (at least reasonably possible / more than remote). Participants also correctly recalled the probability threshold $89 \%$ of the time. Together, the results of these two questions suggest that my manipulation of disclosure type was successful. Results of my hypothesis testing are unchanged if those participants who failed to correctly recall the number of lawsuits disclosed and/or the probability threshold are removed from the analyses. 


\subsection{Tests of Hypotheses}

\subsubsection{Introduction}

In this section, I present my hypotheses tests. My hypotheses predict relationships between the two independent variables (investor position and disclosure type) and the dependent variable (investors' litigation risk assessments). I test my hypotheses using a $3 \times 3$ ANCOVA model and contrast tests where applicable. Tests are one-tailed when I have directional expectations and are two-tailed otherwise.

ANCOVA is appropriate when there is ancillary information related to the dependent variable available for each participant (Keppel and Wickens 2004). Consistent with this, I measure participants' prior beliefs about the litigiousness of the pharmaceutical industry and find that these beliefs are correlated with their loss likelihood judgments $(\mathrm{r}=0.253, \mathrm{p}=0.002)$, and that individuals who believe the industry to be more litigious tend to assess litigation risk higher across experimental conditions ( $\mathrm{F}$ $=10.22, \mathrm{p}=0.002)$. As such, I include this variable as a covariate when testing my hypotheses. Results are similar if the covariate is removed from the model.

Table 4 shows an ANCOVA of participants' litigation risk assessments, while Figure 3 shows their mean assessments from this model by experimental condition. The ANCOVA includes participants' prior beliefs about industry litigiousness as a covariate. The investor position $\times$ disclosure type interaction $(\mathrm{F}=2.37, \mathrm{p}=0.055$, two-tailed $)$ is displayed graphically in Figure 3.

Figure 3 also shows that the ordering of long, prospective, and short investors' litigation risk assessments under the current, higher SFAS 5 probability threshold is consistent with their motivated reasoning goals. Long investors judge litigation risk 
lowest (4.92), followed by prospective investors (6.73), with short investors judging litigation risk highest (7.18). A Jonckheere-Terpstra test confirms that this ordering of investors' judgments under the SFAS 5 threshold is statistically significant $(\mathrm{z}=-2.92, \mathrm{p}=$ 0.002, one-tailed).

\section{TABLE 4 Analysis of Covariance}

\begin{tabular}{lrrrrr} 
Source & $\begin{array}{r}\text { Sum of } \\
\text { Squares }\end{array}$ & df & $\begin{array}{r}\text { Mean } \\
\text { Square }\end{array}$ & F & p-value \\
\hline Industry Litigiousness (covariate) & 42.36 & 1 & 42.36 & 10.22 & 0.002 \\
Investor Position & 59.32 & 2 & 29.66 & 7.16 & 0.001 \\
Disclosure Type & 59.55 & 2 & 29.78 & 7.18 & 0.001 \\
Investor Position $\times$ Disclosure Type & 39.37 & 4 & 9.84 & 2.37 & 0.055 \\
Error & 580.34 & 140 & 4.15 & & \\
\hline
\end{tabular}

\section{Notes:}

Dependent variable: Litigation Risk Assessments. Participants assessed the likelihood that the firm will incur a future material loss due to the disclosed litigation. Participants recorded their responses on an eleven-point scale, where $0=$ "material loss not at all likely" and $10=$ "material loss very likely".

Independent variables: Investor Position is manipulated as participants' position in the firm (long, short, or prospective investor). Disclosure Type manipulated whether participants received pending litigation disclosures in compliance with SFAS 5 (i.e., "at least reasonably possible" threshold), the FASB's proposed amendment (i.e., "more than remote" threshold) presented more objectively, or the FASB's proposed amendment presented more opportunistically. Analysis includes a covariate, participants' perceptions of Industry Litigiousness, which is participants' responses to a post-experimental question about the litigiousness of the pharmaceutical industry (eleven-point scale where $0=$ "not at all litigious" and $10=$ "very litigious").

\subsubsection{Test of $\mathrm{H1}$}

H1 predicts that prospective investors' assessments of the risk from disclosed litigation will decrease under the proposed standard even though more lawsuits are disclosed. H1 is formally stated as follows: 


\section{FIGURE 3}

\section{Litigation Risk Assessments}

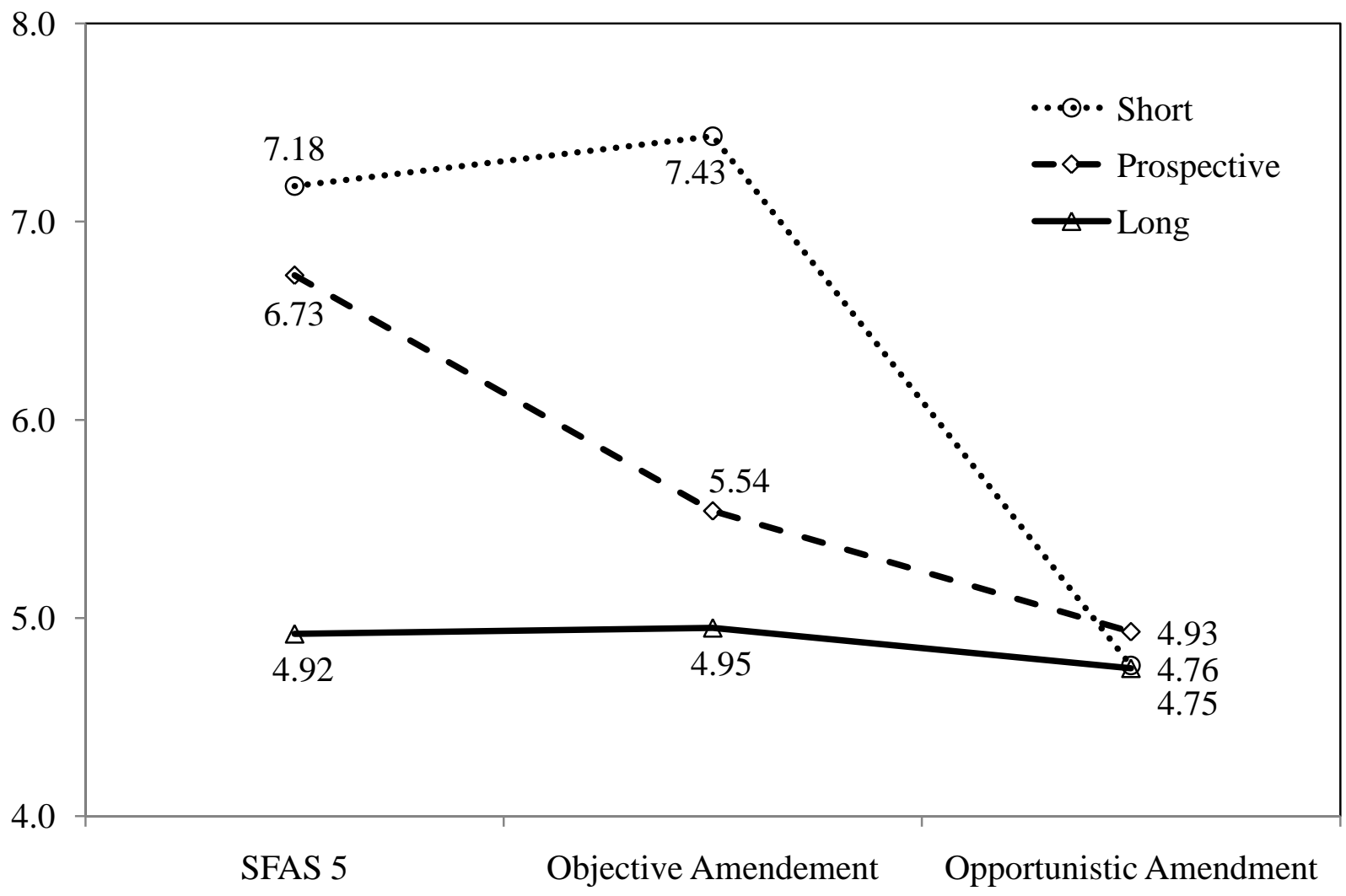

Notes:

Dependent variable (vertical axis): Litigation Risk Assessments. Participants assessed the likelihood that the firm will incur a future material loss due to the disclosed litigation. Participants recorded their responses on an eleven-point scale, where $0=$ "material loss not at all likely" and $10=$ "material loss very likely". Means reported above are derived from the ANCOVA presented in Table 4.

Independent variables: Investor Position is manipulated as participants' position in the firm (long, short, or prospective investor). Disclosure Type manipulated whether participants received pending litigation disclosures in compliance with SFAS 5 (i.e., "at least reasonably possible" threshold), the FASB's proposed amendment (i.e., "more than remote" threshold) presented more objectively, or the FASB's proposed amendment presented more opportunistically. 
H1: Prospective investors will judge the risk from disclosed litigation lower under the lower "more than remote" threshold than under the higher "at least reasonably possible" threshold, even though additional lawsuits are disclosed.

As Figure 3 shows, prospective investors' litigation risk assessments decreased from 6.73 in the current SFAS 5 condition to 5.54 in the objective amendment condition $(\mathrm{t}=1.77, \mathrm{p}=0.040$, one-tailed). This result supports H1. It appears that the influence of the reasonably possible lawsuit on prospective investors' litigation risk assessments is diluted by the low probability lawsuits under the lower threshold. Thus, prospective investors assess litigation risk lower under a lower threshold, even though more lawsuits are disclosed.

\subsubsection{Tests of $\mathrm{H} 2 \mathrm{a}$ and $\mathrm{H} 2 \mathrm{~b}$}

Hypothesis 2a predicts that long investors' litigation risk judgments in the objective amendment condition will be less than or equal to those in the current SFAS 5 condition. Hypothesis $2 \mathrm{~b}$ similarly predicts that short investors' judgments in the objective amendment condition will be greater than or equal to those in the current SFAS 5 condition. $\mathrm{H} 2 \mathrm{a}$ and $\mathrm{H} 2 \mathrm{~b}$ are formally stated as follows:

H2a: Long investors' judgments of litigation risk under the lower "more than remote" threshold will be less than or equal to their judgments under the higher "at least reasonably possible" threshold.

H2b: Short investors' judgments of litigation risk under the lower "more than remote" threshold will be greater than or equal to their judgments under the higher "at least reasonably possible" threshold.

As Figure 3 shows, long and short investors' judgments did not change significantly between the current SFAS 5 condition and the objective amendment condition (4.92 vs. $4.95, \mathrm{t}=0.03, \mathrm{p}=0.485$ and 7.18 vs. $7.43, \mathrm{t}=0.32, \mathrm{p}=0.374$ respectively, both one-tailed). These results are consistent with $\mathrm{H} 2 \mathrm{a}$ and $\mathrm{H} 2 \mathrm{~b}$, and 
suggest that long and short investors' judgments were at or close to the bounds of their reasonableness constraints in both the current SFAS 5 and objective amendment conditions. This is also consistent with my relatively strong manipulation of directional goals, as noted in Chapter 3.

\subsubsection{Tests of $\mathrm{H3a}$ and $\mathrm{H} 3 \mathrm{~b}$}

Following the PKM, H3a predicts that the differences across long, prospective, and short investors' loss likelihood judgments will be larger in the opportunistic amendment than in the objective amendment condition. In contrast, and consistent with emphasis framing theory, $\mathrm{H} 3 \mathrm{~b}$ makes the competing prediction that those differences will be smaller in the opportunistic amendment condition. $\mathrm{H} 3 \mathrm{a}$ and $\mathrm{H} 3 \mathrm{~b}$ are formally stated as follows:

H3a: The differences across long, prospective, and short investors' litigation risk judgments when litigation disclosures are presented opportunistically under the lower threshold will be greater than or equal to the differences when litigation disclosures are presented more objectively under the lower threshold.

H3b: The differences across long, prospective, and short investors' litigation risk judgments will be smaller when litigation disclosures are presented opportunistically under the lower threshold than when they are presented more objectively under the lower threshold.

As Figure 3 shows, short and prospective investors' judgments appear to converge toward long investors' judgments in the opportunistic amendment condition, consistent with $\mathrm{H} 3 \mathrm{~b}$ and inconsistent with $\mathrm{H} 3 \mathrm{a}$. First, to test whether the differences across long, prospective, and short investors change at all, I conducted a $3 \times 2$ ANCOVA across the three investment positions (long, prospective, and short) and the two relevant amendment conditions (objective and opportunistic), and find a statistically significant interaction (F 
$=3.28, \mathrm{p}=0.042 ;$ non-tabulated). ${ }^{7}$ Next, a Jonckheere-Terpstra test shows that the ordering of long, prospective, and short investors' litigation risk judgments is significant within the objective amendment condition (i.e., across 4.95, 5.54, and 7.43, respectively; $\mathrm{z}=-3.40, \mathrm{p}<0.001$, one-tailed), but insignificant within the opportunistic amendment condition (i.e., across 4.75, 4.93, and 4.76, respectively; $z=0.02, p=0.984$ ). Similarly, the difference between long and short investors' judgments is significant within the objective amendment condition (4.95 vs. $7.43, \mathrm{t}=3.17, \mathrm{p}=0.001$, one-tailed), but insignificant within the opportunistic amendment condition $(4.75$ vs. $4.76, \mathrm{t}=0.00, \mathrm{p}=$ 0.988). That is, the difference between long and short investors' judgments is significantly smaller in the opportunistic amendment condition than in the objective amendment condition $(\mathrm{t}=2.85, \mathrm{p}=0.003$, one-tailed $)$. These results support $\mathrm{H} 3 \mathrm{~b}$, but not H3a.

Additional analysis suggests that the disclosure in the opportunistic amendment condition led short investors to view pending litigation as favorably for the firm as even long investors, despite their directional preferences. As Figure 3 shows, long investors' judgments remain flat across all three disclosure conditions $(4.92,4.95$, and 4.75), suggesting that (as in my tests of $\mathrm{H} 2 \mathrm{a}$ ), long investors were evaluating the disclosed litigation at the boundaries of their reasonableness constraints. Specifically, long investors' judgments do not change between the objective amendment and opportunistic amendment condition $(\mathrm{t}=0.28, \mathrm{p}=0.779)$. In contrast, short investors' loss likelihood judgments decrease significantly from the objective amendment condition to the opportunistic amendment condition ( 7.43 vs. $4.76, \mathrm{t}=3.47, \mathrm{p}=0.001)$. Moreover, within

\footnotetext{
${ }^{7}$ Keppel and Wickens (2004) suggest using such analyses when comparing three or more groups within a larger experiment.
} 
the opportunistic amendment condition, both short and prospective investors' judgments appear to be as favorable to the firm as long investors' judgments ( 4.76 vs. $4.75, \mathrm{t}=0.00$, $\mathrm{p}=0.988$ and 4.93 vs. $4.75, \mathrm{t}=0.25, \mathrm{p}=0.802$, respectively). Thus, my findings demonstrate that firms can use the opportunistic disclosures allowed by a lower threshold to their advantage, potentially persuading prospective investors and even short investors to view the disclosure as favorably for the firm as do long investors.

\subsection{Post-Experimental and Demographic Questions}

After making their litigation risk assessments, I asked participants to answer a number of post-experimental questions and demographic questions. In one set of postexperimental questions, I asked participants to provide their opinions about the firm's legal disclosures. Participants responded to the following four items on 11-point likert scales:

1. "How objective are Karlow's [Bower's] legal disclosures?" (Not At All Objective / Very Objective)

2. "How credible are Karlow's [Bower's] legal disclosures?" (Not At All Credible / Very Credible)

3. "How forthcoming are Karlow's [Bower's] legal disclosures?" (Not At All Forthcoming / Very Forthcoming)

4. "How reliable are Karlow's [Bower's] legal disclosures?" (Not At All Reliable / Very Reliable) I included these variables as covariates in the analyses I used to test my hypotheses. The results of my hypotheses tests are not significantly affected when I control for these variables. 
In addition, I asked participants to provide their opinions about the litigiousness of the pharmaceutical industry, the outlook for the pharmaceutical industry, and the outlook for the stock market. Participants responded to the following three items on 11point likert scales:

1. "How litigious is the pharmaceutical industry, in your opinion?" (Not At All Litigious / Very Litigious)

2. "What do you believe is the current outlook for the pharmaceutical industry?" (Very Negative Outlook / Very Positive Outlook)

3. "What do you believe is the current outlook for the stock market in general?" (Very Negative Outlook / Very Positive Outlook)

I included these variables as covariates in the analyses I used to test my hypotheses. I found that individuals who believe the industry to be more litigious tend to assess litigation risk higher across experimental conditions $(\mathrm{F}=10.22, \mathrm{p}=0.002)$. Conversely, I found that participants did not assess industry outlook $(\mathrm{F}=1.54, \mathrm{p}=0.217)$ or stock market outlook $(\mathrm{F}=0.51, \mathrm{p}=0.477)$ differently across experimental conditions. Furthermore, participants' assessments of the litigiousness of the industry still remained significant after controlling for industry outlook and stock market outlook both separately and jointly. As such, I included participants' perceptions of the litigiousness of the pharmaceutical industry as a covariate when testing my hypotheses, as noted earlier in this chapter.

I also asked participants to provide some demographic information in the postexperimental questionnaire. For example, I asked participants to provide information about their educational background as follows: 
1. "In which program are you enrolled?"

$\begin{array}{ll}\circ & \text { MBA } \\ \circ & \text { PMBA } \\ \circ & \text { MSA } \\ \circ & \text { MSF } \\ \circ & \text { Undergraduate Program } \\ \circ & \text { Other }\end{array}$

2. "Please indicate the name of the university where you are enrolled in the program above:"

3. "How many accounting and finance courses have you taken, including the courses in which you are currently enrolled?"

(sliding scale with endpoints 0,20 courses)

4. "Have you previously taken, or are you currently taking, a Financial Statement Analysis course?" (Yes / No)

In general, I found that the results of my hypotheses tests are not significantly affected by including these demographic variables as covariates in my analyses.

Participants' program type $(F=0.73, p=0.393)$ and university $(F=0.16, p=0.687)$ were not significant explanatory variables. The number of accounting $(\mathrm{F}=0.02, \mathrm{p}=0.889)$ and finance $(F=0.006, p=0.940)$ courses participants had taken and whether they had completed a financial statement analysis course $(F=1.55, \mathrm{p}=0.215)$ also were not significant explanatory variables.

Next, I asked participants to indicate whether they had work experience as a financial analyst and whether they ever invested in the stock market or planned to do so in the future. I gathered this demographic information to support the notion that my participants were, generally, nonprofessionals with investing experience / interest (i.e., 
appropriate participants for my investment task). Results support this assertion. I found that $95 \%$ had previously invested or planned to invest in the stock market. I also included these variables as covariates and found that previous investing experience $(F=0.006, p=$ $0.939)$ and future investing plans $(\mathrm{F}=0.21, \mathrm{p}=0.650)$ were not significant explanatory variables. Further, excluding the $5 \%$ of participants who had neither previously invested nor planned to invest in the future did not affect the results of my hypotheses tests. Only $8 \%$ of participants had worked as a financial analyst, but this was not a significant explanatory variable $(\mathrm{F}=0.22, \mathrm{p}=0.641)$. Results remain similar when these participants are excluded from my hypotheses tests. I also asked participants about their work history and advanced education as follows:

1. Have you, or has anyone in your immediate family, ever worked in the pharmaceutical industry? (Self / Family Member / No)

2. Have you, or has anyone in your immediate family, worked in the legal field (e.g., lawyer, paralegal, etc.)? (Self / Family Member / No)

3. Do you hold any advanced degrees (e.g., M.D., D.O., J.D., Ph.D., etc.)? (Yes (if yes, please specify which degree) / No)

The results of my hypotheses tests are not significantly affected by including these demographic variables as covariates in my analyses. Having work experience in the pharmaceutical industry $(\mathrm{F}=0.25, \mathrm{p}=0.618)$ or in the legal field $(\mathrm{F}=0.619, \mathrm{p}=$ 0.433) were not significant explanatory variables. Having an advanced degree was also not a significant covariate $(\mathrm{F}=0.02, \mathrm{p}=0.899)$. 
I also gathered demographic information about participants' years of business experience and gender. I found that my results were not sensitive to years of professional business experience $(\mathrm{F}=0.02, \mathrm{p}=0.896)$ or gender $(\mathrm{F}=0.003, \mathrm{p}=0.957)$.

\subsection{Summary of Results}

The results of this study suggest there may be unintended consequences of lowering a disclosure threshold, such as the one recently proposed by the FASB (2008). First, I find that adding low probability lawsuits to the disclosure of reasonably possible lawsuits lowers prospective investors' litigation risk assessments, even though more lawsuits are disclosed. Second, lowering the threshold allows firms to portray the entire disclosure opportunistically, diverting attention from higher probability to lower probability lawsuits. I find evidence that firms can use such an opportunistic presentation under a lower threshold to their advantage. Specifically, prospective investors' and even short investors' litigation risk assessments were as favorable for the firm as long investors' when the disclosure threshold was lower and firms adopted an opportunistic disclosure strategy. Thus, my findings suggest that the FASB's proposal to require disclosure of lower probability loss contingencies may have unintended consequences for investors' perceptions of firms' loss exposure. 


\section{CHAPTER 5}

\section{CONCLUSIONS}

\section{$5.1 \quad$ Introduction}

This study investigates two unintended consequences of lowering a disclosure threshold, motivated by recent FASB proposals. In my experiment, nonprofessional investors were provided financial statements and legal disclosures for a hypothetical pharmaceutical company and were asked to assess the likelihood of material loss due to disclosed pending litigation. Participants were randomly assigned to a long, prospective, or short investment position, and to one of three disclosure conditions. Participants received disclosures: (1) with a probability threshold of "at least reasonably possible" (i.e., consistent with existing SFAS 5); (2) with a probability threshold of "more than remote" (i.e., consistent with the FASB's proposed amendment); or (3) with a probability threshold of "more than remote" (i.e., consistent with the FASB's proposed amendment) and an opportunistic reporting strategy allowed by the lower threshold. The same reasonably possible lawsuit was presented in all three disclosure conditions, since both SFAS 5 and the proposed amendment would require disclosure of lawsuits at this probability threshold. However, in the two lower probability threshold conditions, three additional lawsuits with a slightly more than remote likelihood of leading to a material loss were also disclosed in either a more objective manner or in a more opportunistic manner designed to persuade investors to perceive the litigation, as a whole, as less serious. The sections that follow provide conclusions, implications, and directions for future research. 


\subsection{Discussion}

Recently, investors have criticized the quality of firms' loss contingency disclosures, by asserting that disclosures under SFAS 5 do not adequately allow them to predict and assess the likelihood, amount, and timing of future cash flows (FASB 2008). In response to investors' assertions, the FASB issued an Exposure Draft that, among other changes, proposes lowering the probability threshold for disclosure of loss contingencies from "at least reasonably possible" to "more than remote" (FASB 2008, paragraph 5). According to the FASB (2008), this lower threshold would require many firms to disclose more pending lawsuits (FASB 2008). My study reports the results of an experiment which investigates two unintended consequences of lowering the disclosure threshold.

My results show that under the current SFAS 5 disclosure threshold, investors' judgments are consistent with their motivated reasoning goals. That is, consistent with their preferences for higher profitability and share price, long investors assess the firm's likelihood of loss due to disclosed litigation lowest, while short investors (who require lower share prices in order to profit) assess the firm's likelihood of loss highest. Prospective investors, who have no position in the firm and therefore an incentive to objectively assess potential losses, fall in between short and long investors. When the probability threshold is lowered to include low probability lawsuits, prospective investors decrease their loss likelihood judgments, even though more litigation is disclosed. This finding suggests that the low probability lawsuits dilute the influence of the higher probability lawsuit on prospective investors' litigation risk assessments. Conversely, long and short investors continue to be influenced by their directional preferences and 
assimilate the additional low probability lawsuits in a manner that biases them toward their preferred conclusions. My results also suggest that the form of management's presentation also influences investors' perceptions of litigation losses. When managers use an opportunistic presentation under the lower probability threshold, they can successfully persuade all investors to perceive pending litigation more favorably for the firm, despite investors' directional preferences.

\subsection{Implications}

My findings have a number of important implications. For example, my results should be of interest to the FASB as they continue to contemplate lowering disclosure thresholds in the ongoing SFAS 5 debate. My findings suggest that the FASB should exercise caution if disclosure thresholds are lowered, as they may not result in better investor judgments. The FASB's Exposure Draft as currently written leaves openings for managers to frame lawsuits in an opportunistic manner, and my results suggest that investors are persuaded by such a presentation. My results suggest that policy makers should consider both whether and how disclosures are presented.

While the SFAS 5 debate provides a timely backdrop for studying the consequences of expanding disclosure requirements, my findings may inform other settings in which similar disclosure expansions are being contemplated. For example, in 2010, the SEC implemented new requirements that publicly traded companies disclose any risks that climate change might pose to their future operations or profits (SEC 2010). Firms could choose to disclose all risks objectively (i.e., present both more and less remote risks in a transparent manner). Alternatively, as this new mandate would require many firms to disclose more items, firms could use the new mandate to disclose 
information opportunistically (e.g., strategically disclosing a number of very remote risks to draw attention away from potentially more serious ones). Thus, similar unintended consequences could potentially occur in a variety of settings in which disclosure requirements are expanded.

\subsection{Directions for Future Research}

While my results may help inform standard setters and regulators about potential unintended consequences of an expansion of disclosure requirements, future research could explore factors that may moderate my findings. For example, there may be factors that would cause a firm's opportunistic disclosure to have no effect on short sellers or even backfire (e.g., disclosures that go overboard, cf., Friestad and Wright 1994). Taskrelevant factors that amplify, impose boundary conditions, or even reverse the effects shown here are interesting possible directions for future research. 


\section{APPENDIX}

\section{RESEARCH INSTRUMENT}

This instrument was administered on a computer. The screens viewed by participants are provided on the following pages.

- EXHIBIT 1. Instructions (Provided to Participants in All Conditions)

- EXHIBIT 2a. Manipulation of Investment Position (Provided to Participants in the Long Investor Condition)

- EXHIBIT 2b. Manipulation of Investment Position (Provided to Participants in the Prospective Investor Condition)

- EXHIBIT 2c. Manipulation of Investment Position (Provided to Participants in the Short Investor Condition)

- EXHIBIT 3a. Disclosure Threshold and Compensation Manipulation Check Screen (Provided to Participants in the Long Investor/SFAS 5 Condition)

- EXHIBIT 3b. Disclosure Threshold and Compensation Manipulation Check Screen (Provided to Participants in the Long Investor/Objective Amendment Condition and the Long Investor/Opportunistic Amendment Condition)

- EXHIBIT 3c. Disclosure Threshold and Compensation Manipulation Check Screen (Provided to Participants in the Prospective Investor/ SFAS 5 Condition)

- EXHIBIT 3d. Disclosure Threshold and Compensation Manipulation Check Screen (Provided to Participants in the Prospective Investor/Objective Amendment Condition and the Prospective Investor/Opportunistic Amendment Condition) 
- EXHIBIT 3e. Disclosure Threshold and Compensation Manipulation Check Screen (Provided to Participants in the Short Investor/SFAS 5 Condition)

- EXHIBIT 3f. Disclosure Threshold and Compensation Manipulation Check Screen (Provided to Participants in the Short Investor/Objective Amendment Condition and the Short Investor/Opportunistic Amendment Condition)

- EXHIBIT 4. Financial Statements Screen (Provided to Participants in All Conditions)

- EXHIBIT 5a. Legal Proceedings and Contingencies and Dependent Variables Screen (Provided to Participants in the SFAS 5 Condition)

- EXHIBIT 5b. Legal Proceedings and Contingencies and Dependent Variables Screen (Provided to Participants in the Objective Amendment Condition)

- EXHIBIT 5c. Legal Proceedings and Contingencies and Dependent Variables Screen (Provided to Participants in the Opportunistic Amendment Condition)

- EXHIBIT 6. Post-Experimental Questionnaire (Provided to Participants in All Conditions)

- EXHIBIT 7a. Compensation Data Screen (Provided to Participants in the Long Investor Condition)

- EXHIBIT 7b. Compensation Data Screen (Provided to Participants in the Prospective Investor Condition)

- EXHIBIT 7c. Compensation Data Screen (Provided to Participants in the Short Investor Condition)

- EXHIBIT 8. Demographic Questions (Provided to Participants in All Conditions) 


\section{EXHIBIT 1}

\section{Instructions (Provided to Participants in All Conditions)}

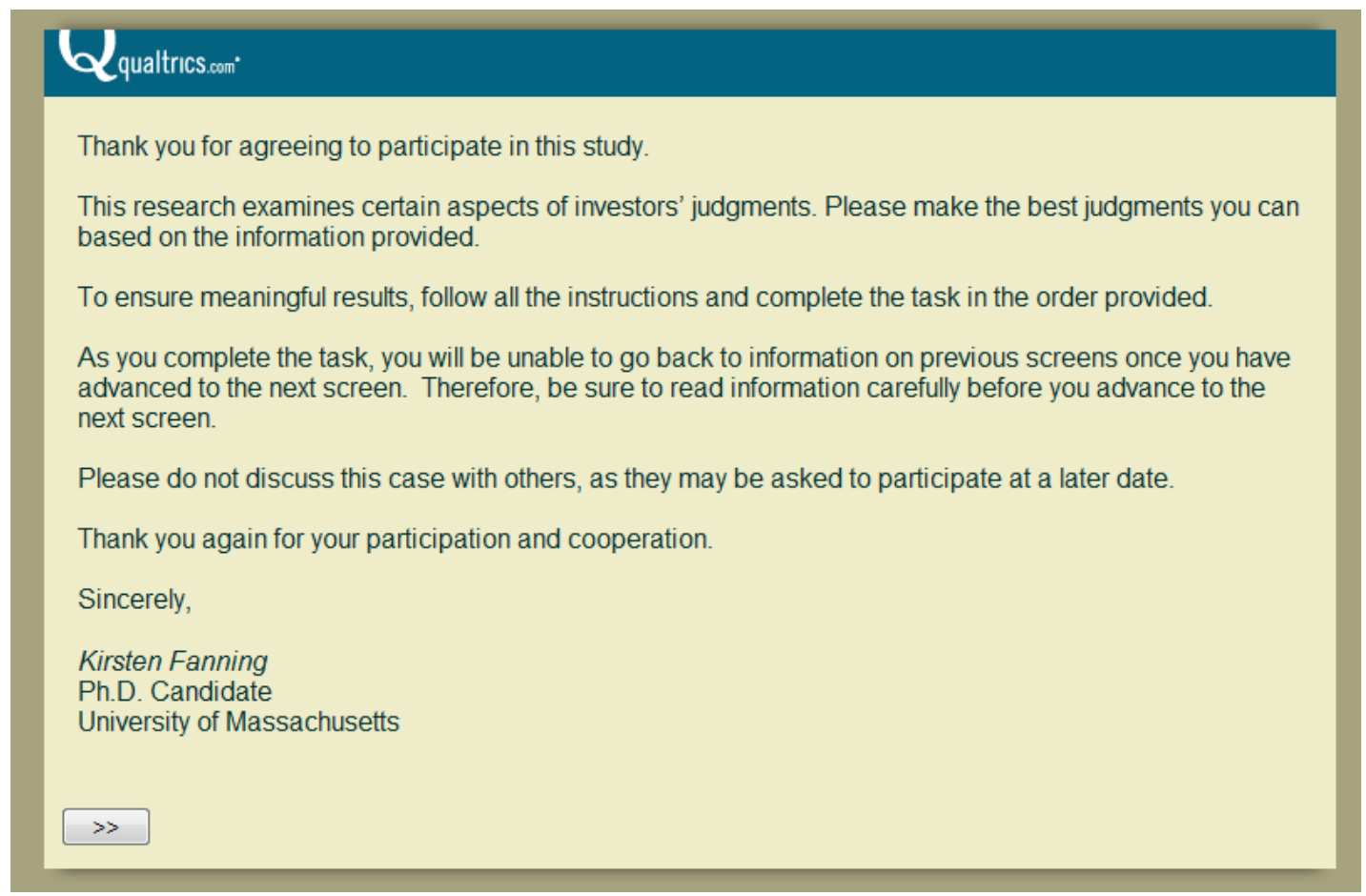




\section{EXHIBIT 2a}

\section{Manipulation of Investment Position (Provided to Participants in the Long Investor Condition)}

\section{$\mathbf{Q}_{\text {qualtrosomi }}$}

This case will ask for your best judgments as a knowledgeable business professional and investor.

Karlow and Bower are two publicly traded companies from the pharmaceutical industry. Upon comparing the two firms, key differences between them have been narrowed to a list of factors. These factors, grouped by firm, are given below.

Your task will be to choose one of these two companies to invest in. Investing in a company is like taking a bet that its stock price will increase. As a result, you would want to choose the stock that will be the better performer of the two in the future. You will be asked to evaluate the company you choose to invest in.

Because you are investing in one of these firms, you will be paid either: $\$ 15$ if the company you select is the better performer of the two or $\$ 5$ if the company you select is the worse performer of the two.

To ensure that you understand your task in this case, which of the following statements is true?

My task is to pick the company that I think will perform better and evaluate it as an investor in that company.

My task is to pick the company that I think will perform worse and evaluate it as an investor taking a short position in that company.

\begin{tabular}{|c|c|c|c|c|c|c|c|}
\hline \multicolumn{4}{|c|}{$\underline{\text { Karlow Pharmaceuticals, Inc. }}$} & \multicolumn{4}{|c|}{ Bower Pharmaceuticals, Inc. } \\
\hline & $\underline{2009}$ & $\underline{2008}$ & $\underline{2007}$ & & $\underline{2009}$ & $\underline{2008}$ & $\underline{2007}$ \\
\hline Net Income Growth Rate & $2.76 \%$ & $1.90 \%$ & $1.71 \%$ & Revenue Growth Rate & $4.16 \%$ & $3.78 \%$ & $2.75 \%$ \\
\hline Net Profit Margin & $24.90 \%$ & $25.24 \%$ & $25.71 \%$ & Operating Profit Margin & $35.19 \%$ & $35.78 \%$ & $36.47 \%$ \\
\hline Return on Equity & $34.99 \%$ & $33.26 \%$ & $32.53 \%$ & Retum on Assets & $21.95 \%$ & $21.50 \%$ & $21.18 \%$ \\
\hline \multicolumn{4}{|c|}{$\begin{array}{l}\text { Opened new manufacturing facilities located in the UK, Spain, } \\
\text { Japan, Morocco, \& China. }\end{array}$} & \multicolumn{4}{|c|}{$\begin{array}{l}\text { Recent Phase III clinical trial data suggests the company's } \\
\text { drug, Precor®, was successful at preventing blood clotting in } \\
\text { patients undergoing knee replacement surgery. }\end{array}$} \\
\hline \multicolumn{4}{|c|}{ Funding stem cell research at the University of Texas Health } & \multirow{2}{*}{\multicolumn{4}{|c|}{$\begin{array}{l}\text { Currently running a successful television marketing campaign } \\
\text { for several top-selling products. This allows for direct to } \\
\text { consumer advertising. }\end{array}$}} \\
\hline \multicolumn{4}{|c|}{$\begin{array}{l}\text { Science Center in Houston. The research is investigating } \\
\text { whether stem cell therapy can reverse the neurological damage } \\
\text { caused by multiple sclerosis. }\end{array}$} & & & & \\
\hline $\begin{array}{l}\text { Launched two new produc } \\
\text { antihistamine lotion, Calm } \\
\text { ointment, CureAll@. }\end{array}$ & $\begin{array}{l}\text { in the cons } \\
\text { ch®, and to }\end{array}$ & pical antiba & $\begin{array}{l}\text { nt: topical } \\
\text { cterial }\end{array}$ & \multicolumn{4}{|c|}{$\begin{array}{l}\text { According to the Senate Office of Public Records, the } \\
\text { company is one of the top spenders in the industry on } \\
\text { Congressional lobbying efforts. }\end{array}$} \\
\hline \multicolumn{4}{|c|}{2010 March of Dimes corporate partner. } & \multicolumn{4}{|c|}{$\begin{array}{l}\text { Recently signed joint ventures with laboratories in Germany, } \\
\text { Mexico, Brazil, \& India. A licensing agreement is also held } \\
\text { with one Australian laboratory. }\end{array}$} \\
\hline
\end{tabular}

All other factors were similar across the two firms, including the prices of the respective stocks. 
Please think carefully about your two options before deciding which firm to invest in. Remember that you want to choose the firm that you believe will outperform the other. As you carefully make your choice, please indicate the reasons you have for the firm you choose in the space below.

Please indicate the firm that you would like to invest in

() Karlow

(1) Bower 


\section{EXHIBIT $2 b$}

\section{Manipulation of Investment Position (Provided to Participants in the Prospective Investor Condition)}

\section{$\alpha_{\text {qualtricsomin }}$}

This case will ask for your best judgments as a knowledgeable business professional and investor

Assume Karlow and Bower are two publicly traded companies from the pharmaceutical industry. Upon comparing the two firms, key differences between them have been narrowed to a list of factors. These factors, grouped by firm, are given below.

Your task will be to evaluate these companies as objectively as possible.

You will be paid $\$ 10$ for providing your objective judgments.

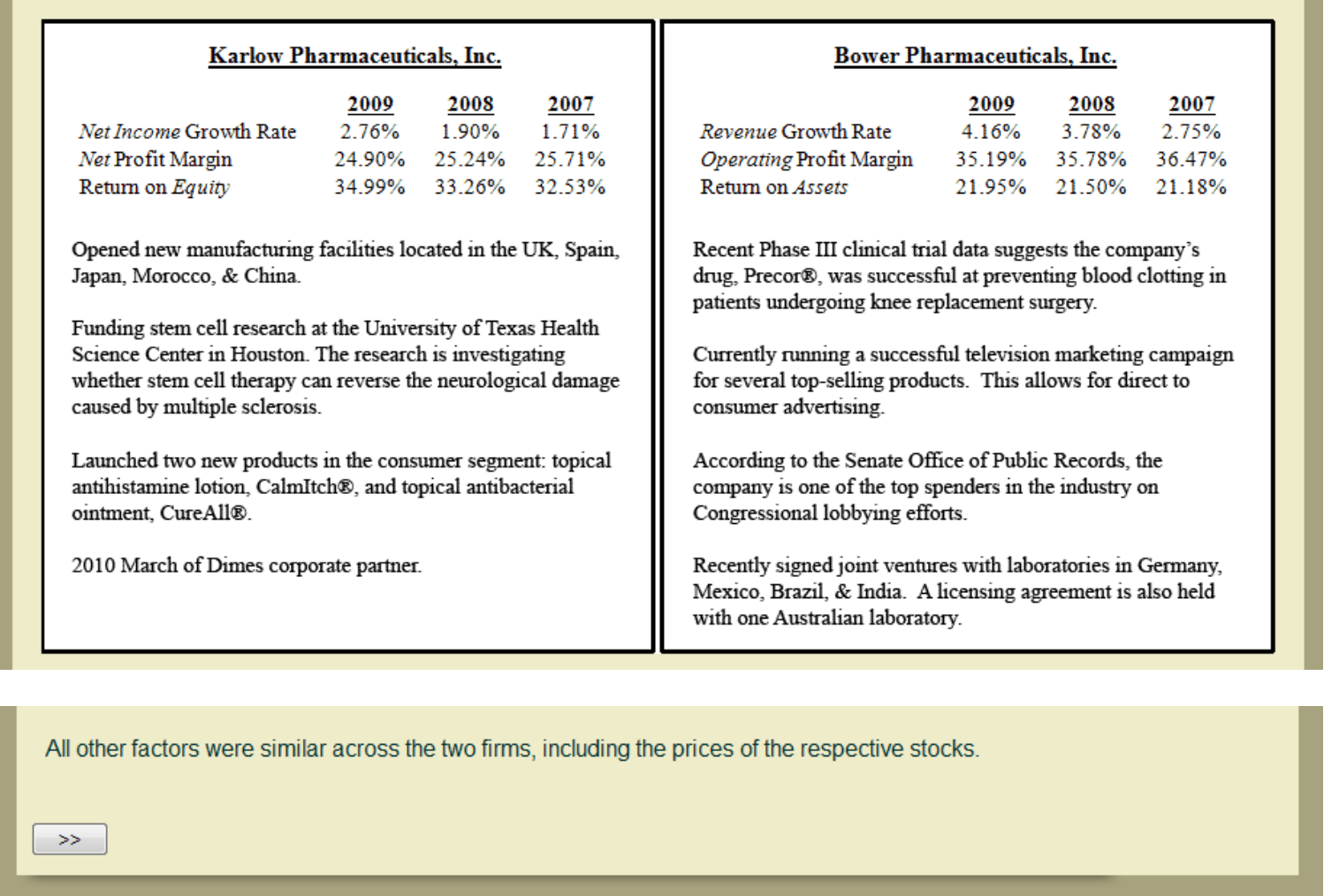




\section{EXHIBIT 2c}

\section{Manipulation of Investment Position (Provided to Participants in the Short Investor Condition)}

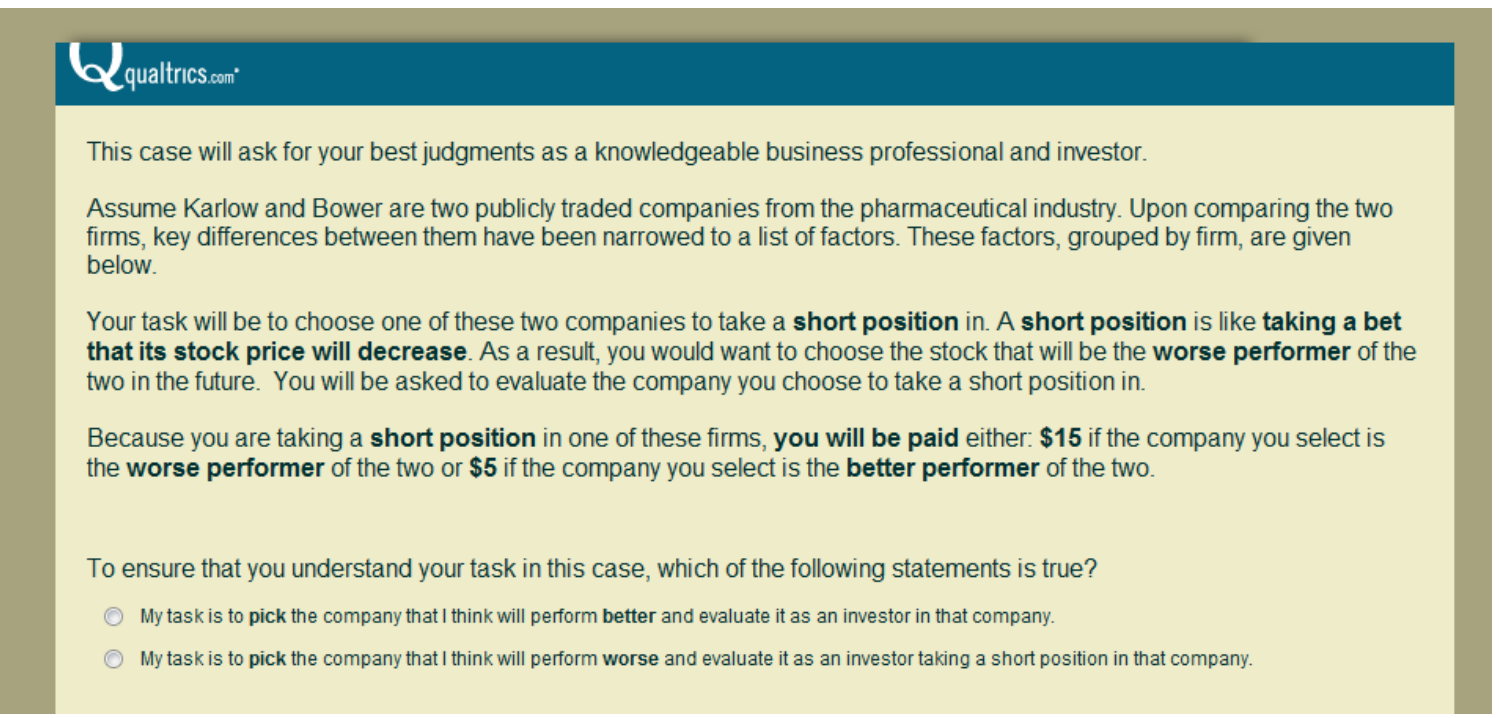

\begin{tabular}{|c|c|c|c|}
\hline \multicolumn{4}{|c|}{ Karlow Pharmaceuticals, Inc. } \\
\hline & $\underline{2009}$ & $\underline{2008}$ & $\underline{2007}$ \\
\hline Net Income Growth Rate & $2.76 \%$ & $1.90 \%$ & $1.71 \%$ \\
\hline Net Profit Margin & $24.90 \%$ & $25.24 \%$ & $25.71 \%$ \\
\hline Return on Equity & $34.99 \%$ & $33.26 \%$ & $32.53 \%$ \\
\hline \multicolumn{4}{|c|}{$\begin{array}{l}\text { Opened new manufacturing facilities located in the UK, Spain, } \\
\text { Japan, Morocco, \& China. }\end{array}$} \\
\hline \multicolumn{4}{|c|}{$\begin{array}{l}\text { Funding stem cell research at the University of Texas Health } \\
\text { Science Center in Houston. The research is investigating } \\
\text { whether stem cell therapy can reverse the neurological damage } \\
\text { caused by multiple sclerosis. }\end{array}$} \\
\hline \multicolumn{4}{|c|}{$\begin{array}{l}\text { Launched two new products in the consumer segment: topical } \\
\text { antihistamine lotion, CalmItch }(\text {, and topical antibacterial } \\
\text { ointment, CureAll } \otimes \text {. }\end{array}$} \\
\hline \multicolumn{4}{|c|}{2010 March of Dimes corporate partner. } \\
\hline
\end{tabular}

\begin{tabular}{|c|c|c|c|}
\hline \multicolumn{4}{|c|}{ Bower Pharmaceuticals, Inc. } \\
\hline & $\underline{2009}$ & $\underline{2008}$ & $\underline{2007}$ \\
\hline Revenue Growth Rate & $4.16 \%$ & $3.78 \%$ & $2.75 \%$ \\
\hline Operating Profit Margin & $35.19 \%$ & $35.78 \%$ & $36.47 \%$ \\
\hline Return on Assets & $21.95 \%$ & $21.50 \%$ & $21.18 \%$ \\
\hline \multicolumn{4}{|c|}{$\begin{array}{l}\text { Recent Phase III clinical trial data suggests the company's } \\
\text { drug, Precor } \$ \text {, was successful at preventing blood clotting in } \\
\text { patients undergoing knee replacement surgery. }\end{array}$} \\
\hline \multicolumn{4}{|c|}{$\begin{array}{l}\text { Currently running a successful television marketing campaign } \\
\text { for several top-selling products. This allows for direct to } \\
\text { consumer advertising. }\end{array}$} \\
\hline \multicolumn{4}{|c|}{$\begin{array}{l}\text { According to the Senate Office of Public Records, the } \\
\text { company is one of the top spenders in the industry on } \\
\text { Congressional lobbying efforts. }\end{array}$} \\
\hline \multicolumn{4}{|c|}{$\begin{array}{l}\text { Recently signed joint ventures with laboratories in Germany, } \\
\text { Mexico, Brazil, \& India. A licensing agreement is also held } \\
\text { with one Australian laboratory. }\end{array}$} \\
\hline
\end{tabular}

All other factors were similar across the two firms, including the prices of the respective stocks. 
Please think carefully about your two options before deciding which firm to take a short position in. Remember that you want to choose the firm that you believe will underperform the other. As you carefully make your choice, please indicate the reasons you have for the firm you choose in the space below.

Please indicate the firm that you would like to take a short position in.

(1) Karlow

(1) Bower 


\section{EXHIBIT 3a}

\section{Disclosure Threshold and Compensation Manipulation Check Screen (Provided to Participants in the Long Investor/SFAS 5 Condition)}

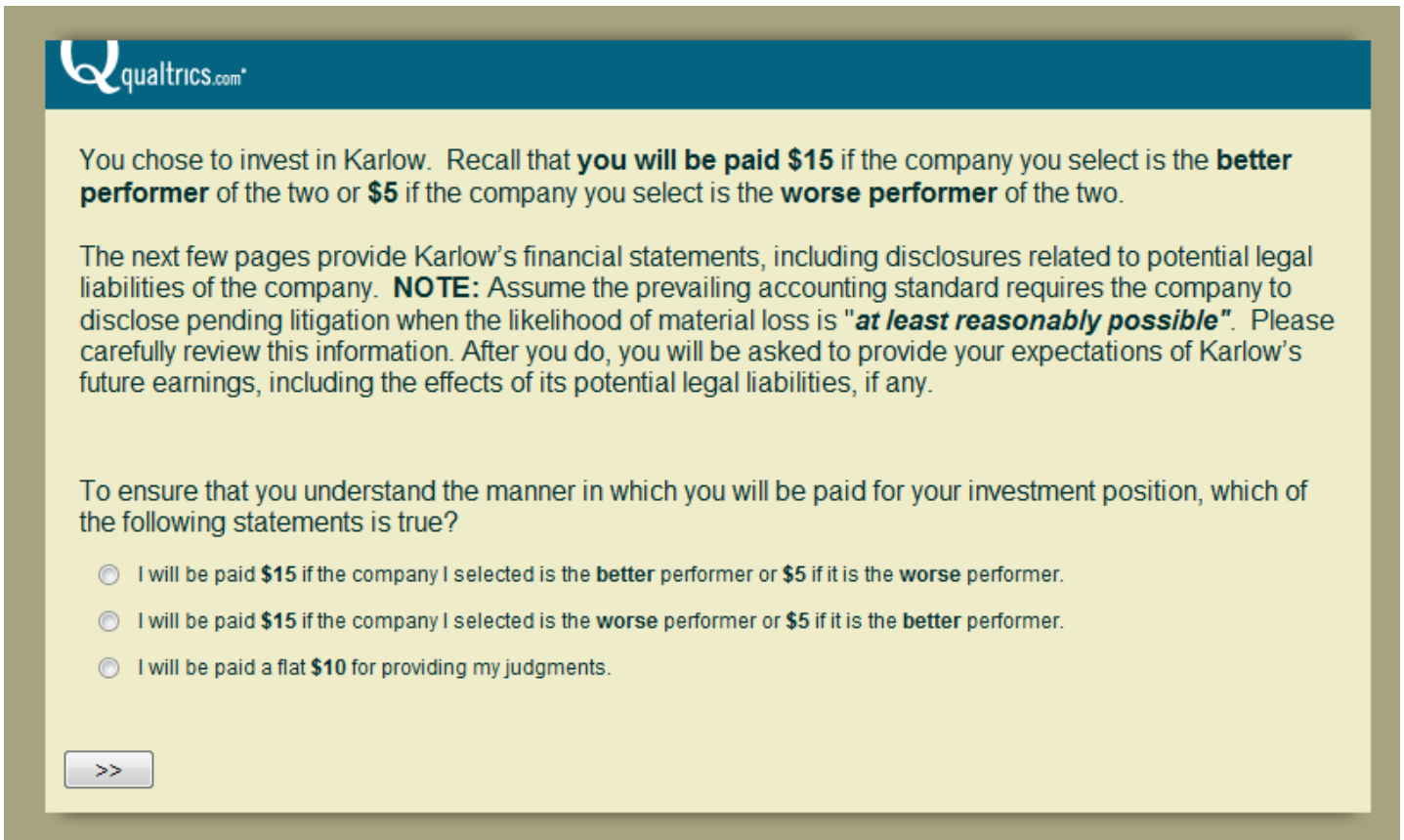

[Note: If the participant chose to invest in Bower, all instances of "Karlow" would read "Bower".] 


\section{EXHIBIT 3b}

Disclosure Threshold and Compensation Manipulation Check Screen (Provided to Participants in the Long Investor/Objective Amendment Condition and the Long Investor/Opportunistic Amendment Condition)

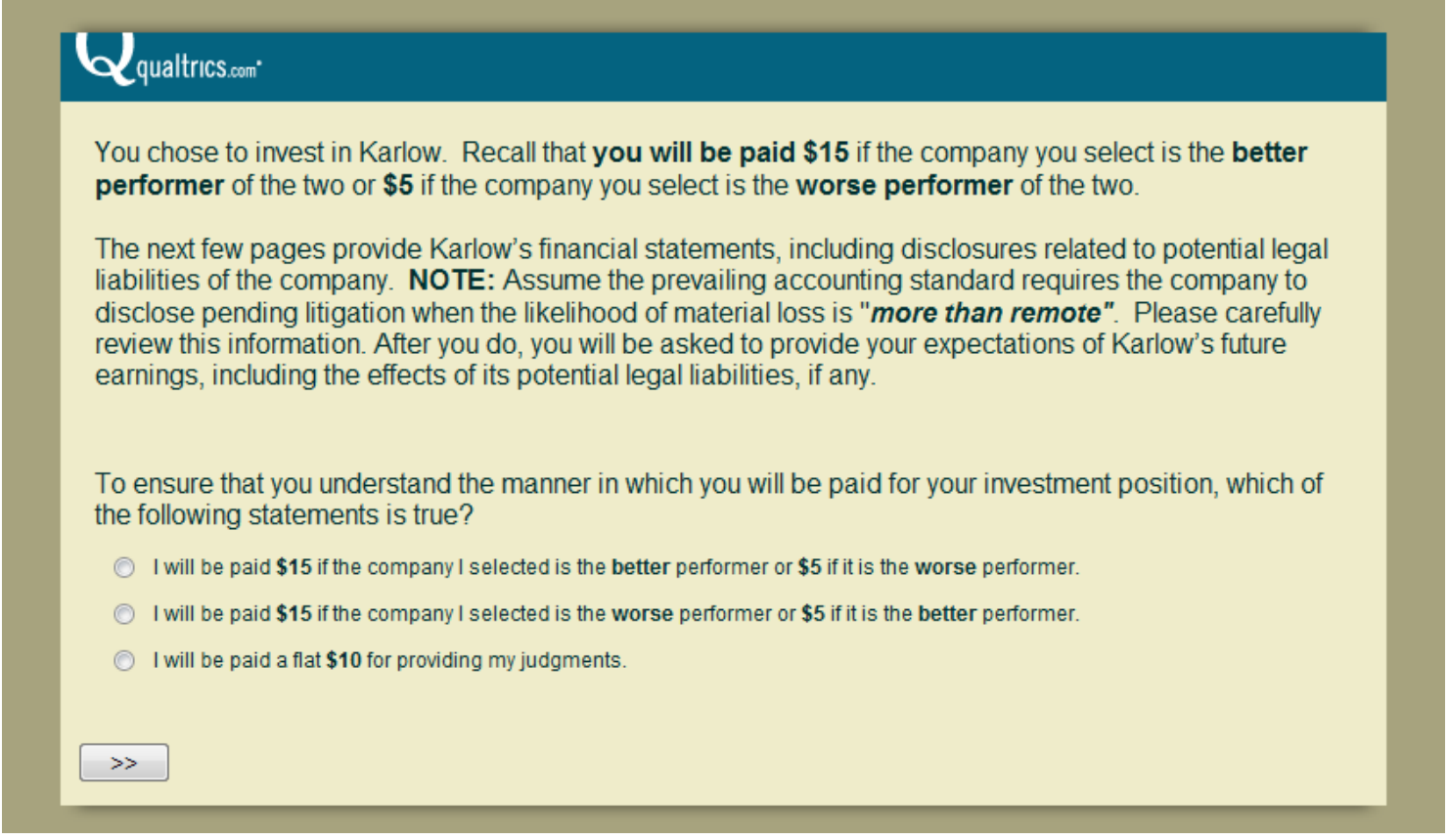




\section{EXHIBIT 3c}

Disclosure Threshold and Compensation Manipulation Check Screen (Provided to Participants in the Prospective Investor/SFAS 5 Condition)

\section{$\alpha_{\text {qualltresen: }}$}

We have chosen one of the two companies at random for you to evaluate further. Recall that you will be paid $\$ 10$ for providing your objective judgments.

The next few pages provide Karlow's financial statements, including disclosures related to potential legal liabilities of the company. NOTE: Assume the prevailing accounting standard requires the company to disclose pending litigation when the likelihood of material loss is "at least reasonably possible". Please carefully review this information. After you do, you will be asked to provide your expectations of Karlow's future earnings, including the effects of its potential legal liabilities, if any.

To ensure that you understand the manner in which you will be paid for your investment position, which of the following statements is true?

I will be paid $\$ 15$ if the company I selected is the better performer or $\$ 5$ if it is the worse performer.

I will be paid $\$ 15$ if the company I selected is the worse performer or $\$ 5$ if it is the better performer

I will be paid a flat $\$ 10$ for providing my judgments. 


\section{EXHIBIT 3d}

Disclosure Threshold and Compensation Manipulation Check Screen (Provided to Participants in the Prospective Investor/Objective Amendment Condition and the Prospective Investor/Opportunistic Amendment Condition)

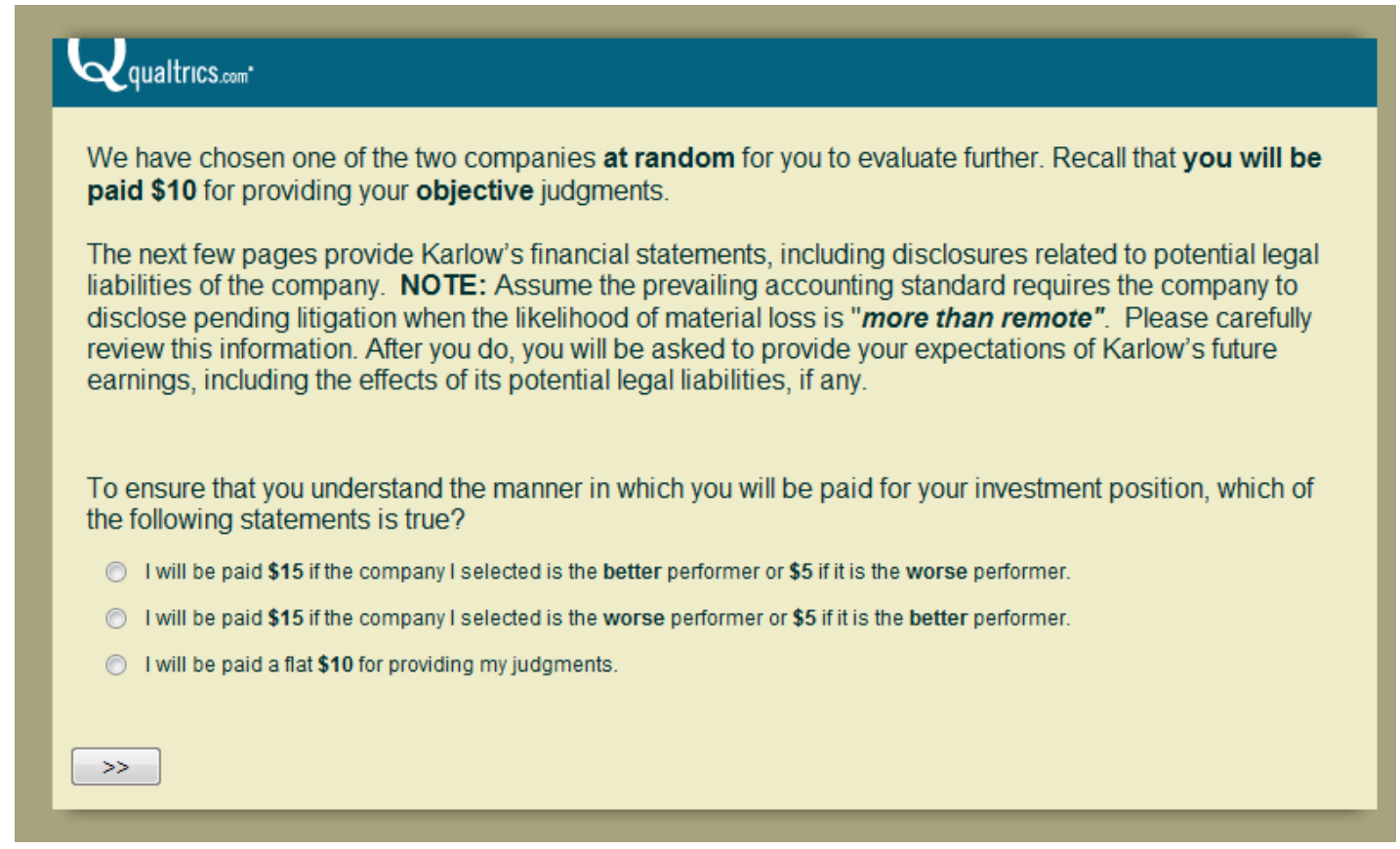




\section{EXHIBIT 3e}

\section{Disclosure Threshold and Compensation Manipulation Check Screen (Provided to Participants in the Short Investor/SFAS 5 Condition)}

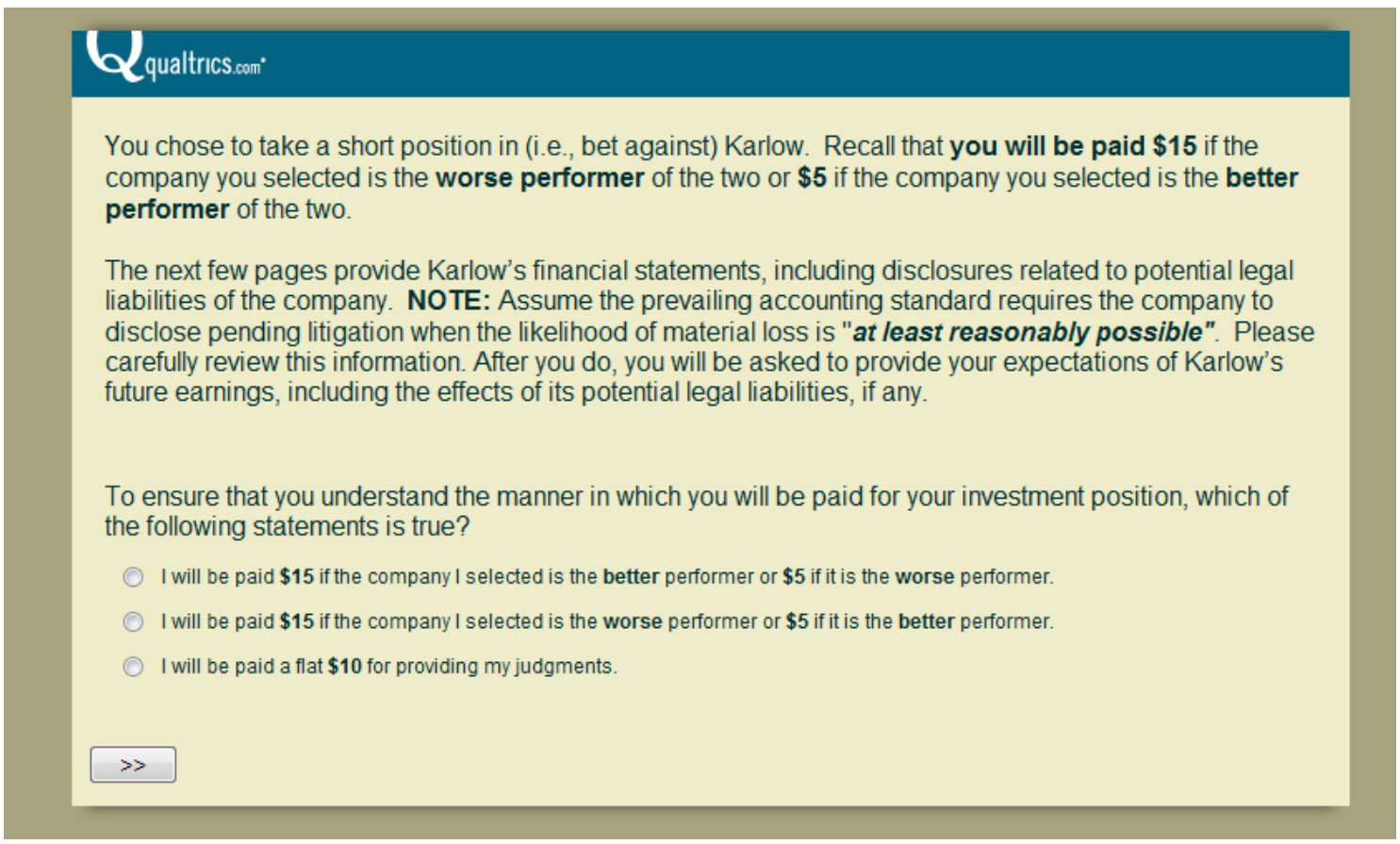




\section{EXHIBIT $3 f$}

Disclosure Threshold and Compensation Manipulation Check Screen (Provided to Participants in the Short Investor/Objective Amendment Condition and the Short Investor/Opportunistic Amendment Condition)

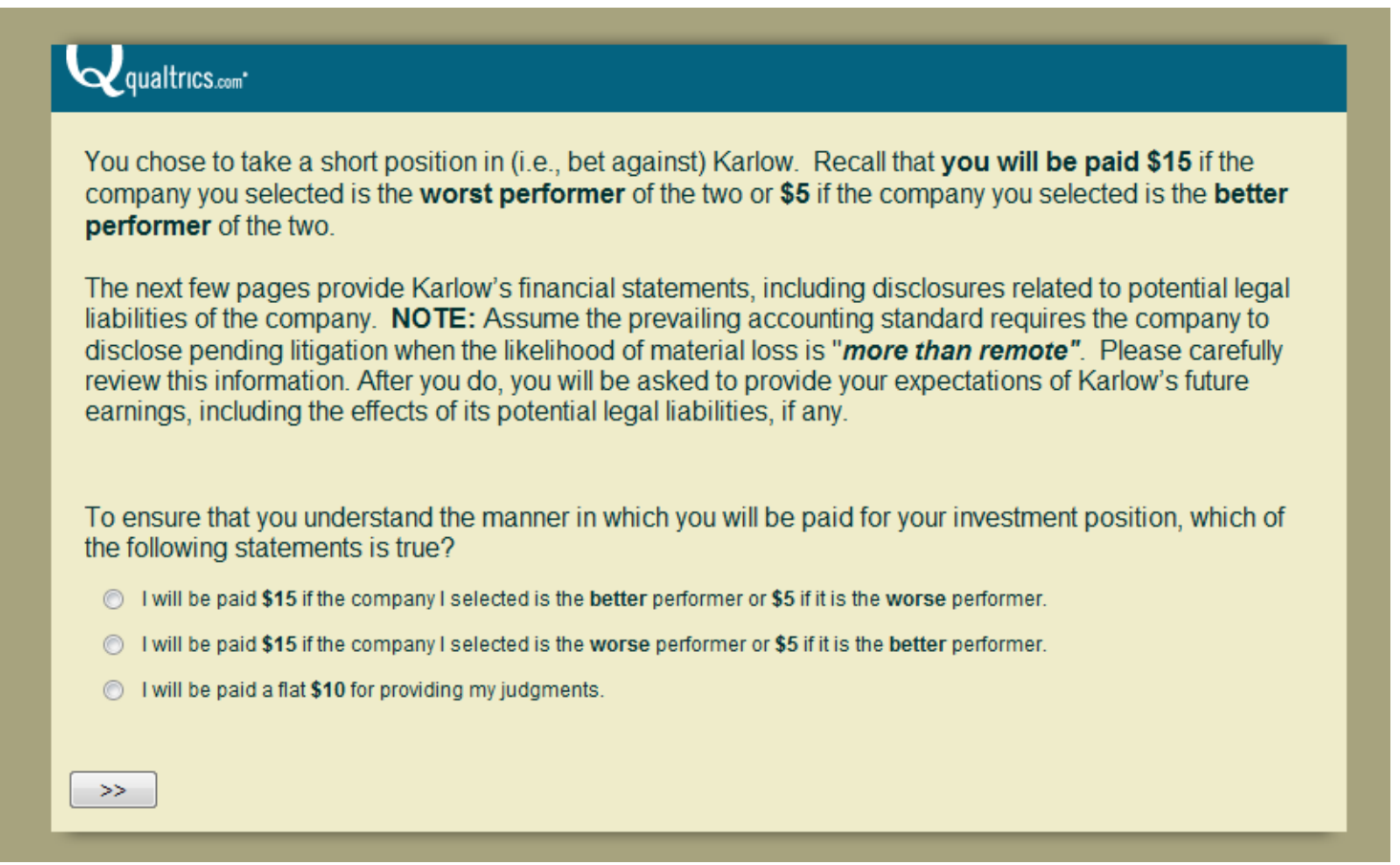




\section{EXHIBIT 4}

Financial Statements Screen (Provided to Participants in All Conditions)

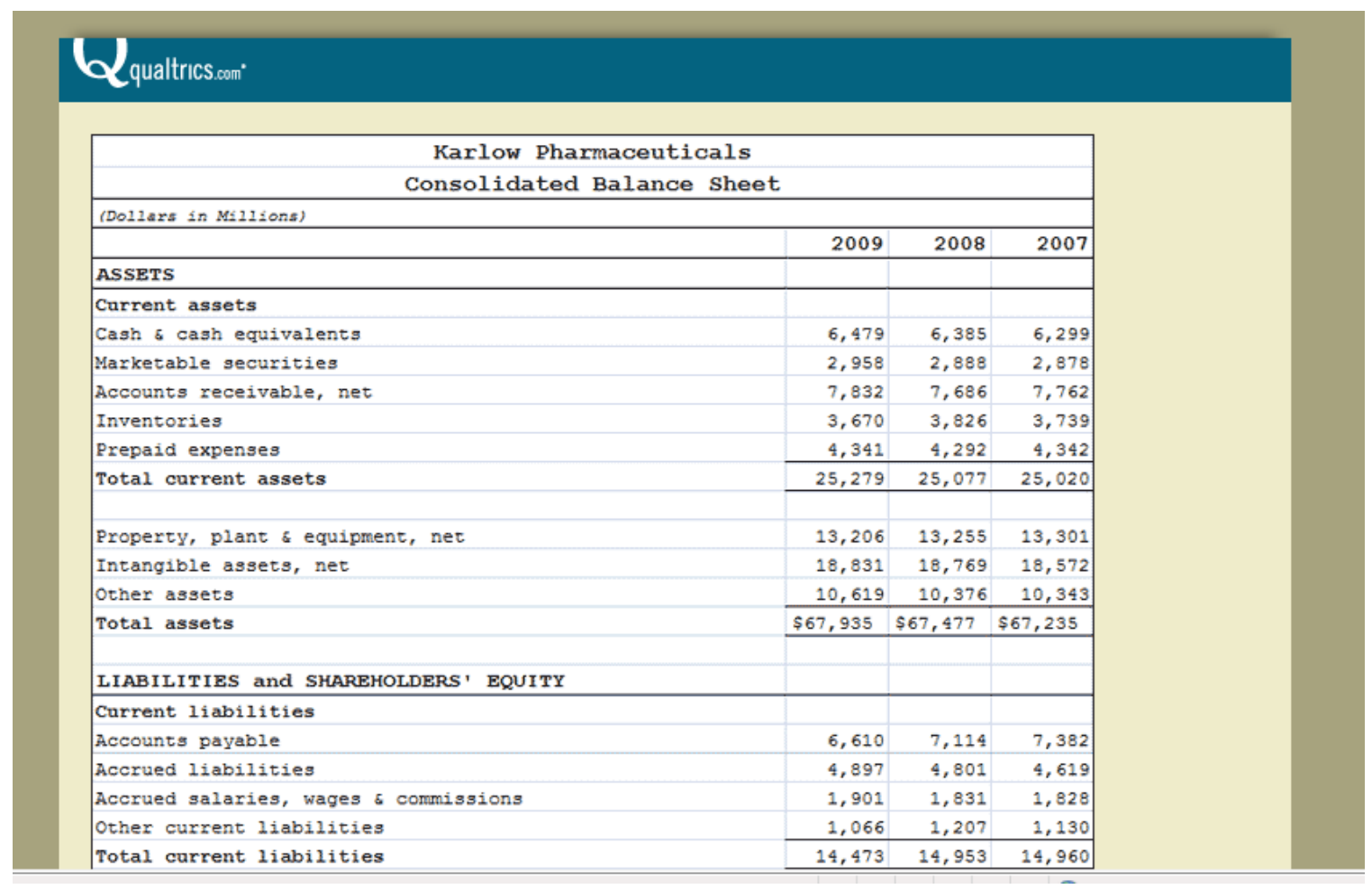




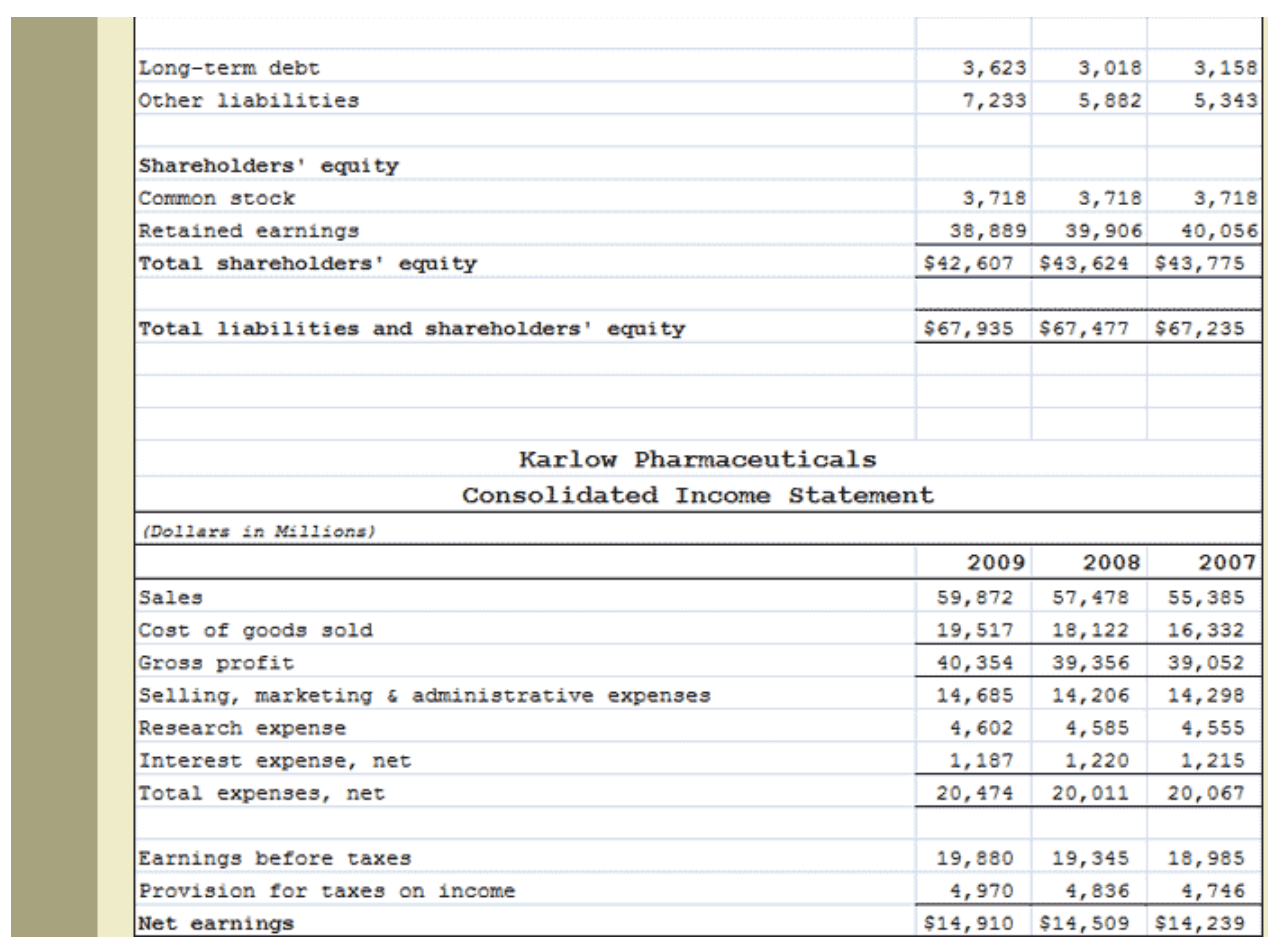

Legal disclosures on the following page. 


\section{EXHIBIT 5a}

\section{Legal Proceedings and Contingencies and Dependent Variables Screen (Provided to Participants in the SFAS 5 Condition)}

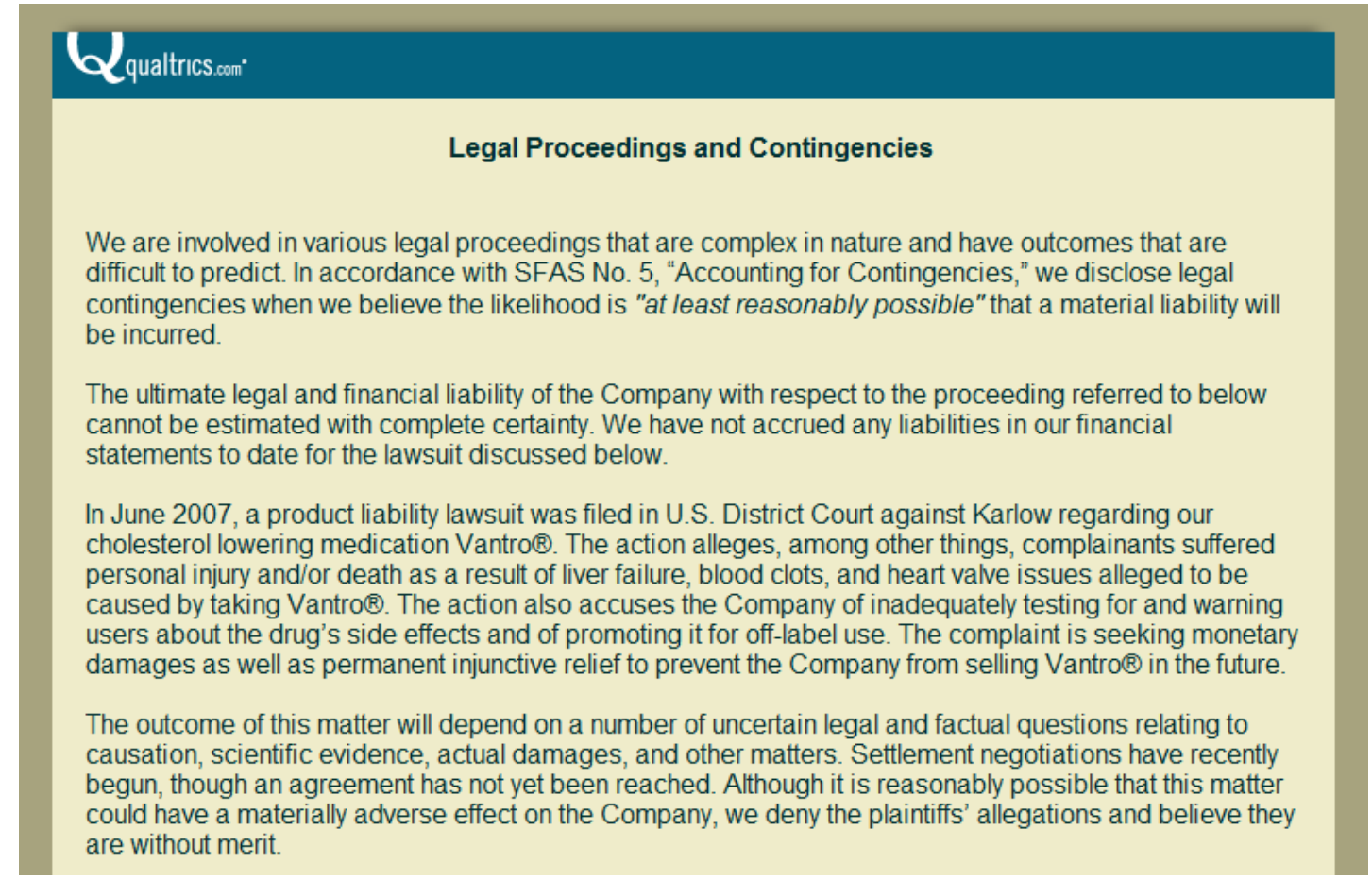

From time to time, we are involved in other routine litigation arising in the ordinary course of business. We believe that it is less than reasonably possible that other litigation would materially adversely affect our financial position. 
Please answer the following questions as you continue evaluating Karlow. Select the number below each question that best corresponds to your assessment.

1. What is the likelihood that Karlow will incur a future material loss due to the disclosed litigation?

\begin{tabular}{c|cccccccccccc} 
Material & \\
Loss \\
Not At \\
All \\
Likely \\
0
\end{tabular}

2. To what extent will Karlow's earnings in future periods be affected by the disclosed litigation?

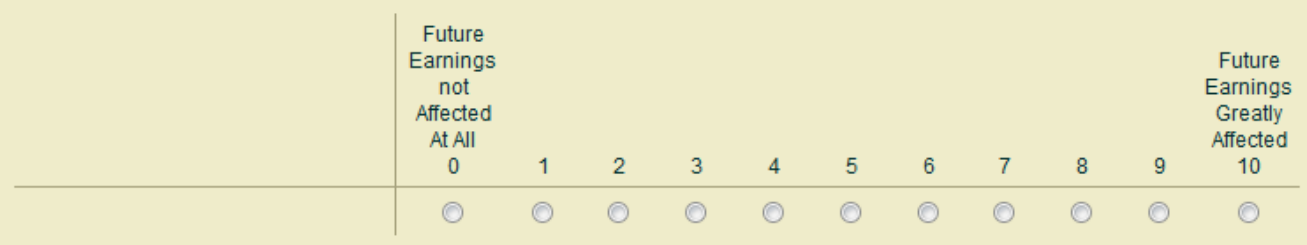




\section{EXHIBIT 5b}

\section{Legal Proceedings and Contingencies and Dependent Variables Screen (Provided to Participants in the Objective Amendment Condition)}

Legal Proceedings and Contingencies
We are involved in various legal proceedings that are complex in nature and have outcomes that are
difficult to predict. In accordance with the recent amendment to SFAS No. 5, "Accounting for
Contingencies," we disclose legal contingencies when we believe the likelihood is "more than remote"
that a material liability will be incurred.
The ultimate legal and financial liability of the Company with respect to the proceedings referred to below
cannot be estimated with complete certainty. Thus, we have not recorded any liabilities in our financial
statements to date for the lawsuits discussed below.
Vantro® Litigation
In June 2007 , a product liability lawsuit was filed in U.S. District Court against Karlow regarding our
cholesterol lowering medication Vantro®. The action alleges, among other things, complainants suffered
personal injury and/or death as a result of liver failure, blood clots, and heart valve issues alleged to be
caused by taking Vantro®. The action also accuses the Company of inadequately testing for and warning
users about the drug's side effects and of promoting it for off-label use. The complaint is seeking monetary
damages as well as permanent injunctive relief to prevent the Company from selling Vantro® in the future.
The outcome of this matter will depend on a number of uncertain legal and factual questions relating to
causation, scientific evidence, actual damages, and other matters. Settlement negotiations have recently
begun in this matter, though an agreement has not yet been reached. Although it is reasonably possible
that this matter could have a materially adverse effect on the Company, we deny the plaintiffs' allegations
...


and believe they are without merit.

\section{Antitrust Litigation}

In January 2005, Karlow was named as a defendant, along with other pharmaceutical manufacturers, in a class action in U.S. District Court. The action alleges that the defendant companies violated federal antitrust statutes and certain state laws by unlawfully agreeing to engage in conduct to prevent U.S. consumers from purchasing defendants' prescription drugs from Canada. Plaintiffs claim that, as a result of the alleged unlawful agreement, the purported class members paid higher prices for the defendants' pharmaceutical products than they otherwise would have paid in the absence of the alleged agreement. Plaintiffs seek various forms of relief, including punitive damages, restitution, injunctive relief, and attorneys' fees.

The outcome of this matter will depend on a number of complex and uncertain legal and factual questions. We believe the likelihood that this matter could have a materially adverse effect on the Company is slightly more than remote. On July 21, 2009, the U.S. District Court dismissed this claim. Plaintiffs have appealed to the United States Court of Appeals for the Eighth Circuit. Briefing on the appeal has been completed. Oral argument on the appeal has not yet been scheduled.

\section{MedDefib $®$ Litigation}

In July 2005, Karlow was named the defendant in a breach of contract lawsuit brought by ElectraTech, Inc. in U.S. District Court arising out of an October 10, 2001 agreement between the Company and ElectraTech. The agreement related to the development of an advanced battery that is a component in our MedDefib $\circledast$ implantable defibrillator. In the agreement, ElectraTech agreed to develop, manufacture, and sell the batteries to the Company in accordance with a planned production schedule. The Company terminated the agreement with ElectraTech in December 2003. The plaintiff alleges that the termination was improper and seeks monetary damages.

The outcome of this matter will depend on a number of complex and uncertain legal and factual questions. The Company believes that the termination was proper and in accordance with the terms of the agreement. We believe the likelihood that this matter could have a materially adverse effect on the Company is slightly more than remote. The Company intends to continue to vigorously defend this action. A trial was held in November 2009 and a verdict was returned in our favor. However, ElectraTech has filed an appeal in the U.S. Court of Appeals for the Second Circuit.

\section{Asthrest@ Litigation}

In February 2009, a patent infringement lawsuit was filed in U.S. District Court by PharmaOne, Inc. against Karlow regarding our Asthrest $($ asthma inhaler medication. This action alleges infringement of U.S. Patent $6,981,701$ by the Company's manufacture, offer for sale, distribution, and sale of Asthrest $($. The complaint is seeking a permanent injunction which would prevent future sales of Asthrest $\circledast$, and unspecified damages.

The outcome of this matter will depend on a number of uncertain legal and factual questions. We assert that PharmaOne, Inc. cannot prove its ownership claim of the patent in question and therefore lacks standing to sue. Furthermore, Karlow strongly stands behind years of independent R\&D that went into our Asthrest $\circledast$ formula, and we assert it was the first product of its kind on the market. We believe the likelihood that this matter could have a materially adverse effect on the Company is slightly more than remote. We believe we have a very strong defense in this matter, and we plan to vigorously defend against this case. The Company has recently moved to dismiss this lawsuit and is now awaiting a decision by the U.S. District Court. 
Please answer the following questions as you continue evaluating Karlow. Select the number below each question that best corresponds to your assessment.

1. What is the likelihood that Karlow will incur a future material loss due to the disclosed litigation?

\begin{tabular}{c|cccccccccccc} 
Material & \\
Loss \\
Not At \\
All \\
Likely \\
0
\end{tabular}

2. To what extent will Karlow's earnings in future periods be affected by the disclosed litigation?

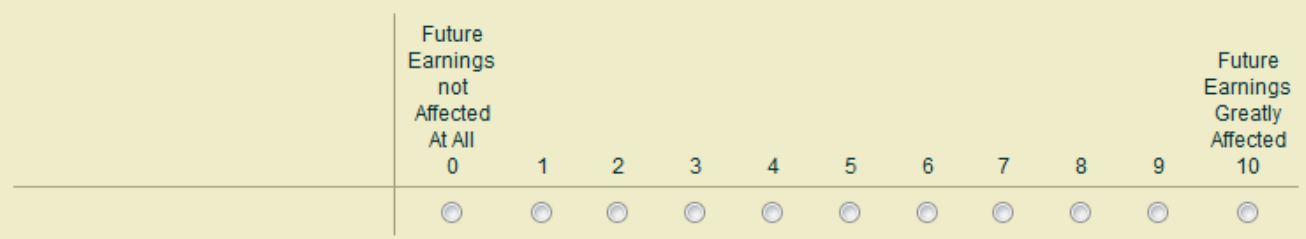




\section{EXHIBIT 5c}

\section{Legal Proceedings and Contingencies and Dependent Variables Screen (Provided to Participants in the Opportunistic Amendment Condition)}

Legal Proceedings and Contingencies

\section{Overview}

In the ordinary course of our business, we are involved in various legal proceedings. In today's litigious society, facing numerous frivolous lawsuits is an ordinary aspect of doing business in the pharmaceutical industry. Too often, lawsuits are filed for publicity or to pressure companies, only to be dropped later. Due to the state of legal affairs in today's business community, each time a new product is developed, the potential benefits the product could provide to patients suffering from debilitating ailments must be weighed against the chance it could lead to nuisance litigation. Karlow manages this aspect of our business as effectively as possible. From time to time, we do face lawsuits as a routine aspect of operating in this industry. However, in management's opinion, much of the litigation that we currently face is without merit. Such cases are very easily defended, often either thrown out of court in summary judgment or dropped before ever reaching trial.

The recent amendment to SFAS No. 5, "Accounting for Contingencies," now requires that we disclose any legal contingencies with "more than a remote" likelihood that a material liability could be incurred, even when the likelihood of loss is not reasonably possible. Because of the FASB's requirement to disclose lawsuits with even a very low likelihood of a material loss, this footnote contains details about lawsuits that management believes are frivolous. They are disclosed in this footnote in compliance with the new accounting rule; however, in management's opinion, they are not reliable indicators of actual future loss. If anything, the frivolous nature of many of these proceedings indicates that we effectively manage our product liability and quality control to limit more serious claims.

The ultimate financial liability of the Company with respect to all of the proceedings referred to below cannot be estimated with complete certainty. As such, we have not accrued any liabilities in our financial statements to date for the lawsuits discussed below. In fact, based on a thorough examination of these matters, knowledge and experience with Karlow's business, and discussions with counsel, we believe we have meritorious defenses against the claims currently asserted against us.

\section{Details}

In January 2005, Karlow was named as a defendant, along with other pharmaceutical manufacturers, in a class action in U.S. District Court. The action alleges that the defendant companies violated federal antitrust statutes and certain state laws by unlawfully agreeing to engage in conduct to prevent U.S. consumers from purchasing defendants' prescription drugs from Canada. Plaintiffs claim that, as a result of the alleged unlawful agreement, the purported class members paid higher prices for the defendants' pharmaceutical products than they otherwise would have paid in the absence of the alleged agreement. Plaintiffs seek various forms of relief, including punitive damages, restitution, injunctive relief, and attorneys' fees.

Although the outcome of this matter will depend on a number of complex and uncertain legal and factual questions, we believe the likelihood that this matter could have a materially adverse effect on the Company is only slightly more than remote. On July 21, 2009, the U.S. District Court dismissed this claim. Plaintiffs have appealed to the United States Court of Appeals for the Eighth Circuit. Briefing on the appeal has been completed. Oral argument on the appeal has not yet been scheduled, but we are confident that it will ultimately be upheld.

In July 2005, Karlow was named the defendant in a breach of contract lawsuit brought by ElectraTech, Inc in U.S. District Court arising out of an October 10, 2001 agreement between the Company and ElectraTech. The agreement related to the development of an advanced battery that is a component in our MedDefib® implantable defibrillator. In the agreement, ElectraTech agreed to develop, manufacture, and sell the batteries to the Company in accordance with a planned production schedule. The Company terminated the aqreement with ElectraTech in December 2003. The plaintiff alleqes that the termination 
was improper and seeks monetary damages.

The outcome of this matter will depend on a number of complex and uncertain legal and factual questions. The Company believes that the termination was proper and in accordance with the terms of the agreement. We believe the likelihood that this matter could have a materially adverse effect on the Company is only slightly more than remote. The Company intends to continue to vigorously defend this action. A trial was held in November 2009 and a verdict was returned in our favor. However, ElectraTech has filed an appeal in the U.S. Court of Appeals for the Second Circuit. We expect a favorable outcome in this matter.

In June 2007, a product liability lawsuit was filed in U.S. District Court against Karlow regarding our cholesterol lowering medication Vantro@. The action alleges, among other things, complainants suffered personal injury and/or death as a result of liver failure, blood clots, and heart valve issues alleged to be caused by taking Vantroß. The action also accuses the Company of inadequately testing for and warning users about the drug's side effects and of promoting it for off-label use. The complaint is seeking monetary damages as well as permanent injunctive relief to prevent the Company from selling Vantro® in the future.

The outcome of this matter will depend on a number of uncertain legal and factual questions relating to causation, scientific evidence, actual damages, and other matters. Settlement negotiations have recently begun in this matter, though an agreement has not yet been reached. Although it is reasonably possible that this matter could have a materially adverse effect on the Company, we deny the plaintiffs' allegations and believe they are without merit.

In February 2009, a patent infringement lawsuit was filed in U.S. District Court by PharmaOne, Inc. against Karlow regarding our Asthrest $($ asthma inhaler medication. This action alleges infringement of U.S. Patent $6,981,701$ by the Company's manufacture, offer for sale, distribution, and sale of Asthrest $\circledast$. The complaint is seeking a permanent injunction which would prevent future sales of Asthrest $\Theta$, and unspecified damages.

The outcome of this matter will depend on a number of uncertain legal and factual questions. We assert that PharmaOne. Inc. cannot prove its ownership claim of the patent in question and therefore lacks

standing to sue. Furthermore, Karlow also strongly stands behind years of independent R\&D that went into our Asthrest( ${ }^{8}$ formula, and we assert it was the first product of its kind on the market. We believe the likelihood that this matter could have a materially adverse effect on the Company is only slightly more than remote. We believe we have a very strong defense in this matter, and we plan to vigorously defend against this case. The Company has recently moved to dismiss this lawsuit and is now awaiting a decision by the U.S. District Court, which we expect will be favorable.

Please answer the following questions as you continue evaluating Karlow. Select the number below each question that best corresponds to your assessment.

1. What is the likelihood that Karlow will incur a future material loss due to the disclosed litigation?

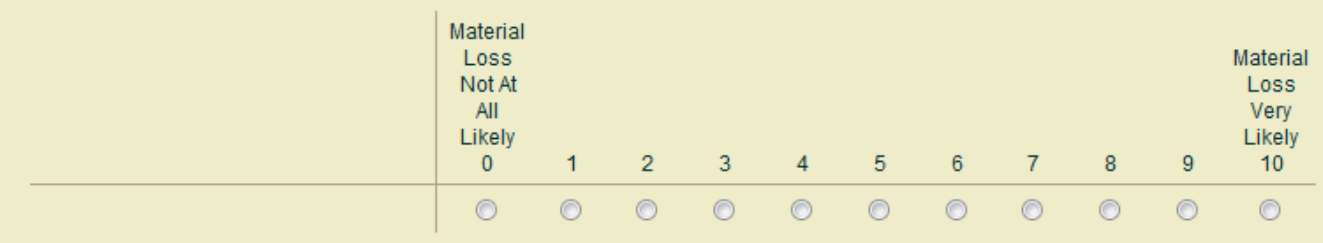

2. To what extent will Karlow's earnings in future periods be affected by the disclosed litigation?

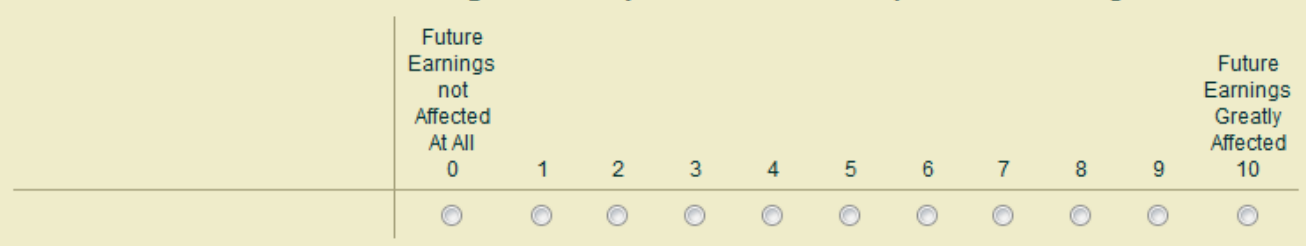




\section{EXHIBIT 6}

Post-Experimental Questionnaire (Provided to Participants in All Conditions)

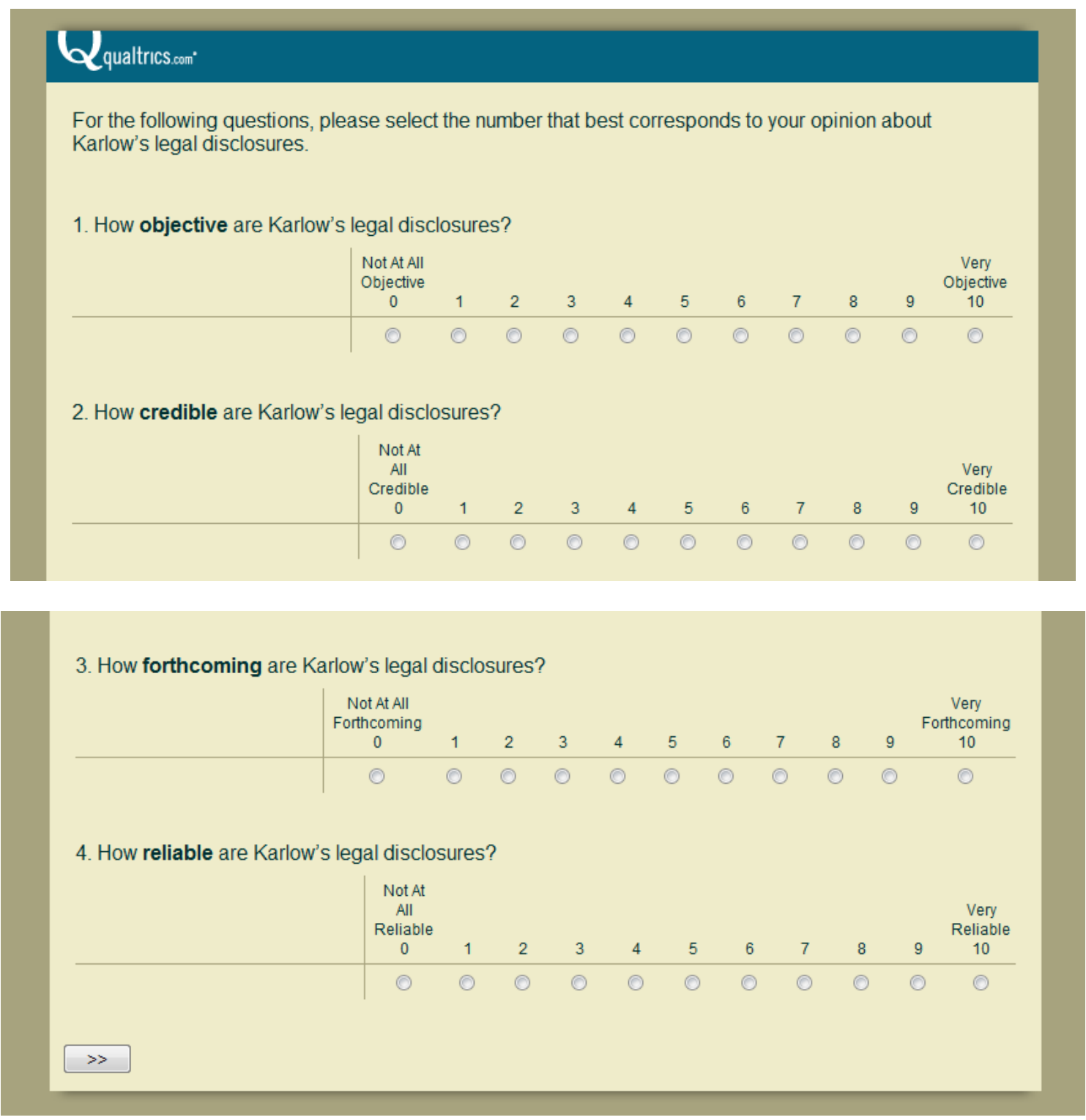


For the statements below, please choose the answer that best corresponds to your memory of the case.

1. Approximately how many lawsuits were disclosed in the footnotes to Karlow's 2009 financial statements?
one
four

2. According to the disclosures in Karlow's financial statements, the prevailing accounting standard requires Karlow to disclose pending lawsuits when the likelihood they would lead to a material loss is:

at least reasonably possible

more than remote

Qqualtrics.oom

1. How litigious is the pharmaceutical industry, in your opinion?

\begin{tabular}{c|ccccccccccc}
$\begin{array}{c}\text { Not At } \\
\text { All } \\
\text { Litigious } \\
0\end{array}$ & 1 & 2 & 3 & 4 & 5 & 6 & 7 & 8 & 9 & $\begin{array}{c}\text { Very } \\
\text { Litigious } \\
10\end{array}$ \\
\hline & 0 & 0 & 0 & 0 & 0 & $\odot$ & 0 & 0 & 0 & 0 & 0
\end{tabular}

2. What do you believe is the current outlook for the pharmaceutical industry?

\begin{tabular}{c|ccccccccccc}
$\begin{array}{c}\text { Very } \\
\text { Negative } \\
\text { Outlook } \\
0\end{array}$ & 1 & 2 & 3 & 4 & 5 & 6 & 7 & 8 & 9 & $\begin{array}{c}\text { Very } \\
\text { Positive } \\
\text { Outlook } \\
10\end{array}$ \\
\hline & 0 & 0 & 0 & 0 & 0 & 0 & 0 & 0 & 0 & 0 & 0
\end{tabular}

3. What do you believe is the current outlook for the stock market in general?

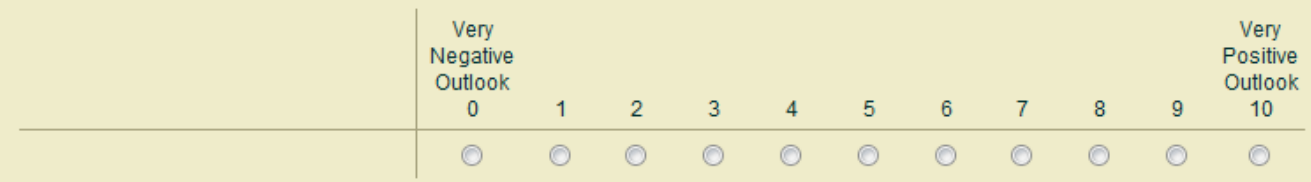




\section{EXHIBIT 7a}

\section{Compensation Data Screen (Provided to Participants in the Long Investor Condition)}

[Note: Each participant receives one of the following screens depending on their firm choice and the resulting payout appropriate for that choice.]
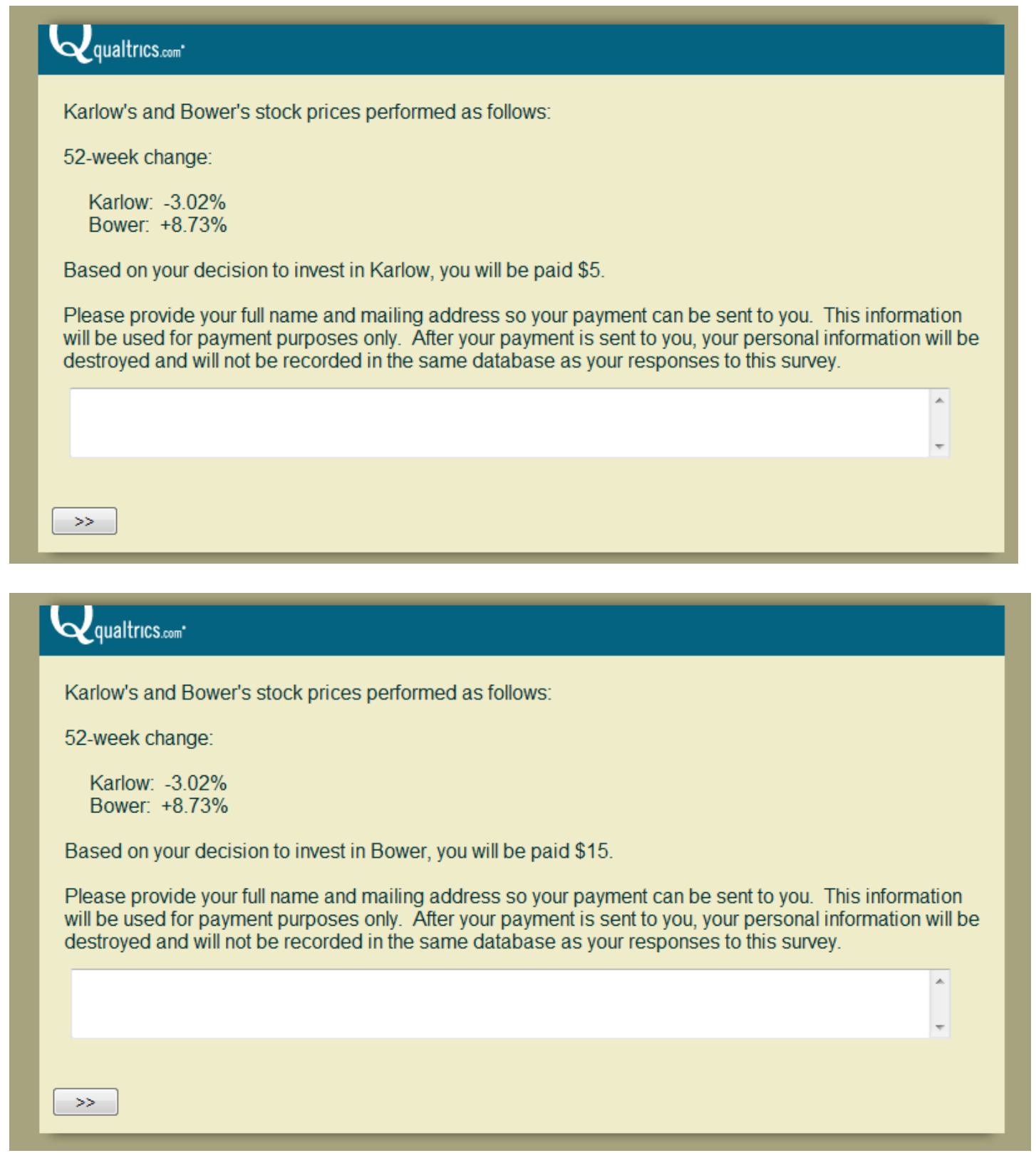


\section{EXHIBIT 7b}

Compensation Data Screen (Provided to Participants in the Prospective Investor Condition)

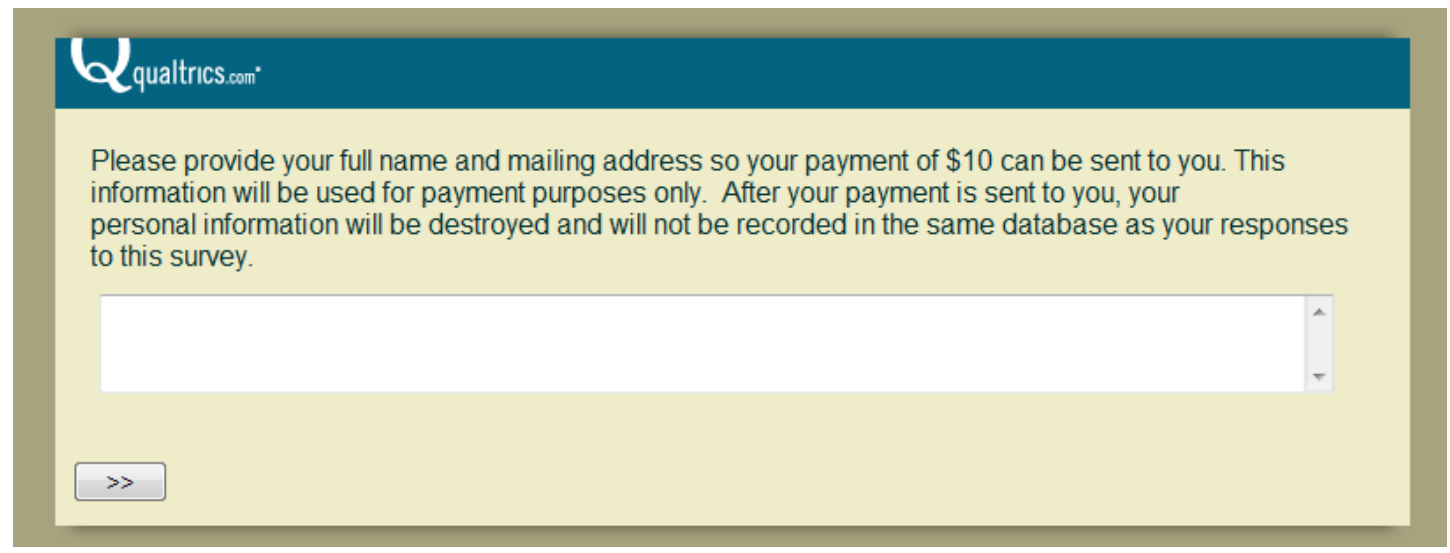




\section{EXHIBIT 7c}

\section{Compensation Data Screen (Provided to Participants in the Short Investor Condition)}

[Note: Each participant receives one of the following screens depending on their firm choice and the resulting payout appropriate for that choice.]

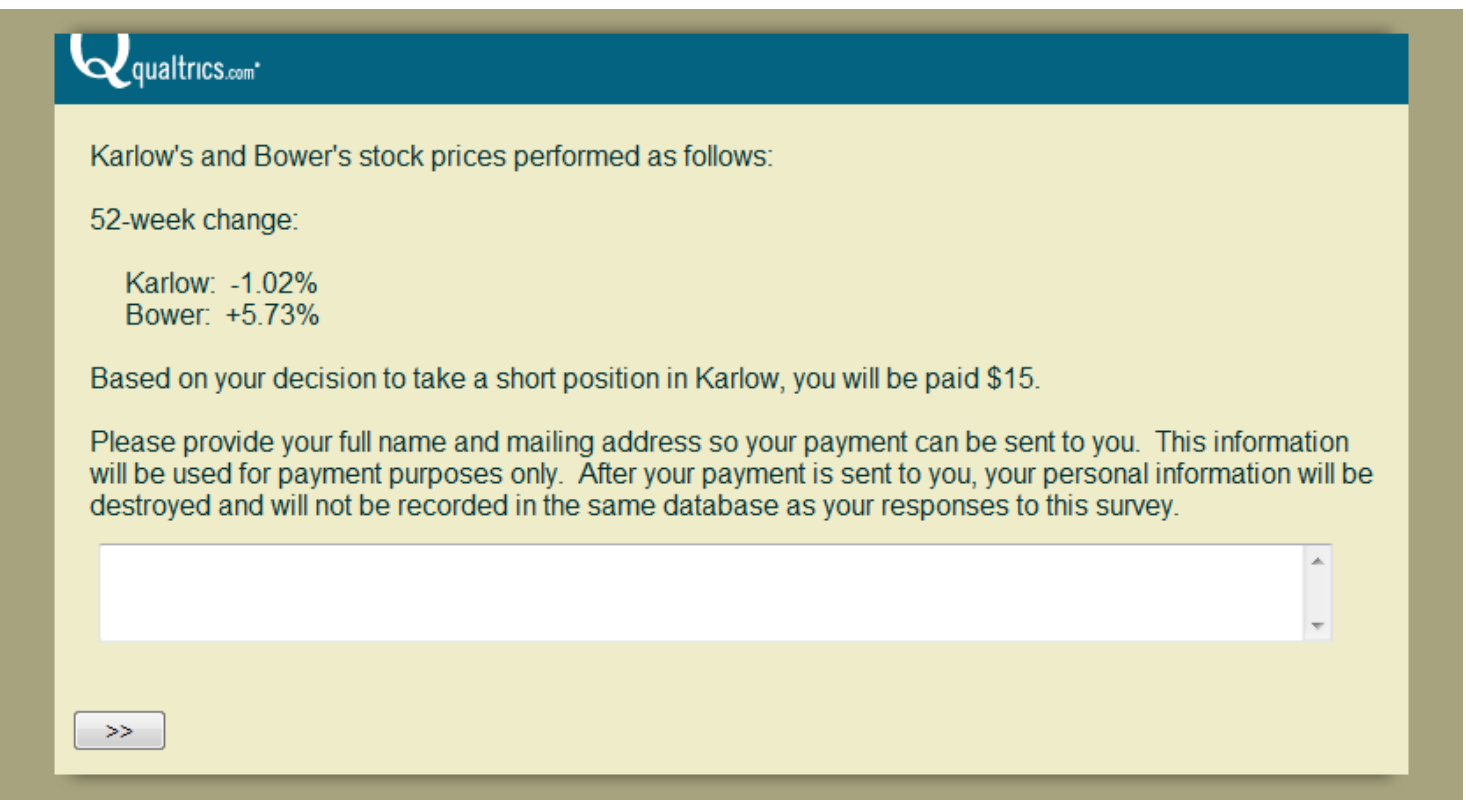

\section{Q Qpalthesem:}

Karlow's and Bower's stock prices performed as follows:

52-week change:

Karlow: $-1.02 \%$

Bower: $+5.73 \%$

Based on your decision to take a short position in Bower, you will be paid $\$ 5$.

Please provide your full name and mailing address so your payment can be sent to you. This information will be used for payment purposes only. After your payment is sent to you, your personal information will be destroyed and will not be recorded in the same database as your responses to this survey. 


\section{EXHIBIT 8}

\section{Demographic Questions (Provided to Participants in All Conditions)}

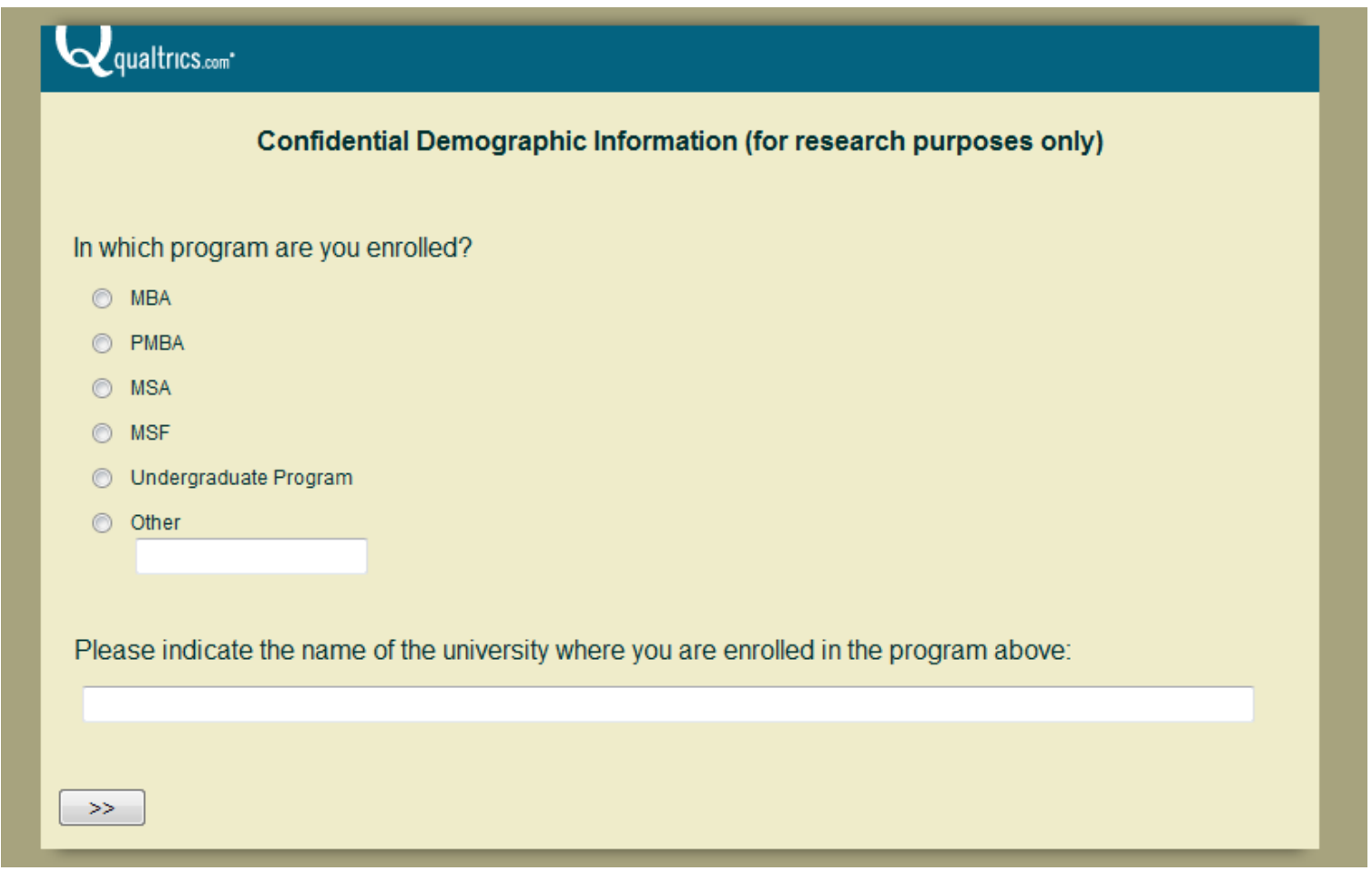

\section{$\mathbf{Q}_{\text {qualtroseswi }}$}

How many accounting and finance courses have you taken, including the courses in which you are currently enrolled?

$\begin{array}{lllllllllllllllllllll}0 & 1 & 2 & 3 & 4 & 5 & 6 & 7 & 8 & 9 & 10 & 11 & 12 & 13 & 14 & 15 & 16 & 17 & 18 & 19 & 20\end{array}$

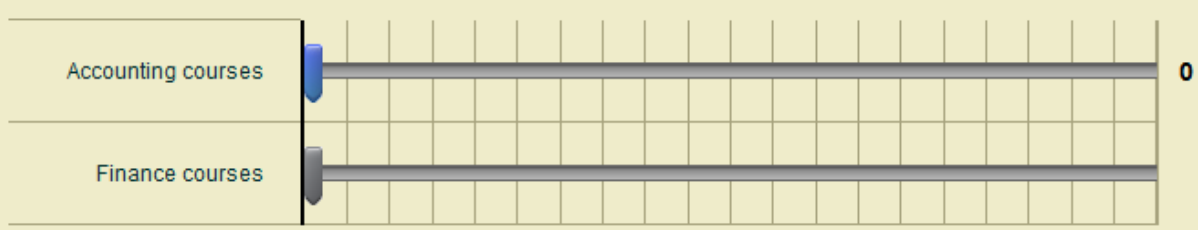

Have you previously taken, or are you currently taking, a Financial Statement Analysis course?
() Yes
(1) No 
qualtrics.com"

Have you ever invested in the stock market?

(1) Yes

ㄱo

Do you plan to invest in the stock market in the future?

Y Yes

( No

\section{$>>$}

$\alpha_{\text {qualtrics.com" }}$

Have you ever worked as a financial analyst?

(-) Yes

No

Have you, or has anyone in your immediate family, ever worked in the pharmaceutical industry?

() Self

Family Member

№

Have you, or has anyone in your immediate family, ever worked in the legal field (e.g., lawyer, paralegal, etc.)?

(1) Self

(-) Family Member

○ No

Do you hold any advanced degrees (e.g., M.D., D.O., J.D., Ph.D., etc.)?

Yes (if yes, please specify which degree)

No 


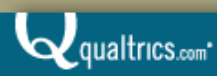

How much professional business experience do you have?

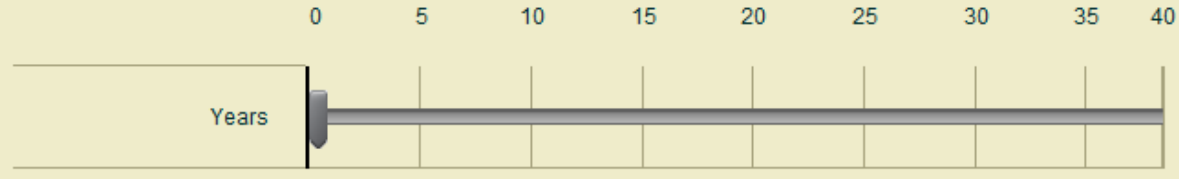

What is your professional title?

What is your gender?

M

( $\mathrm{F}$

Q $\mathbf{Q u a l t h r s e m}$

We thank you for your time spent taking this survey. Your response has been recorded. 


\section{BIBLIOGRAPHY}

Agoglia, C.P., C. Beaudoin, and G.T. Tsakumis. 2009a. The Effect of Documentation Structure and Task-Specific Experience on Auditors' Ability to Identify Control Weaknesses. Behavioral Research in Accounting 21 (1): 1-17.

Agoglia, C.P., R.C. Hatfield, and J.F. Brazel. 2009b. The Effect of Audit Review Format on Review Team Judgments. Auditing: A Journal of Practice and Theory 28 (1): 95-111.

Amer, T., K. Hackenbrack, and M. Nelson. 1994. Between-auditor differences in the interpretation of probability phrases. Auditing. 13(1): 126.

Amer, T., K. Hackenbrack, and M. Nelson. 1995. Context-Dependence of Auditors' Interpretations of the SFAS No. 5 Probability Expressions. Contemporary Accounting Research 12 (1): 25-39.

Baginski, S., J. Hassell, and W. Hillison. 2000. Voluntary causal disclosures: tendencies and capital market reaction. Review of Quantitative Finance and Accounting 15, 371-389.

Barton, J. and M. Mercer. 2005. To blame or not to blame: Analysts' reactions to external explanations for poor financial performance. Journal of Accounting and Economics 39 (3): 509-533.

Baumeister, R.F. 1982. A self-presentational view of social phenomena. Psychological Bulletin 91: 3-26.

Bloomfield, R.J. 2002. The "Incomplete Revelation Hypothesis" and Financial Reporting. Accounting Horizons 16 (3): 233-243.

Bogle, J.C. 2006. The ownership of corporate America: Rights and Responsibilities. $20^{\text {th }}$ Anniversary Meeting of the Council of Institutional Investors, April 11, 2005, Washington, DC: Bogle Financial Markets Research Center.

Bonner, S.E. 2008. Judgment and Decision Making in Accounting. Upper Saddle River, NJ: Pearson Prentice Hall.

Bouwman, M. 1982. The Use of Accounting Information: Expert vs. Novice Behavior. In G. Ungson and D. Braunstein (Ed.), Decision Making: An Interdisciplinary Inquiry. Boston, MA: Kent.

Campbell, M.C. and A. Kirmani. 2000. Consumers' Use of Persuasion Knowledge: The Effects of Accessibility and Cognitive Capacity on Perceptions of an Influence Agent. Journal of Consumer Research 27: 69-83. 
Cheney, G. 2008, September 22. FASB on trial over litigation disclosure; Angry Herz responds to WSJ op-ed. Accounting Today: 8.

Cuccia, A.D., K. Hackenbrack, and M.W. Nelson. 1995. The Ability of Professional Standards to Mitigate Aggressive Reporting. The Accounting Review 70 (2): 227248.

DeLong, J., A. Scleifer, L. Summers, and R. Waldman. 1989. The size and incidence of the losses from noise trading. Journal of Finance 44: 681-686.

DeLong, J., A. Scleifer, L. Summers, and R. Waldman. 1991. The survival of noise traders in financial markets. Journal of Business 64: 1-19.

Desir, R., K. Fanning, and R. Pfeiffer. 2010. Are Revisions to SFAS No. 5 Needed? Accounting Horizons (forthcoming).

Ditto, P.H. and D. Lopez. 1992. Motivated Skepticism: Use of Differential Decision Criteria for Preferred and Nonpreferred Conclusions. Journal of Personality and Social Psychology 63 (4): 568-584.

Druckman, J.N. 2001. The Implications of Framing Effects for Citizen Competence. Political Behavior 23 (3): 225-256.

Druckman, J.N. 2004. Political Preference Formation: Competition, Deliberation, and the (Ir)relevance of Framing Effects. American Political Science Review 98 (4): 671686.

Elliott, W.B., J.L. Hobson, and K.E. Jackson. 2010. Disaggregating Management Forecasts to Reduce Investors' Susceptibility to Earnings Fixation. The Accounting Review (forthcoming).

Elliott, W., F. Hodge, J. Kennedy, and M. Pronk. 2007. Are M.B.A. Students a Good Proxy for Nonprofessional Investors? The Accounting Review 82: 139-168.

Elsbree, D. and J. Milne. 2009, August 6. Disclosures of Certain Loss Contingencies Final Comment Letter Summary Memorandum.

Entman, R.M. 1993. Framing: Toward clarification of a fractured paradigm. Journal of Communication 43 (4): 51-58.

FASB's Lawyer Bonanza. 2008, August 7. The Wall Street Journal, A12.

Financial Accounting Standards Board. 1975. Accounting for Contingencies. Statement of Financial Accounting Standards No. 5. Norwalk, CT. 
Financial Accounting Standards Board. 1995. Accounting for Stock-Based Compensation. Statement of Financial Accounting Standards No. 123. Norwalk, CT.

Financial Accounting Standards Board. 2008. Exposure Draft: Disclosure of Certain Loss Contingencies: an amendment of FASB Statements No. 5 and 141(R). Norwalk, CT.

Financial Accounting Standards Board. 2009. Board Meeting, August 19, 2009. Norwalk, CT.

Fiske, S. T., and S.L. Neuberg. 1990. A continuum of impression formation, from category-based to individuating processes: Influences of information and motivation on attention and interpretation. In M. P. Zanna (Ed.), Advances in experimental social psychology (Vol. 23, pp. 1-74). New York: Academic Press.

Fiske, S.T. and S.E. Taylor. 2008. Social Cognition: From Brains to Culture. New York: McGraw-Hill.

Frederick, D.M. and R. Libby. 1986. Expertise and Auditors' Judgments of Conjunctive Events. Journal of Accounting Research 24 (2): 270.

Friestad, M. and P. Wright. 1994. The Persuasion Knowledge Model: How People Cope with Persuasion Attempts. Journal of Consumer Research 21: 1-31.

Glover, S.M. 1997. The Influence of Time Pressure and Accountability on Auditors' Processing of Nondiagnostic Information. Journal of Accounting Research 35 (2): 213-226.

Hackenbrack, K. 1992. Implications of Seemingly Irrelevant Evidence in Audit Judgment. Journal of Accounting Research 30 (1): 126-136.

Hackenbrack, K., and M.W. Nelson. 1996. Auditors' incentives and their application of financial accounting standards. The Accounting Review 71 (1): 43-59.

Hales, J. 2007. Directional preferences, information processing, and investors' forecasts of earnings. Journal of Accounting Research 45(3): 607-628.

Han, J. and H.T. Tan. 2010. Investors' Reactions to Management Earnings Guidance: The Joint Effect of Investment Position, News Valence, and Guidance Form. Journal of Accounting Research 48 (1): 123.

Herz, R. H. 2008, August 18. FASB Seeks to Inform Investors, Not Whack Companies [Letter to the Editor]. The Wall Street Journal, A4.

Higgins, E.T. and J.A. Bargh. 1987. Social perception and social cognition. Annual Review of Psychology. 38: 369-425. 
Higgins, E.T., C.J.R. Roney, E. Crow, and C. Hymes. 1994. Ideal Versus Ought Predilections for Approach and Avoidance Distinct Self-Regulatory Systems. Journal of Personality and Social Psychology 66 (2): 276-286.

Hirst, D.E., L. Koonce, and S.Venkataraman. 2007. How Disaggregation Enhances the Credibility of Management Earnings Forecasts. Journal of Accounting Research 45(4): 811-837.

Hoffman, V.B. and J.M. Patton. 1997. Accountability, the Dilution Effect, and Conservatism in Auditors' Fraud Judgments. Journal of Accounting Research 35 (2): 227-237.

Hunton, J., and R. McEwen. 1997. An Assessment of the Relation between Analysts' Earnings Forecast Accuracy, Motivational Incentives and Cognitive Information Search Strategy. The Accounting Review 72 (4): 497-515.

Kachelmeier, S.J. and R.R. King. 2002. Using Laboratory Experiments to Evaluate Accounting Policy Issues. Accounting Horizons 16 (3): 219-232.

Kadous, K. S.J. Kennedy, and M.E. Peecher. 2003. The effect of quality assessment and directional goal commitment on auditors' assessment of client-preferred accounting methods. The Accounting Review 78 (3): 759-778.

Kadous, K., L. Koonce, and K.L. Towry. 2005. Quantification and Persuasion in Managerial Judgment. Contemporary Accounting Research 22 (3): 643-686.

Kadous, K., A.M. Magro, and B.C. Spilker. 2008. Do effects of client preference on accounting professionals' information search and subsequent judgments persist with high practice risk? The Accounting Review 83 (1): 133-156.

Kahneman, D. and A. Tversky. 1972. Subjective probability: A judgment of representativeness. Cognitive Psychology 3: 430-454.

Kaplan, S.E., E.F. O’Donnell, and B.M. Arel. 2008. The Influence of Auditor Experience on the Persuasiveness of Information Provided by Management. Auditing 27 (1): 67.

Keppel, G. and T.D. Wickens. 2004. Design and Analysis: A Researcher's Handbook. Upper Saddle River, NJ: Pearson Prentice Hall.

Kerlinger, F.N. and H.B. Lee. 2000. Foundations of Behavioral Research, 4th ed. New York: Thomson Learning.

Kirmani, A. and M.C. Campbell. 2004. Goal Seeker and Persuasion Sentry: How Consumer Targets Respond to Interpersonal Marketing Persuasion. Journal of Consumer Research 31: 573-582. 
Kirmani, A. and R.J. Zhu. 2007. Vigilant Against Manipulation: The Effect of Regulatory Focus on the Use of Persuasion Knowledge. Journal of Marketing Research 44 (4): 688-701.

Klayman, J. and Y.W. Ha. 1987. Confirmation, Disconfirmation, and Information in Hypothesis Testing. Psychological Review, 94 (2): 211-228.

Krische, S. 2005. Investors' Evaluations of Strategic Prior-Period Benchmark Disclosures in Earnings Announcements. The Accounting Review 80 (1): 243-268.

Kunda, Z. 1990. The case for motivated reasoning. Psychological Bulletin 108:480-498.

Kunda, Z. 1999. Social Cognition: Making Sense of People. Cambridge, MA: The MIT Press.

Kunda, Z. and R. Sanitioso. 1989. Motivated changes in the self-concept. Journal of Experimental Social Psychology. 25 (3): 272-285.

Lambert, T.A. and C.P. Agoglia. 2010. Closing the Loop: The Effect of Reviewer Delay and Review Note Frame on Audit Staff Follow-through. Working paper, University of Massachusetts Amherst.

Laswad, F. and Y.T. Mak. 1997. Interpretations of Probability Expressions by New Zealand Standard Setters. Accounting Horizons 11 (4): 16-23.

Leary, M.R. and R.M. Kowalski. 1990. Impression management: A literature review and two-component model. Psychological Bulletin 107: 34-47.

Lipe, M.G. and S. Salterio. 2002. A note on the judgmental effects of the balanced scorecard's information organization. Accounting, Organizations and Society 27: $531-540$.

Maines, L.A. and L.S. McDaniel. 2000. Effects of Comprehensive-Income Characteristics on Nonprofessional Investors' Judgments: The Role of FinancialStatement Presentation Format. The Accounting Review 75 (2): 179-207.

Maule, J. and G. Villejoubert. 2007. What lies beneath: Reframing framing effects. Thinking \& Reasoning 13 (1): 25-44.

McCaffery, E.J. and J. Baron. 2004. Framing and taxation: Evaluation of tax policies involving household composition. Journal of Economic Psychology 25: 679-705.

Mercer, M. 2005. The Fleeting Effects of Disclosure Forthcomingness on Management's Reporting Credibility. The Accounting Review 80 (2): 723-744. 
Nelson, T.E. and Z.M. Oxley. 1999. Issue Framing Effects on Belief Importance and Opinion. The Journal of Politics 61 (4): 1040-1067.

Nelson, T.E., Z.M. Oxley, and R.A. Clawson. 1997. Toward a Psychology of Framing Effects. Political Behavior 19 (3): 221-246.

Nezlek, J.B. and M.R. Leary. 2002. Individual differences in self-presentational motives in daily social interaction. Personality and Social Psychology Bulletin 28 (2): 211-223.

Ng, T.B.-P. and P.G. Shankar. 2010. Effects of Technical Department's Advice, Quality Assessment Standards and Client Justification on Auditors' Propensity to Accept Client-Preferred Accounting Methods. The Accounting Review (forthcoming).

Nisbett, R.E., H. Zukiee, and R.E. Lemley 1981. The Dilution Effect: Nondiagnostic Information Weakens the Implications of Diagnostic Information. Cognitive Psychology 13: 248-277.

Peecher, M. E., M. D. Piercey, J. S. Rich, and R. M. Tubbs. 2010. The effects of a supervisor's intervention in subordinates' judgments, directional goals, and perceived technical knowledge advantage on audit team judgments. The Accounting Review 85 (5): forthcoming.

Piercey, M.D. 2009. Motivated reasoning and verbal vs. numerical probability assessment: Evidence from an accounting context. Organizational Behavior and Human Decision Processes 108 (2): 330-341.

Pyszczynski, T., and J. Greenberg. 1987. Toward an integration of cognitive and motivational perspectives on social inference: A biased hypothesis-testing model. In Advances in Experimental Social Psychology, edited by L. Berkowitz, Volume 20. New York: Academic Press.

Reimers, J.L. 1992. Additional Evidence on the Need for Disclosure Reform. Accounting Horizons 6 (1): 36-41.

Ricchiute, D. 1999. The Effect of Audit Seniors' Decisions on Working Paper Documentation and on Partners' Decisions. Accounting, Organizations and Society 24: 155-171.

Rich, J.S., I. Solomon, and K.T. Trotman. 1997. The Audit Review Process: A Characterization from the Persuasion Perspective. Accounting, Organizations and Society 22 (5): 481-505.

Ruble, D. N., and C. Stangor. 1986. Stalking the elusive schema: Insights from developmental and social psychological analysis of gender schemas. Social Cognition. 4: 227-261. 
Schrand, C.M. and B.R. Walther. 2000. Strategic benchmarks in earnings announcements: The selective disclosure of prior-period earnings components. The Accounting Review 75 (2): 151-177.

Securities and Exchange Commission. 2010. Commission Guidance Regarding Disclosure Related to Climate Change. Washington, DC.

Sedor, L.M. 2002. An Explanation for Unintentional Optimism in Analysts' Earnings Forecasts. The Accounting Review 77 (4): 731-753.

Shankar, P.G. and H.T. Tan. 2006. Determinants of Audit Preparers' Workpaper Justifications. The Accounting Review 81 (2): 473-495.

Shelton, S.W. 1999. The Effect of Experience on the Use of Irrelevant Evidence in Auditor Judgment. The Accounting Review 74 (2): 217-224.

Simon, J. 2002. Interpretation of probability expressions by financial directors and auditors of UK companies. The European Accounting Review 11 (3): 601-629.

Slothuus, R. 2008. More than Weighting Cognitive Importance: A Dual-Process Model of Issue Framing Effects. Political Psychology 29 (1): 1-28.

Tan, H.T. and J. Yip-Ow. 2001. Are reviewers' judgments influenced by memo structure and conclusions documented in audit work papers? Contemporary Accounting Research 18 (4): 663-678.

Tetlock, P.E. and R. Boettger. 1989. Accountability: A Social Magnifier of the Dilution Effect. Journal of Personality and Social Psychology 57 (3): 388-398.

Thayer, J. 2011. Determinants of Investors' Information Search: Credibility and Confirmation. The Accounting Review (forthcoming).

Tversky, A. and D. Kahneman. 1983. Extensional versus intuitive reasoning: The conjunction fallacy in probability judgment. Psychological Review 90 (4): 293315 .

Wilks, T.J. 2002. Predecisional Distortion of Evidence as a Consequence of Real-Time Audit Review. The Accounting Review 77 (1): 707-725.

Zukier, H. 1982. The dilution effect: The role of the correlation and the dispersion of predictor variables in the use of nondiagnostic information. Journal of Personality and Social Psychology 43 (6): 1163-1174.

Zukier, H. and D.L. Jennings. 1983. Nondiagnosticity and typicality effects in prediction. Social Cognition 2 (3): 187-198. 